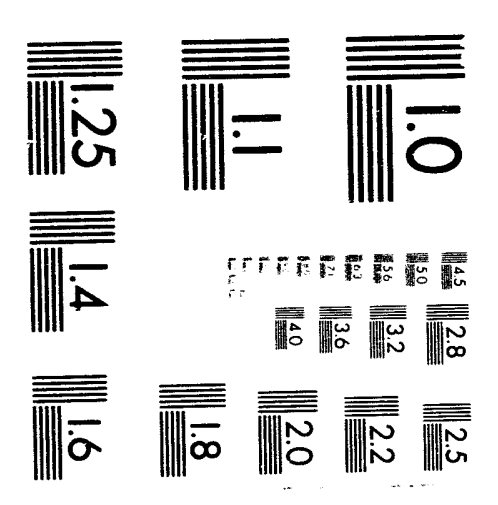



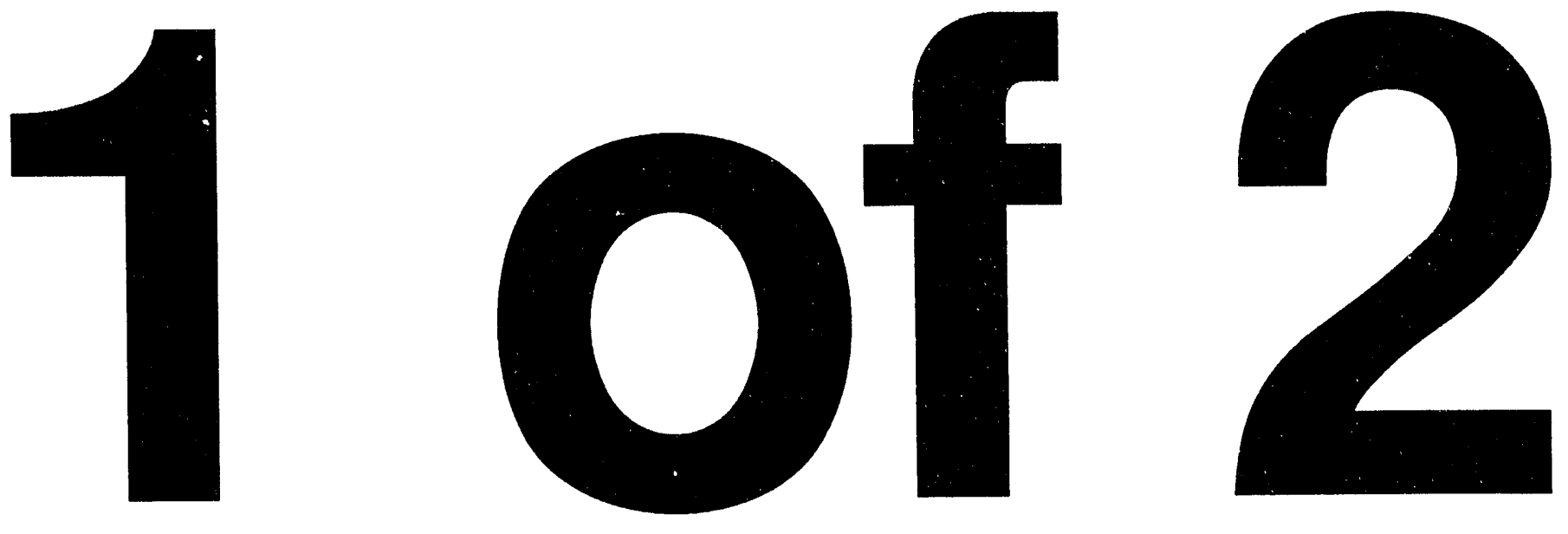
NUREG/GR-0008

\section{Validation of Seismic Probabilistic Risk Assessments of Nuclear Power Plants}

Manuscript Completed: December 1993

Date Published: January 1994

Prepared by

B. Ellingwood

Department of Civil Engineering

The Johns Hopkins University

3400 N. Charles Street

Baltimore, MD 21218

Prepared for

Division of Engineering

Office of Nuclear Regulatory Research

U.S. Nuclear Regulatory Commission

Washington, DC 20555-0001

NRC FIN G1108 


\section{ABSTRACT}

A seismic probabilistic risk assessment (PRA) of a nuclear plant requires identification and information regarding the seismic hazard at the plant site, dominant accident sequences leading to core damage, and structure and equipment fragilities. Uncertainties are associated with each of these ingredients of a PRA. Sources of uncertainty due to seismic hazard and assumptions underlying the component fragility modeling may be significant contributors to uncertainty in estimates of core damage probability. Design and construction errors also may be important in some instances. When these uncertainties are propagated through the PRA, the frequency distribution of core damage probability may span three orders of magnitude or more. This large variability brings into question the credibility of PRA methods and the usefulness of insights to be gained from a PRA.

The sensitivity of accident sequence probabilities and highconfidence, low probability of failure (HCLPF) plant fragilities to seismic hazard and fragility modeling assumptions was examined for three nuclear power plants. Mean accident sequence probabilities were found to be relatively insensitive (by a factor of two or less) to: uncertainty in the coefficient of variation (logarithmic standard deviation) describing inherent randomness in component fragility; truncation of lower tail of fragility; uncertainty in random (non-seismic) equipment failures (e.g., diesel generators); correlation between component capacities; and functional form of fragility family. On the other hand, the accident sequence probabilities, expressed in the form of a frequency distribution, are affected significantly by the seismic hazard modeling, including slopes of seismic hazard curves and likelihoods assigned to those curves. When the fragility modeling and plant logic are effectively uncoupled from the seismic hazard analysis in a seismic margin study, the influence of the large uncertainty in the seismic hazard is eliminated. Other modeling assumptions and sources of uncertainty become relatively more important. It appears that in seismic margin studies, uncertainties in fragility modeling take on a different significance than they do in seismic PRA studies.

Questions have been raised in seismic PRAs concerning the potential for gross design and construction errors and their impact on estimates of seismic risk. Methodologies for dealing with errors are in a developmental stage and supporting data are limited. The error problem can be dealt with in an approximation by postulating various error scenarios and their effect on component fragilities, recalculating the core damage probabilities, and comparing the results to the error-free case. 
Although such analyses indicate that plausible design/construction errors have little effect on mean core damage probabilities, such conclusions are valid only to the extent that errors can be incorporated in the PRA through adjustments in component fragility models.

\section{KEYWORDS}

Earthquakes; Nuclear power plants; Probability; Reliability; Risk; Safety; Statistics; Structural engineering; Systems engineering. 
Abstract

List of Tables

List of Figures

1.0 Introduction

1.1 Probabilistic risk assessment methods

1.1.1 Seismic PRA at Level I

1.1.2 Seismic margins analysis

1.2 Insights from existing PRAs

1.2.1 Seismic hazard

1.2.' Plant logic models

1.2.3 Fragility models

1.2.4 Probability of core damage

1.3 Barriers to implementation of PRAs in decision-making

1.4 Study objectives and scope

2.0 Plant system logic and system models

2.1 Limerick generating station

10

2.2 Millstone 3

2.3 Maine Yankee

3.0 Seismic fragility 21

$\begin{array}{lll}3.1 & \text { Basic fragility models } & 21\end{array}$

$\begin{array}{lll}3.2 & \text { Seismic margins analysis } & 25\end{array}$

$\begin{array}{lll}3.3 & \text { Appraisal of fragility analysis and data } & 26\end{array}$

$\begin{array}{lll}3.4 & \text { Fragility parameters for plants studied } & 29\end{array}$

$\begin{array}{ll}\text { Addendum } A 3 \text { Estimation of fragility parameters } & 29\end{array}$

A3.1 Estimation of $A m$ and $\beta R$ with limited data 29

A3.2 Standard error in estimation of median 30

$\begin{array}{lll}4.0 & \text { Seismic hazard analysis } & 37\end{array}$

4.1 Limerick Generating Station 41

4.2 Millstone $3 \quad 42$

4.3 Maine Yankee 42

5.0 Accident sequence probabilities and seismic margins 51

$\begin{array}{ll}5.1 \quad \text { Method of analysis } & 51\end{array}$

5.2 Limerick generating station 53

5.2.1 Baseline case 53

5.2.2 Point estimates of core damage probability 54 
5.2.3 Fragility modeling 55

$\begin{array}{lll}\text { 5.2.4 Random nonseismic equipment failures } & 60\end{array}$

5.2.5 Dependent (common cause) failures 62

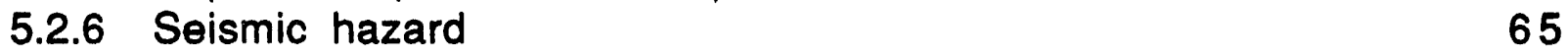

$\begin{array}{lll}5.3 & \text { Millstone } 3 & 66\end{array}$

5.4 Maine Yankee 68

Addendum A5 Seismic hazard - fragility interactions 69

A5.1 Introduction $\quad 69$

A5.2 Method of analysis $\quad 70$

A5.3 Results $\quad 71$

A5.3.1 Lognormal fragility model 71

A5.3.2 Modified lognormal fragilities 73

A5.3.3 Weibull fragility model 73

A5.4 Simplified estimates of core damage probability 74

A5.5 Estimating core damage probability from HCLPF 76

$\begin{array}{ll}\text { A5.6 Summary } & 77\end{array}$

6.0 Role of error in safety evaluation 103

6.1 Design/construction errors 103

$\begin{array}{lll}6.2 & \text { Significance of error for nuclear plant safety } & 104\end{array}$

6.3 Sensitivity of risk estimates to postulated errors 107

$\begin{array}{ll}\text { 6.3.1 Limerick generating station } & 108\end{array}$

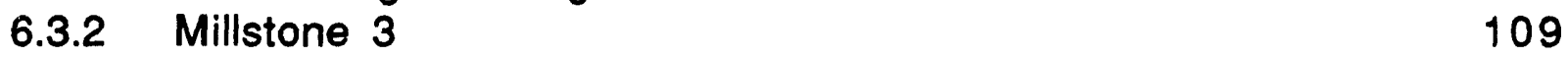

$\begin{array}{lll}6.4 & \text { Summary } & 110\end{array}$

$\begin{array}{ll}\text { 7.0 Conclusions and recommendations } & 113\end{array}$

$\begin{array}{lll}8.0 & \text { Acknowledgements } & 121\end{array}$

$\begin{array}{lll}9.0 & \text { References } & 123\end{array}$ 
Tables

2.1(a) Component and seismic fragility parameters - Limerick 16

2.1(b) Nonseismic random failure rates - Limerick 17

2.2(a) Component and seismic fragility parameters - Millstone $3 \quad 18$

2.2(b) Nonseismic random failure rates - Millstone $3 \quad 18$

2.3(a) Component and seismic fragility parameters - Maine Yankee 19

2.3(b) Nonseismic random failure rates - Maine Yankee 19

A3.1 Sampling distribution of MLE $Y_{1} \quad 34$

A3.2 Sampling distribution of $Y_{2}=\left(X_{L} X_{U}\right)^{1 / 2} \quad 34$

A3.3 Sampling distribution of $Y_{3}=X_{(n+1) / 2} \quad 34$

4.1 Seismic hazard curve parameters - Limerick 44

4.2 Seismic hzard curve parameters - Millstone $3 \quad 44$

4.3 Seismic hazard curve parameters - Maine Yankee 44

5.1 Fractiles and mean values of core damage probability - LGS 78

5.2 Comparison of mean core damage sequence probabilities - LGS 78

5.3 HCLPF and core damage probability fractiles using condensed Booleans - LGS $\quad 78$

5.4 Effect of structural fragility parameters on $P(C D)$ - LGS 79

5.5 Effect of uncertainty in $\beta_{R}$ on sequence probabilities - LGS 79

5.6 Effect of fragility modeling on sequence probabilities - LGS 79

5.7 Random failures of diesel generators - LGS 80

5.8 Effect of random equipment failures - LGS 80

5.9 Effect of correlation on $P\left(T_{S} E_{S} U X\right)$ and $P(C D)$ - LGS 81

5.10 Role of uncertainty in seismic hazard - LGS 81

5.11 Plant damage state probabilities for Millstone $3 \quad 82$

5.12 Core damage probabilities for Maine Yankee 83

A5.1 Modal value, $x_{0} / S S E$, of risk integrand, $I(x) \quad 83$

$\begin{array}{lll}\text { A5.2 } & x_{0} / S S E \text { contributing most to } P_{f} & 84\end{array}$

A5.3 Calculation of $P(C D)$ from $P(A>$ HCLPF $) \quad 84$

6.1 Modifications to median fragility due to D/C error - LGS 111

6.2 Effect of D/C error on core damage probability - LGS 111

6.3 Modifications to median fragility due to $D / C$ error -Millstone $3 \quad 111$

$\begin{array}{lll}6.4 & \text { Effect of } D / C \text { error on plant damage state probability } \\ \text {-Millstone } 3 & 111\end{array}$ 


\section{Figures}

3.1 Lognormal fragility model for LGS reactor enclosure structure

4.1 Typical seismic hazard curve showing annual probability that acceleration is exceeded

4.2 Annual probability vs peak ground acceleration - LGS (SARA, 1983)

4.3 Seismic hazard curves for Millstone Unit 3 (Dames and Moore, 1983)

4.4 Seismic hazard curves for Millstone 3 (Bernreuter, et al, 1984)

4.5 Seismic hazard curves for Maine Yankee (Bernreuter, et al, 1987)

5.1 Illustration of latin hypercube sampling

5.2 Limerick - Fragility for sequence $T_{s} E_{s} \cup X$

5.3 Limerick - Frequency distribution of core damage probability for sequence $T_{s} E_{s} U X$

5.4 Limerick - Fragility for sequence $C D$

5.5 Limerick - Frequency distribution of core damage probability for sequence CD

5.6 Limerick - Sampling distributions for $E\left[P\left(T_{s} E_{s} \cup X\right)\right]$ and $E[P(C D)]$

5.7 System fragility $-F_{\text {sys }}=F_{1}+F_{2}$

5.8 System fragility $-F_{\text {sys }}=F_{1}{ }^{*} F_{2}$

5.9 Millstone 3 - Fragility for plant damage state TE

5.10 Millstone 3 - Fragility for plant damage state $A E$

5.11 Millstone 3 - Fragility for plant damage state SE

5.12 Millstone 3 - Fragility for plant damage state V3

96

5.13 Maine Yankee - Fragility for sequence 1

5.14 Maine Yankee - Fragility for sequence 2

A5.1 Illustration of seismic hazard - fragility interface and convolution

A5.2 Relative contribution of accelerations to core damage probability

A5.3 Accelerations contributing $90 \%$ of estimated failure probability 


\subsection{INTRODUCTION}

A probabilistic risk assessment (PRA) provides a structured framework for evaluating uncertainty and the performance and reliability of safety-related systems in a nuclear plant. A PRA focuses on what might go wrong as a result of extreme operating, environmental or accident conditions and portrays in a quantitative fashion how plant systems must operate in order to mitigate such conditions. It thus represents a different philosophy from that taken in routine design. The PRA methodology allows for the efficient processing of new data on component performance and displays the effects of redundancy in meeting required performance goals. It also allows for the integration of limited data in the form of expert opinion.

When PRAs were initiated in the mid 1970's, the focus was on the ability of the plant systems to mitigate internal initiating events (WASH$1400,1975)$. Later, it was recognized that initiating events arising from external sources, such as earthquake, wind and flood, might also contribute significantly to plant risk. During the past decade, over two dozen seismic probabilistic risk assessments (PRAs) have been completed for nuclear plants in the United States, seven of which have been published (Sues, Amico and Campbell, 1990). These PRA's have shed light on the operation of plant safety systems, and have indicated where existing plants are particularly vulnerable to earthquake effects. They also have raised a number of interpretive and regulatory questions that must be addressed in order for them to be useful as decision tools. Primary among these are how credible are the results and what conclusions can be drawn for regulatory decision-making. Validation of seismic PRAs or, conversely, identifying their limitations clearly is required in order to establish their end uses in regulatory decisionmaking. This issue is of particular revelance now that the NRC has requested that utilities perform an individual plant examination for seismic events as part of the IPEEE Program.

\subsection{Probabilistic Risk Assessment Methods}

A probabilistic risk assessment can be approached on basically three levels (PRA Procedures, 1983). A Level I PRA is limited to the assessment of the probability of severe core damage. Containment failure and offsite consequences are not considered. A Level II PRA considers containment failure modes subsequent to core melt and quantities and release of fission products (source term), but does not consider offsite consequences. A level III PRA includes offsite consequences in the form of prompt fatalities and latent health effects. While the dominant core damage sequences are not always those most important for offsite risk, the Level I PRA allows insight on which systems provide frontline defense 
for plant safety. Moreover, level I PRAs focus on the safety goals for the plant itself and avoid the need to consider the large uncertainties in source term analysis and offsite consequences. This study will consider only PRAs at Level I. Some authors refer to a Level I PRA as a probabilistic safety assessment, or PSA.

\subsubsection{Seismic PRA at Level I}

All level I seismic PRAs involve the same basic ingredients:

1. Identify the seismic hazard at the plant site through a sitespecific analysis that considers causative faults (Western United States) or seismotectonic sources (Eastern United States) with potential to cause significant ground motions at the plant site.

2. Develop plant logic models (event trees, fault trees) to describe the collection of plant systems that must operate in order to mitigate initiating events such as loss-of-coolant accidents, or transients that might lead to core damage.

3. Develop probabilistic models (fragilities) that describe the capacity of structures and components identified in the plant logic models to withstand earthquakes of various sizes.

4. Calculate point estimates of core damage probability by convolving the seismic hazard and component fragilities. Propagate the uncertainties in seismic hazard and fragility modeling through the plant logic models to determine frequency distributions on estimated core damage.

\subsubsection{Seismic Margins Analysis}

A seismic margin study is aimed at demonstrating that the plant is capable of withstanding an earthquake in excess of the safe-shutdown earthquake (SSE) without endangering plant safety (Budnitz, et al, 1985; Prassinos, et al, 1986). In a seismic margins analysis, the seismic hazard analysis is effectively uncoupled from the plant logic and component fragility modeling. Steps 2 and 3 are performed as described above. The uncertainties in component fragility are propagated through the plant logic models to determine a "high-confidence, low probability of failure (HCLPF)" value of plant capacity, expressed in terms of acceleration, which can be checked against a margin review earthquake. This margin review earthquake might be determined from a seismic hazard analysis or might be set by regulatory authority, depending on the resources and data available. In any event, step 1 is diminished in importance and step 4 is not performed. This allows the rationale of probabilistic systems 
analysis to be retained and, at the same time, simplifies the safety analysis of the plant by separating the issues of seismic hazard determination and plant logic and fragility. Recent trends are toward the use of seismic margin analysis to determine plant system vulnerability.

Two variants of the margins methodology have been developed (Budnitz, 1992), differing in the treatment of plant logic. The first and older approach focuses on failure paths, as in a traditional PRA, and was developed under NRC sponsorship (Budnitz, et al, 1985). The second approach, developed under EPRI sponsorship, focuses on "success paths," or ways by which the plant can reach safe shutdown (EPRI, 1988). Issues related to treatment of uncertainty arising from inherent randomness, lack of data, and modeling uncertainty are germane to both, of course. Either way, margins analysis stops at Level I; plant damage states and offsite consequences are not considered.

\subsection{Insights from Existing PRAs}

A sufficient number of seismic PRAs have been completed for some general conclusions to be drawn (Probabilistic, 1984; Special, 1990). Some results are described in the following paragraphs. They are organized along the lines of the four items in section 1.1.1.

\subsubsection{Seismic Hazard}

Most studies have shown that uncertainties in the seismic hazard curve dominate uncertainty in risk due to seismic events and that orderof-magnitude changes in the seismic hazard curve yields similar changes in core damage probability (Reed and McCann, 1984; Ravindra, et al, 1984).

Below a certain magnitude, ground motion is insufficient to cause any damage to a properly designed plant. Ground motions above a certain level are physically impossible. Thus, the possible ground motion parameters (e.g., effective peak ground acceleration) are limited from above and below. However, because of insufficient data, lack of agreement among experts, etc., the seismic hazard curves usually are assumed to be unbounded from above and below (Bernreuter, 1987; EPRI, 1989). There is an issue as to whether the seismic hazard curves should be truncated and, if so, where. Several studies (e.g., Ravindra, et al, 1984; Ravindra, et al, 1985) have shown that the major contribution to core damage probability comes from ground accelerations in the range of 2 to 4 times the SSE. Although truncating the hazard curve above 5 SSE or below 1 SSE would seem to have little effect on the core damage probabilities, others have concluded that as much as 20 percent of the core damage probability may come from earthquakes smaller than the SSE (Shiu, Reed and McCann, 1985). 
Core damage frequency is only moderately affected by the SSE chosen as a basis for design because the seismic hazard curves for typical plants in the Eastern United States are so flat.

\subsubsection{Plant Logic Models}

Boolean expressions describing severe core damage consist of a union of component failure events (minimum cutsets). In the dominant accident sequences, the cutsets often appear as singletons, i.e., they describe failure of a single component. A small number of components have ground acceleration capacities that are much less than other components. Low-capacity components appearing as singletons dominate the risk calculations and are not affected by seismic hazard curve truncation (Ravindra, et al 1984). However, these low-capacity components may not be dominant risk contributors if they appear in higher-order cutsets (e.g., if they must fail in conjunction with other systems to endanger the plant). In such cases, system redundancy may be important.

In most PRAs, it has been found that relatively few accident sequences dominate the core damage probability.

\subsubsection{Fragility Models}

Loss of offsite power due to failure of ceramic insulators will occur during any earthquake large enough to damage major structural systems or components within the plant. On the basis of the seismic PRAs published so far, the following systems warrant careful scrutiny (Ravindra, et al, 1985):

a. Structural - shear walls, slab failures, foundation uplift. A structural failure may impact several other systems simultaneously and the effects thus are amplified.

b. Electrical - motor control centers, switchboards and DC power supply may have low seismic capacities (Bandyopadhyay, et al, 1987). Relay chatter may affect operability; this is difficult to model in a PRA because it is intermittent and may be mitigated by appropriate operator action.

c. Mechanical - reactor internals, anchorage of tanks and other equipment. 


\subsubsection{Probability of Core Damage}

The frequency distribution of core damage probability spans several orders of magnitude due mainly to the large uncertainty in seismic hazard at the plant site. Random (nonseismic) failure and operator errors do not appear to have a major impact on seismic core damage frequencies (Reed and McCann, 1984); however, the assumptions regarding relay chatter and operator response are closely linked. Plausible changes in fragility parameters due to design and construction error or in failure ratio due to operator error affect the core damage probability by a factor of two or less. Comparisons of probabilities from plant to plant are made difficult by the inconsistent way in which uncertainties have been treated.

\subsection{Barriers to Implementation of PRAs in Decision-Making}

There are inherent difficulties with the use of probability in decision-making. Uncertainties are always present. Some of these uncertainties are inherent in nature and irreducible. Others are statistical, arising from limited data. Still others are due to modeling assumptions, omissions and calculation error. They arise in all phases of a seismic PRA. Because of these modeling uncertainties, the risk, expressed as a core damage probability or as a product of probability and offsite consequences (PRA Procedures, 1983) is difficult to interpret when presented as a point estimate. Rather, risk is expressed in the form of a frequency distribution, the distribution reflecting the uncertainty in the ability to model the system accurately. This frequency distribution typically spans several orders of magnitude. In the PRA conducted for Zion, for example, the median probability of release was computed to be $3.0 \times 10^{-5}$, and the 10 to 90 percent confidence band on the release frequency was 3 orders of magnitude. This uncertainty is of concern to any decision-maker who would like one point estimate of probability because decision-making is binary in nature. What should that point estimate be? The large uncertainty brings into question the credibility of the PRA and can obscure the basis for regulatory decision-making.

Most seismic PRAs have taken modeling uncertainties in the seismic hazard and fragilities into account explicitly (Ravindra, et al, 1985). In contrast, internal event PRAs have not included this modeling uncertainty in a consistent manner. Since the modeling uncertainty is a significant contributor to the overall dispersion in estimated core damage, the results from external and internal event PRA are not comparable because the levels of confidence in the two results are not comparable. Several PRAs have indicated that external initiators, such as earthquake, are relatively more important than suggested by the Reactor Safety Study WASH, 1400, 1975). In part, this is because of the very large uncertainties associated with external events and plant response; these 
uncertainties are due to limitations in data, state of knowledge, and ability to model these effects properly in a complex engineered facility.

Stability (or lack of it) in the estimate of core damage probability is of equal concern. When several experts (or panels) perform the same PRA with the same objective database, the estimate core damage probabilities (or uncertainty bands on point estimates) may vary significantly. This occurs because experts may not share the same information or may interpret the same data differently. This lack of stability is disquieting. One might stabilize the estimates by specifying a normative procedure; this is common in ordinary building codes, where the calculation procedures are laid out in advance. However, such an approach conceals limitations in data and brushes the issues of uncertainty aside. It is easier to design a system to be safe than it is to calculate its risk.

Most fragility studies have used the lognormal fragility model with a lower tail value of zero. Structural, mechanical and electrical components actually have a minimum strength larger than zero. The existence of this lower limit and the shape of the lower fragility tail might be expected to affect core melt probability estimates in some circumstances.

Failures due to external initiating events may be functionally or statistically dependent. Functional dependence can be accounted for through the plant logic, while statistical dependence is reflected in the correlation structure assumed for the component fragilities. Although studies to date indicate that this dependence is relatively unimportant because of the dominance of the seismic hazard in plant risk (Ravindra, et al, 1984; Reed and McCann, 1984), there may be areas as of yet unidentified where these considerations are important. Dependence in component fragilities is different from dependence in component failures. Moreover, the significance of stochastically dependent failures in a seismic margin rather than risk assessment needs to be evaluated.

Design and construction errors primarily affect component fragilities. Such errors may affect a large number of components simultaneously and have not been addressed in seismic PRAs that have been published to date. A systematic collection of statistical data on D/C error seems unfeasible; yet, there is a need to consider whether such errors would have a significant impact on core damage probability. Nor have operator actions generally been taken into account. There are some instances, e.g., relay chatter, where operator action may be beneficial and reduce plant risk.

The sensitivity of PRA results to some common assumptions in baseline data has been examined for a limited number of plants (Ravindra, 
et al 1984). Other studies also have developed tools for this examination (George and O'Connell, 1985; Mensing, 1985).

\subsection{Study Objectives and Scope}

This study is directed toward determining how uncertainties due to inherent variability, modeling and analysis, incomplete data, and error affect risk estimates and inferences made for purposes of regulation and engineering decision-making.

Three operating plants were selected as a basis for this assessment with the assistance of a steering committee. The main criteria for plant selection was the availability of well-documented PRAs with published peer reviews. No inferences are made about the relative safety, reliability or performance of the plants selected, and it is inappropriate to draw any such conclusions from the results presented herein. The hazard, fragility modeling and plant logic modeling are reviewed, and sequence and core damage probabilities are evaluated independently. From this evaluation, some observations are made on the conduct of Level I seismic PRA and seismic margin analyses and the use of the quantitative performance goals in safety assessment. 


\subsection{PLANT SYSTEM LOGIC AND SYSTEM MODELS}

An accident sequence consists of an initiating event and a combination of system successes and failures that leads to an identifiable plant damage or success state (PRA Procedures, 1983). The responses of structural, mechanical and electrical components in mitigating an accident are related for probabilistic risk assessment purposes through Boolean expressions developed from accident event trees and component fault trees.

Event trees are inductive in nature and describe the development of accident sequences from an initiating event. Each branch point in the event tree is related to a safety function. The safety functions represented in the event tree headings are ordered in time. Although the event trees are plant-dependent to a degree, there are common elements among them for different plants with the same power system because of the engineered safety features that all have in common. Each sequence in the event tree is dependent on the successes and failures of various plant systems. If the plant logic is structured properly, the sequences are mutually exclusive and collectively exhaustive. Fault trees, in contrast, are deductive in nature, generally are developed for a specific function or system, and are plant-specific to take into account differences in siting, configuration and equipment. Generally speaking, each branch in an event tree can be modeled at the system or subsystem level by a fault tree. Functional dependencies caused by shared support systems are taken into account by linking the fault trees in constructing the Boolean expressions for plant safety functions.

The early PRA studies did not include external events in the construction of the plant logic Booleans. However, an internal events PRA furnishes information about relevant plant safety systems which can be used for analyzing response to external events as well. Simplified plant models usually are sufficient for this purpose. When seismic PRA studies were initiated, analysts began with the plant logic from the internal events PRA and expanded the scope to include passive structural components (shear walls, slabs, etc.) not originally included in the internal events PRA. The resulting Boolean expressions reflect the possibility of both seismic-induced failures and nonseismic random function failures. Components that are important in external and internal event analysis may not be the same. For example, structural components usually do not appear in an internal event PRA. Moreover, external events affect multiple components simultaneously and thus make failure or survival events stochastically dependent.

The construction of event trees and fault trees has been automated to a degree, and there are numerous computer programs to perform the 
system analyses and reductions that are usually necessary for PRA purposes. The discussion of these operations is outside the scope of this report. It is assumed that the Boolean expressions describing the accident sequences have been determined in a rational way and are available for subsequent sensitivity analysis purposes.

Three plants in the Eastern United States were evaluated. One boiling water reactor (BWR) plant and one pressurized water reactor (PWR) plant were considered. The main criterion in the selection of the plants was that the original PRA had to be scrutable and well documented and available for inspection and that a published independent peer review was to be available. On this basis, Limerick Generating Station, and Millstone 3 were selected. A third plant, Maine Yankee, was also evaluated because of its role in an early seismic margins study. No shortcoming in the performance of any of these three plants is to be inferred by their selection.

\subsection{Limerick Generating Station}

The Limerick Generating Station (LGS) is situated near Philadelphia, PA in an area of relatively high population density. It is a General Electric BWR housed in a Mark II containment. Its seismic PRA (included in the LGS Severe Accident Risk Assessment, or SARA, 1983 ) is well-documented and relatively uncomplicated, and has been subjected to a published external peer review (Azarm, et al, 1984). The peer review judged that the SARA and its predecessor PRA were complete with regard to identification of initiation events and accident sequences. LGS does not have any unique design features that are significant to the dominant accident sequences. LGS was originally designed for an SSE of $0.15 \mathrm{~g}$.

A series of event trees identifying possible accident sequences and fault trees identifying components or human actions that contribute to failure of systems or functions were developed in the original PRA of the Limerick Generating Station (1981). The event trees link together the top events resulting from the fault tree analysis. The original PRA (1981) considered only internal events, and did not treat earthquake, fire, or flooding. A total of eight initiating events were considered: 3 LOCA (large, medium, small) and 5 Transient (turbine trip, manual shutdown, MSIV closure/feedwater loss, loss of offsite power, and inadvertent open safety relief valve). These eight initiating events resulted in 86 core damage sequences, which were grouped into four basic classes (I - IV), in accordance with whether core melt occurs prior to or after containment failure and whether the reactor scram system operates. Nine of these 86 contributed $90 \%$ of core damage frequency; 7 of the 9 were initiated by transients. 
The seismic PRA was initiated after the internal events PRA was completed. A seismic-induced loss of offsite power (LOSP) (resulting from failure of ceramic insulators at relatively low acceleration levels) was found to be the dominating initiating event; seismic-induced LOCA had a very small likelihood in comparison. External events contribute approximately $25 \%$ of the core damage frequency at LGS.

The Limerick SARA (1983) identified the following six dominant sequences that lead to core damage and are initiated by a seismic event:

\begin{tabular}{|c|c|c|}
\hline TSESLX & $=$ & TSES $^{*}\left(A+X_{R^{*}} S_{2}{ }^{*} S_{17}+X_{R^{*}} H_{R^{*}} R_{R}+X_{R^{*}} G^{*} S_{2}\right)$ \\
\hline $\mathrm{TSR}_{\mathrm{B}}$ & $=$ & $\overline{\mathrm{S}}_{6} * \mathrm{~S}_{4} * \overline{\mathrm{C}}_{\mathrm{m}}$ \\
\hline TSRPV & $=$ & $S_{6}$ \\
\hline SESW & - & $\mathrm{T}_{\mathrm{S}} \mathrm{E}_{\mathrm{S}} * \overline{\mathrm{A}} *\left(\overline{\mathrm{H}}_{\mathrm{R}}+\overline{\mathrm{R}}_{\mathrm{R}}\right) *\left(\mathrm{~S}_{2} * \mathrm{~S}_{17}+\mathrm{S}_{2} * \mathrm{~W}_{\mathrm{R}}+\mathrm{S}_{17} * \mathrm{G} * \mathrm{~W}_{\mathrm{R}}\right)$ \\
\hline $\mathrm{TSESC}_{m} \mathrm{C}_{2}$ & $=$ & TSES $C_{m} *\left(A+S_{8}+S_{9}+S_{10}+S_{L} C_{R}\right)$ \\
\hline$c_{m}$ & $=$ & $\overline{\mathrm{S}}_{6} * \mathrm{~S}_{4} * \mathrm{C}_{\mathrm{m}}$ \\
\hline
\end{tabular}

in which,

$$
\begin{aligned}
\text { TSES } & =\bar{S}_{6} * \overline{\mathrm{S}}_{4} * \mathrm{~S}_{1} * \overline{\mathrm{C}}_{\mathrm{m}} \\
\text { TsEsCm } & =\overline{\mathrm{S}}_{6} * \overline{\mathrm{S}}_{4} * \mathrm{~S}_{1} * \mathrm{C}_{\mathrm{m}} \\
A & =S_{11}+S_{12}+S_{13}+S_{14}+S_{15}+S_{16}+D G_{R} \\
C_{m} & =C_{R}+S_{3}+S_{5}+S_{7}
\end{aligned}
$$

In equations $2.1-2.10^{n}+"$ denotes a union of events $n * n$ denotes an intersection of events, and a superbar denotes the complement of the event. The Boolean expressions contain a combination of seismic-induced and nonseismic failures. The components in Eqns. 2.1 - 2.10 are identified in Tables 2.1 (a) for earthquake-induced failures and 2.1 (b) for random nonseismic equipment failures*. The seismic fragility parameters defined in these Tables are described in Section 3.

The Boolean expressions in Eqns. 2.1 - 2.10 were simplified by eliminating some of the higher order cut sets that contribute a negligible amount to core damage probability. In a simplified form, these become,

$$
\begin{aligned}
& T_{s} E_{s} U X=S_{1} * A \\
& T_{S} R P V=S_{6}
\end{aligned}
$$

* Figures and tables appear at the end of each chapter throughout the report. 


$$
\begin{aligned}
& T_{S} R_{B}=S_{4} \\
& T_{S} E_{s} C_{m} C_{2}=S_{1} *\left(C_{R}+S_{3}\right)^{*}\left(A+S_{10}+S L C_{R}\right) \\
& T_{S} R_{B} C_{m}=S_{4}^{*}\left(C_{R}+S_{3}\right) \\
& T_{S} E_{s} W=S_{1} A^{*}\left(S_{17} W_{R}+S_{2} S_{17}\right)
\end{aligned}
$$

Sequence $T_{s} E_{s} U X$ involves loss of high pressure coolant injection followed by failure to depressurize reactor, and is dominated by failure of emergency electrical equipment following a seismic-induced loss of offsite power. Sequence $T_{s} E_{s} U X$ is dominated by 5 electrical components in series. Sequences $T_{S} R_{B}$ and $T_{S} R P V$ involve failure of shear walls in the reactor control building and failure of the reactor vessel upper lateral support bracket, respectively, and thus are primarily structural in nature. Sequence $T_{s} E_{s} W$ involves failure of the long-term heat removal system. The last two sequences involve failure of the control rods to insert and scram the reactor; in sequence $T_{s} E_{s} C_{m} C_{2}$, the standby liquid control system fails. Other sequences contribute a negligible amount to core damage. The simplified sequences are useful in obtaining risk insights and are believed to be consistent with the level of understanding of the phenomena involved.

Core damage is defined as the union of the above six accident sequences.

$$
C D=S_{4}+S_{6}+S_{1}{ }^{*}\left[A+\left(S_{3}+C_{R}\right)^{*}\left(S_{10}+S L C_{R}\right)+\left(S_{17}+W_{R}\right)\right]
$$

Although the core damage Boolean for LGS is dominated by electrical equipment failures, it also includes failures from plant structures and from the reactor protection system.

The computations of core damage probability require a knowledge of and fragilities of the individual components (Section 3 ) and the seismic hazard at the plant site (Section 4).

\subsection{Millstone 3}

Millstone 3 is located near New London, CT relatively near a high population center. It is a 4-loop Westinghouse PWR housed in a subatmospheric containment. Like LGS, its PRA was relatively well documented and had been subjected to a thorough external peer review (Garcia, at al, 1986). The plant was designed for SSE of $0.17 \mathrm{~g}$. The original external events PRA was based on a large event tree - small fault tree model, and the initiating events were transients and LOCAs. In the original PRA, the seismic hazard analysis was overly optimistic, and the fragility analysis contained errors. These were corrected subsequently 
and the revised plant logic and fragility models below reflect these corrections.

In Millstone 3, loss of offsite power followed by station blackout and reactor coolant pump seal LOCA is the largest single identifiable contributor to core damage probability. Four plant damage states were found to be important. Sequence TE involved an initiating transient, followed by :eactor coolant pump seal failure and early core melt.

Sequence $A E$ involved a large pipe break LOCA followed by failure of core injection, containment sprays, and early core melt. Sequence SE involved a small LOCA followed by early core melt. Sequence V 3 was an interfacing systems LOCA resulting from failure of the containment crane wall.

$$
\begin{aligned}
& T E=S_{1}^{*}\left(B+S_{4}^{*} S_{17}+S_{4}{ }^{*} R_{5}\right) \\
& A E=\left(S_{4}+B\right)^{*}\left(S_{15}+S_{30}+S_{32}\right) \\
& S E=\left(S_{4}+B\right)^{*}\left(S_{6}+S_{9}+S_{16}\right) \\
& V 3=S_{27}+S_{29}
\end{aligned}
$$

in which

$$
B=S_{3}+S_{5}+S_{7}+S_{12}+S_{20}+S_{31}+S_{35}+R_{19}
$$

Core damage is considered to be the union of these four mutually exclusive events. Thus,

$$
P(C D)=P(T E)+P(A E)+P(S E)+P(V 3)
$$

The components (and fragility parameters) for Eqns $2.18-2.22$ are identified in Table 2.2 (a) and 2.2 (b). The numbering corresponds to that in the original seismic PRA. Components that did not contribute to core damage are omitted from Table 2.2 (a) for brevity.

\subsection{Maine Yankee}

Maine Yankee is a PWR Plant located approximately 4 miles south of Wiscasset, Maine. The original design of the Category I structures and components was based on a "Housner Spectrum" anchored to $0.05 \mathrm{~g}$ for the OBE and $0.10 \mathrm{~g}$ for the SSE. However, since the plant started commercial operation in 1972, certain upgrades have been made to improve the seismic capacity of the plant, e.g. additional anchoring of electrical equipment.

Maine Yankee was selected for the trial application of the newly developed seismic margin review methodology (Budnitz, et al, 1985; Prassinos, et al, 1986). The NRC staff specified a review earthquake level 
of $0.3 \mathrm{~g}$ peak ground acceleration (PGA) anchored to the median NUREG/CR0098 ground response spectrum for rock sites. This definition of a spectrum is needed to relate the dependence of fragility and HCLPF capacity on frequency content as well as PGA. In computing structural response, it was assumed that the review earthquake is defined by the same spectrum in the two orthogonal horizontal directions and by twothirds in the vertical direction.

In the seismic margins review methodology, certain categories of plant structures and equipment which invariably have high seismic capacities are screened out before the systems analysis is performed. A plant walkdown is performed to confirm that the screening is reasonable. This preliminary screening simplifies the system analysis considerably and focuses attention on those structures and equipment that are critical for safe operation of the plant in the event of an earthquake. It is assumed that there will be a loss of offsite power which will be irrecoverable during the period of interest. Only seismic-induced transients and small LOCAs are addressed. Generally, only systems needed to maintain the reactor in a subcritical condition, cool the core and prevent core damage are considered.

At Maine Yankee, the interior of the containment was not accessible during the walkdown. Several components were identified during the margin evaluation as potentially having low capacities. These components were upgraded by the utility during the course of the study. Electrical relay chatter was excluded from this margin study. Initial and subsequent data collection efforts concentrated on structures and components identified in the systems analysis as being required to bring the reactor to subcriticality and for early emergency core cooling (Prassinos, et al, 1987).

Seismic-induced core damage at Maine Yankee was dominated by two sequences. Sequence $A_{1}$ involves seismically-induced loss of offsite power (LOSP) followed by a small LOCA(SL). Sequence $A_{2}$ involves seismically induced loss of offsite power without LOCA. The Booleans are

$$
\begin{aligned}
A_{1}= & \operatorname{LOSP} * S L *\left(S_{4}+S_{7}+S_{20}\right) \\
A 2= & \operatorname{LOSP} * \overline{S L} *\left[\left(S_{4}+S_{20}\right) *\left(S_{8}+R_{15}+R_{17}+R_{22}\right)\right. \\
& \left.+S_{8}^{*}\left(R_{14}+R_{16}\right)+R_{15} * S_{7}\right]
\end{aligned}
$$

The components (and seismic fragility parameters) in these equations are identified in Table 2.3 (a). Nonseismic random equipment failure rates are identified in Tables 2.3 (b). 
An exact expression for core damage probability could not be derived because lack of accessibility of the containment interior prevented SL from being quantified. An approximate expression is

$$
P(C D)=P(S L) P\left(A_{1}\right)+P(\overline{S L}) P\left(A_{2}\right)
$$

in which $P(S L)=$ probability that a small LOCA occurs, given that there is a loss of offsite power. 
TABLE 2.1(a)

Component and Seismic Fragility Parameters - Limerick

\begin{tabular}{|c|c|c|c|c|c|c|}
\hline No. & Component & $\begin{array}{c}\text { Failure cause or } \\
\text { mode }\end{array}$ & $\begin{array}{c}\text { Median } \\
\text { ground } \\
\text { acceleration } \\
\text { capacity } \\
g\end{array}$ & BR & BU & HCLPF \\
\hline$S_{1}$ & $\begin{array}{l}\text { Offsite power } \\
\text { (500/230- kV } \\
\text { switchyard) }\end{array}$ & $\begin{array}{l}\text { Ceramic } \\
\text { insulator } \\
\text { breakage }\end{array}$ & 0.20 & 0.20 & 0.25 & 0.10 \\
\hline $\mathrm{S}_{2}$ & $\begin{array}{c}\text { Condensate storage } \\
\text { tar,k }\end{array}$ & $\begin{array}{l}\text { Tank-wall } \\
\text { rupture }\end{array}$ & 0.24 & 0.23 & 0.31 & 0.10 \\
\hline$S_{3}$ & Reactor internals & $\begin{array}{c}\text { Loss of shroud } \\
\text { support }\end{array}$ & 0.67 & 0.28 & 0.32 & 0.25 \\
\hline $\mathrm{S}_{4}$ & $\begin{array}{l}\text { Reactor enclosure } \\
\text { and control structure }\end{array}$ & $\begin{array}{l}\text { Shear-wall } \\
\text { failure }\end{array}$ & 1.05 & 0.31 & 0.25 & 0.42 \\
\hline $\mathrm{S}_{5}$ & CRD guide tube & Excess bending & 1.37 & 0.28 & 0.35 & $\overline{0.49}$ \\
\hline$\overline{S_{6}}$ & $\begin{array}{c}\text { Reactor pressure } \\
\text { vessel }\end{array}$ & $\begin{array}{l}\text { Loss of upper } \\
\text { support bracket }\end{array}$ & 1.25 & 0.28 & 0.22 & 0.55 \\
\hline $\mathrm{S}_{7}$ & $\begin{array}{l}\text { Hydraulic control } \\
\text { unit }\end{array}$ & $\begin{array}{l}\text { Loss of } \\
\text { function }\end{array}$ & 1.24 & 0.36 & 0.52 & 0.29 \\
\hline $\mathrm{S}_{8}$ & SLC test tank & Loss of support & 1.71 & 0.27 & 0.37 & 0.25 \\
\hline $\mathrm{S}_{9}$ & $\begin{array}{c}\text { Nitrogen accumulator } \\
\text { (SLC) }\end{array}$ & $\begin{array}{l}\text { Anchor-bolt } \\
\text { shearing }\end{array}$ & 1.80 & 0.27 & 0.20 & 0.37 \\
\hline$S_{10}$ & SLC tank & Wall buckle & 1.33 & 0.27 & 0.19 & 0.62 \\
\hline$S_{11}$ & $\begin{array}{c}440-V \text { bus } / S G \\
\text { breakers }\end{array}$ & Power circuit & 1.46 & 0.38 & 0.44 & 0.38 \\
\hline$S_{12}$ & $\begin{array}{c}\text { 440-V bus } \\
\text { transformer breaker }\end{array}$ & $\begin{array}{l}\text { Loss of } \\
\text { function }\end{array}$ & 1.49 & 0.36 & 0.43 & 0.41 \\
\hline$S_{13}$ & $125 / 250-V$ dc bus & $\begin{array}{l}\text { Loss of } \\
\text { function }\end{array}$ & 1.49 & 0.36 & 0.43 & 0.41 \\
\hline$S_{14}$ & 4-kV bus/SG & Breaker trip & 1.49 & 0.36 & 0.43 & 0.41 \\
\hline$S_{15}$ & $\begin{array}{c}\text { Diesel-generator } \\
\text { circuit }\end{array}$ & $\begin{array}{l}\text { Loss of } \\
\text { function }\end{array}$ & 1.56 & 0.32 & 0.41 & 0.47 \\
\hline$S_{16}$ & $\begin{array}{l}\text { Diesel-generator } \\
\text { heat and vent }\end{array}$ & Structural & 1.55 & 0.28 & 0.43 & 0.48 \\
\hline$S_{17}$ & RHR heat exchangers & $\begin{array}{l}\text { Loss of lower } \\
\text { support (anchor } \\
\text { bolts) }\end{array}$ & 1.09 & 0.32 & 0.34 & 0.37 \\
\hline
\end{tabular}


TABLE 2.1(b)

Nonseismic Random Failure Rates - Limerick

\begin{tabular}{|l|c|c|c|}
\hline \multicolumn{1}{|c|}{ System } & Designation & Mean & Error Factor ${ }^{*}$ \\
\hline Diesel Generators & $D_{R}$ & $1.25-3$ & 3.0 \\
\hline ADS & $X_{R}$ & $2.0-3$ & 10.0 \\
\hline RHR system & $W_{R}$ & $2.6-4$ & 6.0 \\
\hline Scram System & $C_{R}$ & $1.5-5$ & 3.75 \\
\hline SLC System & SLC $_{R}$ & $1.0-2$ & 2.8 \\
\hline HPCI System & $H_{R}$ & $8.8-2$ & 2.0 \\
\hline RCIC System & $R_{R}$ & $7.6-2$ & 2.3 \\
\hline Transfer & $G$ & $1.4-3$ & 3.0 \\
\hline
\end{tabular}

* Error factor equals $95 \%$ confidence value/median value 
TABLE 2.2(a)

Component and Seismic Fragility Parameters - Millstone 3

\begin{tabular}{|c|l|c|c|c|c|}
\hline & \multicolumn{1}{|c|}{ Structure/Equipment } & $\begin{array}{c}\mathrm{A} \\
(\mathrm{g})\end{array}$ & $\beta \mathrm{R}$ & $\beta \mathrm{U}$ & $\begin{array}{c}\text { HCLPF } \\
(\mathrm{g})\end{array}$ \\
\hline 1. & $\begin{array}{l}\text { Loss of Off-site Power (ceramic } \\
\text { insulator failure) }\end{array}$ & 0.20 & 0.20 & 0.25 & 0.10 \\
\hline 3. & $\begin{array}{l}\text { Emergency Generator Enclosure } \\
\text { Building (wall footing failure) }\end{array}$ & 0.88 & 0.20 & 0.46 & 0.30 \\
\hline 4. & Refueling Water Storage Tank & 0.88 & 0.30 & 0.36 & 0.30 \\
\hline 5. & $\begin{array}{l}\text { Emergency Diesel Generator (oil } \\
\text { cooler anchor bolt failure) }\end{array}$ & 0.91 & 0.24 & 0.43 & 0.30 \\
\hline 6. & $\begin{array}{l}\text { Reactor Vessel Core Geometry } \\
\text { Distortion }\end{array}$ & 0.99 & 0.31 & 0.33 & 0.34 \\
\hline 7. & $\begin{array}{l}\text { Gontrol Building Failure } \\
\text { (diaphragm) }\end{array}$ & 1.00 & 0.24 & 0.33 & 0.39 \\
\hline 9. & $\begin{array}{l}\text { Control Rod Drive System (failure } \\
\text { to SCRAM) }\end{array}$ & 1.00 & 0.30 & 0.38 & 0.33 \\
\hline 12. & $\begin{array}{l}\text { Service Water Pumphouse Failure } \\
\text { (sliding) }\end{array}$ & 1.30 & 024 & 0.49 & 0.39 \\
\hline 15. & $\begin{array}{l}\text { Reactor Coolant System Piping } \\
\text { (large LOCA) }\end{array}$ & 1.59 & 0.48 & 0.51 & 0.31 \\
\hline 16. & $\begin{array}{l}\text { Reactor Coolant System Piping } \\
\text { (small LOCA) }\end{array}$ & 1.59 & 0.48 & 0.51 & 0.31 \\
\hline 17. & Demineralized Water Storage Tank & 1.60 & 0.25 & 0.43 & 0.52 \\
\hline 20. & $\begin{array}{l}\text { Engineered Safeguard Features } \\
\text { Bldg.(base mat shear wall failure) }\end{array}$ & 1.70 & 0.23 & 0.43 & 0.57 \\
\hline 27. & Containment Crane Wall (collapse) & 2.20 & 0.39 & 0.38 & 0.62 \\
\hline 29. & Steam Generator Tube Rupture & 2.28 & 0.48 & 0.42 & 0.52 \\
\hline 30. & $\begin{array}{l}\text { Reactor Vessel } \\
\text { (support pads fail) }\end{array}$ & 2.35 & 0.48 & 0.44 & 0.52 \\
\hline 31. & Service Water System Pumps & 2.40 & 0.31 & 0.53 & 0.61 \\
\hline 32. & Reactor Coolant Pumps (large LOCA) & 2.68 & 0.43 & 0.47 & 0.61 \\
\hline 35. & Cable Trays & 2.70 & 0.48 & 0.42 & 0.62 \\
\hline & & & & & \\
\hline
\end{tabular}

TABLE 2.2(b)

Nonseismic Random Failure Rates - Millstone 3

\begin{tabular}{|c|c|c|c|}
\hline System & Designation & Median & Error Factor \\
\hline R5 & auxiliary feedwater & $5 \times 10-5$ & 4 \\
\hline R19 & onsite emergency power & $2 \times 10-4$ & 3 \\
\hline
\end{tabular}


TABLE 2.3(a)

Component and Seismic Fragility Parameters - Maine Yankee

\begin{tabular}{|c|c|c|c|c|c|}
\hline $\begin{array}{c}\text { Item } \\
\text { No. }\end{array}$ & Item & $A_{m}(g)$ & $\beta R$ & $\beta U$ & $\begin{array}{c}\text { HCLPF } \\
\text { Capacity (g) }\end{array}$ \\
\hline 4 & $\begin{array}{c}\text { Transformers } \\
(\times 507, \times 508)\end{array}$ & 0.84 & 0.30 & 0.32 & 0.30 \\
\hline 7 & $\begin{array}{c}\text { RWST } \\
(\text { TK }-4)\end{array}$ & 0.45 & 0.20 & 0.25 & 0.21 \\
\hline 8 & DWST & 0.36 & 0.20 & 0.26 & 0.17 \\
\hline 20 & $\begin{array}{c}\text { Circulating Water } \\
\text { Pumphouse }\end{array}$ & 0.69 & 0.24 & 0.27 & 0.30 \\
\hline
\end{tabular}

TABLE 2.3(b)

Nonseismic and random failure rates - Maine Yankee

\begin{tabular}{|c|c|c|c|}
\hline Item No. & Description & $\begin{array}{c}\text { Median } \\
\text { Unavailability } \\
\text { (per demand) }\end{array}$ & $\begin{array}{c}\text { Error } \\
\text { Factor }\end{array}$ \\
\hline 10 & $\begin{array}{c}\text { Operator Failure to Close PCC } \\
\text { Isolation Valves }\end{array}$ & $8.0 \mathrm{E}-02$ & 2 \\
\hline 11 & Random Failure of DG-1B & $4.2 \mathrm{E}-02$ & 5 \\
\hline 12 & Random Failure of DG-1A & $4.2 \mathrm{E}-02$ & 5 \\
\hline 13 & $\begin{array}{c}\text { Operator Failure to Place AFW } \\
\text { Pump Train B in Service Locally }\end{array}$ & $1.5 \mathrm{E}-01$ & 2 \\
\hline 14 & $\begin{array}{c}\text { Nonseismic Common Cause } \\
\text { Failure of DGS }\end{array}$ & $1.6 \mathrm{E}-03$ & 5 \\
\hline 15 & $\begin{array}{c}\text { Nonseismic Common Cause } \\
\text { Failure of AFW }\end{array}$ & $1.2 \mathrm{E}-04$ & 5 \\
\hline 16 & $\begin{array}{c}\text { Operator Failure to Refill DG } \\
\text { Fuel Tanks by Opening Valve or } \\
\text { Running P-33A,B }\end{array}$ & & 3 \\
\hline 17 & $\begin{array}{c}\text { Operator Failure to Place AFW } \\
\text { Pump Train B in Service from } \\
\text { MoR }\end{array}$ & & $3.0 \mathrm{E}-03$ \\
\hline 22 & $\begin{array}{c}\text { Random Failure of the Turbine } \\
\text { Driven Aux Feedwater Pump }\end{array}$ & $3.0 \mathrm{E}-02$ & 5 \\
\hline
\end{tabular}

"Error factor equals $95 \%$ Confidence Value/Median Value. 


\subsection{SEISMIC FRAGILITY}

\subsection{Basic Fragility Models}

The fragility of a component is defined as the probability of its reaching a limit state, conditioned on a particular value, $x$, of a random demand parameter, $X$ (Collins and Hudson, 1981; Kennedy and Ravindra, 1984; Casciati and Faravelli, 1991). In equation form,

$$
\text { Fragility }=P[L S \mid X=x, \theta]=F_{R}(x)
$$

in which $P[L S \mid X=x, \theta]$ is the conditional limit state probability given that $X=X$ and $\theta$ is a vector of fragility parameters, described subsequently. The first step in generating seismic fragilities is to develop a clear definition of what constitutes failure in critical plant components. Identification of credible modes of failure is largely based on the analyst's experience and judgement. The limit state LS, can be a functional failure, such as relay chatter or other erratic behavior of an electrical or mechanical component, loss of pressure boundary (e.g., rupture of the reactor pressure vessel or piping), or structural failures which range from inelastic deformations large enough to interfere with the operation of safety-related equipment to collapse. Functional failures or loss of pressure boundary may ensue from structural failures, making the latter particularly significant.

In a seismic PRA, the demand parameter commonly is peak ground acceieration or spectral acceleration (Kennedy and Ravindra, 1984), so the fragility defines the probability of failure given a value of acceleration. A seismic fragility evaluation of a particular component in a plant determines the acceleration value at or above which it fails. A point estimate of the limit state probability can be obtained by convolving the fragility with a seismic hazard curve, $G_{A}(x)$, thus removing the conditioning on acceleration:

$$
P[L S, \theta]=-\int_{0}^{\infty} P[L S \mid A=x, \theta] \frac{d_{A}}{d x} d x
$$

The parameters at the fragility-hazard interface (peak ground acceleration, spectral acceleration) must be consistent for the risk estimates to be meaningful.

There are numerous sources of variability in the prediction of component seismic fragility. These arise from inherent randomness in the strengths of components, dynamic characteristics of the plant systems, variability in response to ensembles of earthquake acceleration records with the same peak ground acceleration but different frequency contents 
and strong-motion durations, and the ability of analysts to model the plant systems accurately. Uncertainties also arise in the functional form of the fragility model itself, whether the supporting data are based on generic or plant-specific data, the manner in which inelastic behavior and energy dissipation is taken into account, whether functional or stochastic dependence is included in the fragility models, and whether the possibility of design/construction errors is included.

The most common method of describing the fragility of a component in a NPP is to use a lognormal model (Kennedy and Ravindra, 1984).

$$
F_{R}(x)=\Phi\left(\frac{\ln \left(x / A_{R}\right)}{\beta_{R}}\right)
$$

in which $\Phi()=$ standard normal probability integral, $A_{R}$ is the median (50th percentile) fragility, and the logarithmic standard deviation $\beta_{R}$ describes the inherent variability in the capacity of a component subjected to an earthquake with peak ground acceleration, $x$. In this approach, uncertainties due to modeling and imperfect information are assumed to affect only the estimated median, $A_{R}$. This modeling uncertainty is taken into account by assuming that $A_{R}$ is also a lognormal variable, with median $A_{m}$ and logarithmic standard deviation $\beta U$, leading to a family of lognormal distributions that describe component fragility. Thus, three parameters, $A_{m}, \beta R$ and $\beta U$ are required to describe the fragility family for any component. A fragility family so determined for the LGS reactor enclosure structure $\left(\mathrm{S}_{4}\right.$ in Table 2.1(a)) is illustrated in Figure 3.1. This fragility family, if plotted on lognormal probability paper, would appear as a set of parallel lines, each with slope $\beta R$. Fragility parameters for the three plants considered are tabulated in Tables 2.1 - 2.3 .

The inherent randomness described by $\beta_{R}$ in the fragility of a component arises from such factors as the variability associated with earthquake input with peak ground acceleration $\times$ (random phasing), structural response and material strength. Conceptually, $\beta R$ represents those sources of uncertainty that are irreducible. Uncertainty $\beta U$ denotes contributions to variability due to the state of knowledge, including modeling uncertainties and imperfect information; the effects of approximate structural analysis, the use of generic rather than plantspecific data in determining $A_{m}$, response of functionally similar components supplied by different manufacturers, errors in assigning damping values, etc., are included in $\beta U$. In contrast with $\beta R, \beta U$ should be reducible with the acquisition of additional data. The distinction between inherent (or frequentist) and subjective uncertainty is not always clearcut. Both types of uncertainty exist for the same variables. It is convenient to separate them in risk analysis because the elements of 
subjectivity can be made explicit for purposes of analysis and review. Of course, what appears to be randomness or uncertainty may change with time as additional data about the phenomenon measured become available.

In some risk studies, the uncertainties due to inherent randomness and modeling are combined, and a composite fragility curve is defined as,

$$
F_{R}(x)=\Phi\left(\frac{\ln \left(x / A_{m}\right)}{\sqrt{\beta_{R}^{2}+\beta_{U}^{2}}}\right)
$$

in which $\beta_{C}=\sqrt{\beta_{R}^{2}+\beta_{U}^{2}}$ is the overall measure of uncertainty (Hwang, 1989). The composite fragility $F R(x)$ may be shown to equal the expected value of $F_{R}$ defined in Eqn 3.3 (Kaplan, et al, 1989), the expectation being taken with respect to the (random) median, $A_{R}$ :

$$
E\left[F_{R}(x)\right]=\int_{0}^{\infty} \Phi\left(\frac{\ln (x / y)}{\beta_{R}}\right) f_{A_{R}}(y) d y
$$

The current treatment of uncertainty in fragility in which randomness $\beta R$ is assumed known and only the median $A_{m}$ is uncertain (measured through $\beta U$ ) is different from the treatment of uncertainty in seismic hazard, which is done through the elicitation of expert opinion. If a similar procedure were used for fragility, both $A_{m}$ and $\beta_{R}$ would be assumed to be uncertain, and the individual fragility curves might cross one another.

The lognormal model is relatively convenient to use. The central limit theorem of probability also provides some theoretical justification for its use in cases where the capacity can be described approximately as the product of several (independent) random variables. The lognormal distribution is the maximum entropy distribution for positive random variables for which only the mean and standard deviation are known (Goodman, 1987; Alderson, 1987). However, the lognormal distribution is defined on the interval $(0, \infty)$ and thus admits a small but finite probability of essentially zero strength. Fragility functions should, in fact, have lower and upper limits since components certainly fail above some value, $x_{\max }$, and certainly survive below a minimum value, $x_{\min }$. The convolution of fragility and hazard to determine a point estimate of core damage probability normally involves only the upper portion of the seismic hazard curve and the lower portion of the fragility (see Eqn 3.2). As a result, the upper tail of the fragility is of little consequence but the shape of the lower tail and whether it is truncated might be significant. Moreover, depending on the plant logic, the shape of the lower tail of the 
component fragility may be amplified in determining the system fragility that is convolved with $G_{A}$ to determine the accident sequence probability. In a series system, if the component fragilities are unbounded to the left, the median of the sequence fragility decreases as the number of components in series increases.

The question of whether neglecting the limits or tails of the distributions is important depends on the relative positioning of the seismic hazard curve with respect to the fragility and the relative dispersion of the two functions in Eqn 3.2. The precise form of the extremes is not important in reliability analyses of common building construction because the design values are not far enough into the tails (Ellingwood, et al, 1982). Although it has been suggestrod that the lower tail of the lognormal fragility might be truncated at, say, 2 logarithmic standard deviations below the median (Kennedy and Ravindra, 1984), such arbitrary truncations are difficult to justify. It may be important to model the lower portion of the fragility accurately.

The Weibull distribution provides an alternative fragility model, one that might be justified on the basis of a weakest link failure hypothesis (Mann, et al, 1974). The Weibull distribution is given (in its general three-parameter form) as,

$$
F_{R}(x)=1-\exp \left[-\left(\frac{x-\mu}{\sigma}\right)^{\gamma}\right] ; x \geq \mu
$$

in which $\mu, \sigma$ and $\gamma$ are parameters of the distribution. The mean and coefficient of variation are related to the distribution parameters through,

$$
\begin{aligned}
& \text { mean }=\mu+\sigma \Gamma\left(1+\frac{1}{\gamma}\right) \\
& \text { median }=\mu+\sigma(\ln 2)^{\frac{1}{\gamma}} \\
& \text { mode }=\mu+\sigma\left(\frac{\gamma-1}{\gamma}\right)^{\frac{1}{\gamma}} \\
& \text { c.o.v. }=\sigma\left[\Gamma\left(1+\frac{2}{\gamma}\right)-\Gamma^{2}\left(1+\frac{1}{\gamma}\right)\right]^{1 / 2} /\left[\mu+\sigma \Gamma\left(1+\frac{1}{\gamma}\right]\right.
\end{aligned}
$$


In the limiting case as the lower limit of the distribution, $\mu$, approaches 0 , we obtain the familiar two-parameter form of the distribution. As with the lognormal fragility model, it may be assumed that modeling uncertainty is vested in the estimate of the median, whence the median is treated as a lognormal variate with logarithmic standard deviation $\beta U$.

A third fragility model is the modified lognormal distribution, sometimes referred to as a Johnson distribution (Goodman, 1985):

$$
F_{R}(x)=\Phi\left[\frac{\ln \left(\frac{x-x_{\min }}{x_{\max }-x}\right)-\lambda}{\zeta}\right]
$$

in which $x_{\max }$ and $x_{\min }$ define the upper and lower limits of the distribution and $\lambda$ and $\zeta$ are distribution parameters. These distribution parameters are related to the mean and coefficient of variation by:

$$
\begin{aligned}
\lambda & =\left(x_{\min }+x_{\max } \theta^{\lambda}\right) /\left(\theta^{\lambda}+1\right) \\
\zeta & =\frac{\left(x_{\min }+x_{\max }\right) A_{m} V_{R}}{\left(X_{m}-x_{\min }\right)\left(x_{\max }-A_{m}\right)}
\end{aligned}
$$

in which $A_{m}$ and $V_{R}=$ median and c.o.v of $R$. As a four-parameter distribution, Eqn 3.9 requires data (or a reasonable assumption) on parameters $x_{\min }$ and $x_{\max }$, as well as on central value and dispersion to estimate $\lambda$ and $\zeta$. Eqn 3.8 is a "maximum entropy" distribution for a random variable in which the mean, standard deviation and range are known (Goodman, 1985). To obtain the fragility family needed to describe modeling uncertainty, one might again assume that the median is described by a lognormal distribution, with logarithmic standard deviation $\beta U$ as before.

\subsection{Seismic Margin Analysis}

A seismic margin study focuses on identifying areas of plant vulnerability to earthquakes rather then on risk (Vollmer, 1987; Budnitz, et al, 1985) and on fragilities of components and plant systems. A review earthquake is selected, generally on the order of two to three times the SSE in the Eastern United States. The analysts then attempt to demonstrate that the "minimum" plant capacity is at least equal to the review earthquake "with high confidence" or, if not, to find the HCLPF defined in the next paragraph.

To establish "minimum" and "high confidence", seismic margin studies utilize a parameter denoted the HCLPF, or "high confidence, low probability of failure" value of fragility. The HCLPF for a component often 
is interpreted as the lower $95 \%$ confidence interval estimate of the $5 \%$ exclusion limit on fragility. The 5-percent exclusion limit is that value of capacity below which 5 percent of all similar component capacities would lie, assuming that median $A_{R}$ and $\beta_{R}$ can be estimated accurately. The, uncertainty in the estimation of the distribution parameters that arise from modeling errors, lack of data, etc., is handled in an approximate way by treating $A_{R}$ as a lognormal random variable as well, with median $A_{m}$ and logarithmic standard deviation $\beta U$.

With the lognormal model described above, the component HCLPF can be estimated as,

$$
H C L P F=A m \exp [-1.645(\beta R+\beta U)]
$$

in which the constant 1.645 is the percent point function of a standard normal variate at its $5 \%$ ile value. The HCLPF value is illustrated in Figure 3.1 for the LGS reacter enclosure building. The plant HCLPF then is determined (it can be determined approximately in terms of the component HCLPF values, as described in Section 5.3) and is compared with the review level earthquake. Development of fragility families for a large number of components in a PRA or in a margin review is time-consuming using the above method. For preliminary screening purposes, it may be sufficient to estimate $A_{m}$ from the results of an analyisis of the structural or component response using best-estimates of the basic variables and to assume simply that $\beta_{R}+\beta_{U} \approx 0.7$. This simplification was done in some of the preliminary screening in Maine Yankee (Prassinos, et al, 1987).

In passing, it may be easier for analysts to estimate the HCLPF directly from a "conservative deterministic failure margin" (CDFM) analysis (Kennedy and Campbell, 1985), particularly if the analyst is not probabilistically trained. It is believed to be is possible to estimate the median (best estimate) and HCLPF (conservative estimate) more reliably with only limited data than it is to estimate $\beta R$ and $\beta U$, which are dispersion parameters that require a minimum amount of test replication. The significance of this estimation procedure in terms of risk will be examined in Section 5 .

\subsection{Appraisal of Fragility Analysis and Data}

Seismic fragilities of mechanical, electrical and structural components are estimated from the original plant design calculations (Reed and M.cCann, 1984), supplemented by information on the dynamic response of the component in the as-built condition using in-situ strengths, dimensions and support conditions. Since design calculations are conservative, the design estimates are adjusted by a series of factors 
in order to obtain best estimates of the in-situ median capacity and variability. In general, the capacity is modeled in the form:

$$
R=F_{S} F_{r S} S S E
$$

in which $F_{S}$ is a strength factor, $F_{r S}$ is a response factor and SSE is the safe-shutdown earthquake acceleration. The strength factor $F_{S}$ is defined by,

$$
F_{s}=F_{s t} F_{\mu}
$$

in which $F_{s t}$ is the margin of strength over design strength and $F_{\mu}$ accounts for additional capacity provided by energy dissipation and ductiiity. The response factor $F_{r s}$ takes into account differences between the actual response and the response computed from the design spectrum, assumptions regarding damping, conservatism in modeling, soil-structure interaction, duration of earthquake, and similar factors;

$$
F_{r s}=F_{r} F_{d} F_{m} F_{s s i} \ldots
$$

This formulation lends itself to the lognormal fragility model, since if the variability in each of the correction factors in Eqns 3.11 is described by a statistically independent lognormal random variable, $R$ will also be lognormal, with a median an logarithmic standard deviation given by,

$$
\begin{aligned}
& R=\prod_{i} F_{i} \text { SSE } \\
& \beta_{R}=\sqrt{\left(\Sigma \beta_{R_{i}}^{2}\right)} \\
& \beta_{U}=\sqrt{\left(\Sigma \beta_{u_{i}}^{2}\right)}
\end{aligned}
$$

A review of fragility analyses of several plants (LGS, Millstone 3, Zion, Indian Point) indicates that fragility determinations for structures usually are plant-specific. Structural failures can be particularly significant because they may affect several systems simultaneously, increasing the possibility of correlated or common-cause failures. Components that are important in internal and external event PRAs may not be the same. Structural components seldom appear in an internal events PRA, for example.

One difficulty in estimating structural fragility is in identifying an appropriate failure point (limit state). Failure generally is based on a level of (inelastic) deformation sufficient to endanger the operability of 
safety-related equipment in the plant (e.g., Kennedy and Ravindra, 1984). It is generally agreed that deformations that affect the operation of equipment are substantially less than those associated with structural failure. Beyond this, however, there seems to be no consistent definition of limiting structural deformations causing failure. The factor $F_{\mu}$ in Eqn $3.11 \mathrm{~b}$ accounts for inelastic deformation capacity in an approximate way. In the velocity and acceleration-amplified region of the response spectrum $F_{\mu}$ can be approximated by $\mu$ and $\sqrt{(2 \mu-1)}$, respectively, in which $\mu=$ ductility factor, the ratio of maximum displacement to yield displacement, or by expressions that depend on damping as well (Riddell and Newmark, 1979; Kennedy, et al 1984). However, if $F_{\mu}$ is based on inelastic cyclic capacity determined, in part, from structural testing, such tests typically involve large deformations and significant structural damage.

Nonlinear behavior is a potentially important aspect of structural fragility and one that is difficult to validate without experimental data. The extrapolation of the results of damage assessments of non-nuclear plant structures to structural component fragility analysis is questionable. On one hand, structural damagis is not a good indicator of function failure of plant structural componants because the structureequipment interaction is not considered. On the other hand, the use of building damage data in estimating structural component fragility is conservative in the sense that there generally is no information on the percentage of buildings damaged.

The determination of fragilities for mechanical and electrical equipment, in contrast to structural components, tends to be generic. Sources of fragility information for mechanical and electrical equipments include the SAFEGUARD program (with testing generally conducted with shock or short-duration sinusoidal excitation), SQUG (based on an evaluation of historical performance), and GERS (Kennedy and Campbell, 1985). Responses of functionally similar components supplied by different manufacturers may not be the same. These differences should be taken into account through the value of $\beta u$ assigned to $A_{m}$. Equipment qualification test data, when used, generally provide a lower bound on fragility (Cover, et al, 1985; Holman and Chou, 1987).

Single-parameter characterizations of fragility such as those described by the above models are convenient but lose something in their simplicity. For example, peak ground acceleration is not a good indicator of structural damage potential (Hall, 1982). Damageability depends on peak response, duration, and number of strong motion cycles, which is difficult to capture in one parameter. Energy imparted to and dissipated by the structure would be a preferable measure of damage. Moreover, design and construction errors have not been included in a systematic way 
in fragility modeling to date. We will return to this topic in Section 6 . In sum, the fragility estimation procedure is not robust and it remains an open question as to how significant this lack of robustness is in terms of seismic PRA or margin results. Many feel that median fragilities tend to be estimated conservatively, while at the same time sources of uncertainty may be neglected. These errors in estimation are selfcompensating to a degree. However, they may affect the validity of PRA results, especially when failures are functionally or statistically dependent.

\subsection{Fragility Parameters for Plants Studied}

The original fragility modeling of critical components at the Limerick, Millstone and Maine Yankee plants utilized the double lognormal fragility model. These are summarized in Tables 2.1(a) - 2.3(a) of Section 2. The medians generally were obtained by scaling up from the SSE elastic design basis to account for factors of safety used in design, differences in the shape of the site-dependent response spectrum from that assumed for design, increases in damping, dissipation of energy through inelastic cycling, soil structure interaction, and other similar effects (viz Eqns 3.11). The capacities of electric components were based on generic test data. The fragility parameters for the LGS are referenced to an "effective" peak ground acceleration. For Millstone 3, and Maine Yankee, the $A_{m}$ are referenced to the instrumental peak. This is discussed further as part of the seismic hazard modeling in Section 4.

\section{Addendum A3. Estimation of Fragility Parameters}

The seismic fragility of a component is defined as the probability of failure, given that the effective peak ground acceleration, EPA, (or spectral acceleration, in some studies) is equal to $x$. The most common way of modeling component seismic fragility is through a lognormal model (Eqn 3.3) in which the three parameters $A_{m}, \beta_{R}$ and $\beta_{U}$ define a family of fragility curves which, collectively, represent inherent and modeling uncertainty in the capacity of a component to withstand earthquake ground motion.

\section{A3.1 Estimation of $A_{m}$ and $\beta_{R}$ with Limited Data}

The estimation of the parameters $A_{m}$ and $\beta_{R}$ invariably are based on limited data and professional judgement. Often, only "minimum" and "maximum" values of component fragility, $X_{L}$ and $X_{U}$, can be postulated. This information can be used to estimate $A_{m}$ and $\beta_{R}$. If $\alpha$ represents the probability that the fragility falls outside the range $\left(X_{L}, X_{U}\right)$, then

$$
X_{L}=A_{m} \exp \left(\Phi^{-1}\left(\frac{\alpha}{2}\right) \beta_{R}\right)
$$




$$
X_{U}=A_{m} \exp \left(\Phi^{-1}\left(1 \frac{\alpha}{2}\right) \beta_{R}\right)
$$

in which $\Phi^{-1}(\quad)=$ percent point function of the standard normal cumulative probability distribution function (c.d.f.). Since this c.d.f. is symmetric about zero, the median capacity can be estimated as,

$$
A_{m}=\sqrt{\left(X_{L} X_{U}\right)}
$$

The mode (most likely value) of capacity is,

$$
\text { Mode }=A_{m} \exp \left(-\beta_{R}^{2}\right)
$$

and the mean is,

$$
\text { Mean }=A_{m} \exp \left(+\beta_{R}^{2} / 2\right)
$$

The lognormal c.d.f. is skew-positive and thus Mode < Median < Mean. The median or mode are more desirable location parameters when limited data are available because their estimation is relatively less sensitive to tail behavior of the fragility and the presence of outliers. Outliers and their significance are particularly difficult to assess in small data sets.

The parameter $\beta_{R}$ also can be evaluated from $X_{L}$ and $X_{U}$. Using Eqn A3.1, we find that

$$
\begin{aligned}
\beta_{R} & =\ln \sqrt{\left(X_{U} / X_{L}\right) /} \Phi^{-1}\left(1 \frac{\alpha}{2}\right) \\
& \approx \ln \left(X_{U} / X_{L}\right)^{1 / 2} \text { if } \alpha=32 \text { percent; } \\
& \approx \ln \left(X_{U} / X_{L}\right)^{1 / 3} \text { if } \alpha=13 \text { percent; } \\
& \approx \ln \left(X_{U} / X_{L}\right)^{1 / 3.29} \text { if } \alpha=10 \text { percent; } \\
& \approx \ln \left(X_{U} / X_{L}\right)^{1 / 4} \text { if } \alpha=5 \text { percent; }
\end{aligned}
$$

\section{A3.2 Standard Error in Estimation of the Median}

The estimation of the median is important in fragility modeling because it positions the fragility family with respect to the seismic hazard or margin review earthquake. In the following sections, several alternate methods for estimating the median fragility are evaluated. Only the lognormal fragility model will be considered because of its prevalence 
in seismic PRA and margin studies. Similar results would be obtained if other models were chosen.

Let $X_{i}, i=1, \ldots, n$, be a random sample drawn from a population represented by the lognormal random variable, $X$. Any estimator of the median, $Y$, from this sample has associated with it a sampling distribution. The qualities of $Y$ as an estimator can be inferred from the characteristics of this sampling distribution.

The maximum likelihood estimate (MLE) of the median can be obtained from,

$$
\ln Y_{1}=\sum_{i=1}^{n} \ln X_{i} / n
$$

or, equivalently,

$$
Y_{1}=\left(X_{1} X_{2} \ldots X_{n}\right)^{1 / n}
$$

The sampling density for $\ln Y_{1}$ is normal. The MLE is asymptotically unbiased (Mann, et al, 1974). Assume that the true (unknown) median of $X$ is $1.0 \mathrm{~g}$ (from past seismic PRAs, median seismic fragilities for structural, electrical and mechanical equipment typically are of this order) and the coefficient of variation ranges from 0.2 to 0.5 , a typical range in fragility analysis. The mean and standard deviation in the estimate of $Y_{1}$ obtained from Eqn A3.7 are summarized in Table A3.1.

Next, consider the estimate of the median from Eqn A3.3, i.e.,

$$
Y_{2}=\left(X_{L} X_{U}\right)^{1 / 2}
$$

The sampling density for $Y_{2}$ is,

$$
f_{Y_{2}}(y)=\int_{0}^{\infty} f_{X_{L}}(x) F X_{U}\left(y^{2} / x\right)(2 y / x) d x
$$

The density $f_{X_{L}}(x)$ and distribution $F_{X}(x)$ can be found from the order statistics of the sample of $n$ (Mann, et al, 1974). The expected value, variance and standard deviation of the median $Y_{2}$ estimated by Eqn A3.9 are,

$$
E[Y]=\int_{0}^{\infty} y f_{Y_{2}}(y) d y=\mu_{Y_{2}}
$$




$$
\begin{aligned}
& V[Y]=\int_{0}^{\infty}\left(y-\mu_{Y_{2}}\right)^{2} f_{y}(y) d y \\
& S D[Y]=\sqrt{\operatorname{Var}[Y]}
\end{aligned}
$$

The results of the evaluation of this estimator are summarized in Table A3.2. The sampling distribution is slightly skew-positive. This estimator is asymptotically unbiased for large $n$.

Finally, suppose (without significant loss of generality) that $n$ is odd. If the samples are rank ordered so that $X_{1}<X_{2}<\ldots<X_{n}$, the median of the sample can be estimated as,

$$
\mathrm{Y}_{3}=\mathrm{X}_{(\mathrm{n}+1) / 2}
$$

Since $n$ is odd, $\frac{\left(\frac{n+1}{2}\right)}{2}$ will always be an integer, which simplifies the subsequent analysis. The sampling density function of estimator $Y_{3}$ can be shown to be,

$$
f_{Y_{3}}(y)=\left(n ! /\left[\left(\frac{n-1}{2}\right) !\right]^{2}\right)\left[F_{X}(y)\left(1-F_{X}(y)\right)\right]^{\frac{n-1}{2}} f_{x}(y)
$$

in which $f_{X}=$ probability density function of $X$. Table A3.3 summarizes the mean and standard deviation of the median $Y_{3}$ for 5 to 25 samples for the same cases as in Tables A3.1 and A3.2. As with the other two estimators, Eqn A3.14 provides an asymptotically unbiased estimate of the median as $n$ becomes large. Under the assumption that the sampling distribution for $\mathrm{Y}_{3}$ is approximately normal, the $95 \%$ confidence bounds on the estimate of the median from a sample of 5 from a population with an inherently large c.o.v. (e.g., $\left.V_{X}=0.4\right)$ are $(0.61,1.43)$.

A comparison of Tables A3.1 - A3.3 shows that while all the estimators are asymptotically unbiased, the standard deviations in the estimators are not the same. Using the standard deviations as a relative measure of efficiency, estimating median fragilities from rank ordered data is nearly as efficient as using the MLE method. SD[Y] is larger than $S D\left[Y_{2}\right]$ for samples of 5 but is smaller than SD[Y, for samples of 15 or greater. Thus, estimator $Y_{2}$ (Eqn A3.9) is best for small samples ( $n=5$ or less). Moreover, $Y_{2}$ is the most practical estimator to use when data are limited and its standard error is not significantly larger than the standard errors associated with the MLE.

In passing, the fragility estimation procedure would not improve significantly if the mean rather than the median were used as as the "best estimate" of fragility and were based on the method of moments: 


$$
Z=\left(X_{1}+X_{2}+\ldots .+X_{n}\right) / n
$$

This estimator is unbiased; however, the standard deviation of $Z$ is $S D[X] / \sqrt{n}$, and for the example above, the $95 \%$ confidence interval on $Z$ is $(0.65,1.35)$, which is not a significant improvement. Moreover, one outlier can skew the estimate of the mean from Eqn A3.16 significantly, whereas the median is less likely to be affected by outliers. 
TABLE A3.1

Sampling Distribution of MLE $Y_{1}$

\begin{tabular}{ccccccccc} 
& \multicolumn{2}{c}{$V_{x}=$} & 0.2 & \multicolumn{2}{c}{$V_{x}=0.3$} & \multicolumn{2}{c}{$V_{X}=0.4$} & \multicolumn{2}{c}{$V_{X}=0.50$} \\
$n$ & Mean & SD & Mean & SD & Mean & SD & Mean & SD \\
5 & 1.004 & 0.089 & 1.009 & 0.133 & 1.015 & 0.176 & 1.023 & 0.218 \\
15 & 1.001 & 0.051 & 1.003 & 0.076 & 1.005 & 0.100 & 1.007 & 0.123 \\
25 & 1.001 & 0.040 & 1.002 & 0.059 & 1.003 & 0.077 & 1.004 & 0.095
\end{tabular}

TABLE A3.2

Sampling Distribution of $Y_{2}=\left(X_{L} X_{U}\right)^{1 / 2}$

\begin{tabular}{ccccccccc} 
& \multicolumn{2}{c}{$V_{x}=0.2$} & \multicolumn{2}{c}{$V_{x}=0.3$} & \multicolumn{2}{c}{$V_{x}=0.4$} & \multicolumn{2}{c}{$V_{x}=0.5$} \\
$n$ & Mean & $S D$ & Mean & SD & Mean & SD & Mean & $S D$ \\
5 & 1.004 & 0.094 & 1.010 & 0.139 & 1.022 & 0.184 & 1.026 & 0.227 \\
15 & 1.003 & 0.077 & 1.007 & 0.114 & 1.011 & 0.151 & 1.017 & 0.185 \\
25 & 1.002 & 0.071 & 1.005 & 0.106 & 1.009 & 0.139 & 1.014 & 0.171
\end{tabular}

TABLE A3.3

Sampling Distribution of $Y_{3}=X_{(n+1) / 2}$

\begin{tabular}{ccccccccc} 
& \multicolumn{2}{c}{$V_{x}=0.2$} & \multicolumn{2}{c}{$V_{x}=0.3$} & \multicolumn{2}{c}{$V_{X}=0.4$} & \multicolumn{2}{c}{$V_{X}=0.5$} \\
$n$ & Mean & SD & Mean & SD & Mean & SD & Mean & SD \\
5 & 1.006 & 0.110 & 1.012 & 0.160 & 1.022 & 0.210 & 1.032 & 0.265 \\
15 & 1.002 & 0.063 & 1.004 & 0.095 & 1.008 & 0.124 & 1.011 & 0.153 \\
25 & 1.001 & 0.050 & 1.003 & 0.073 & 1.005 & 0.097 & 1.007 & 0.119
\end{tabular}




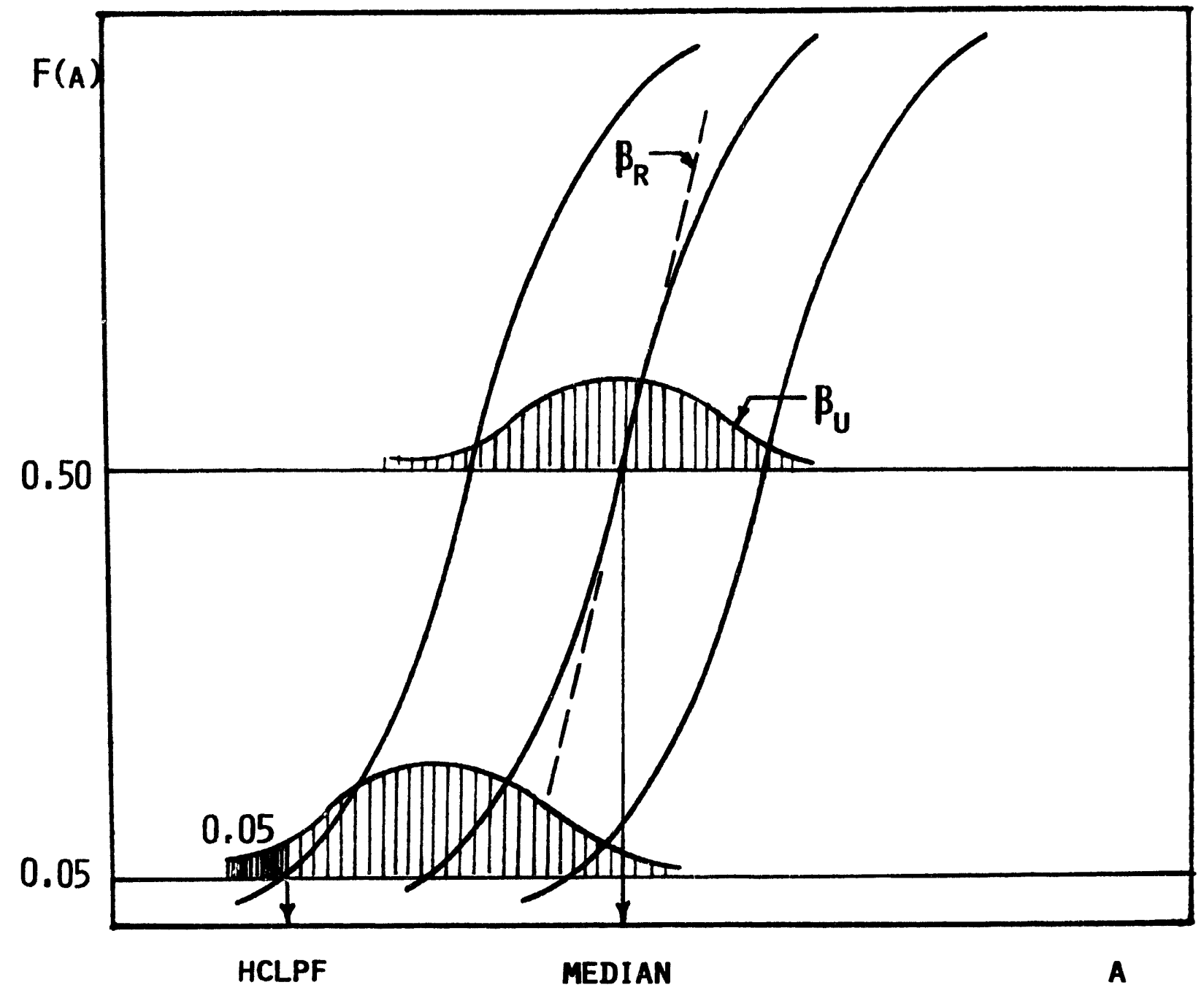

Figure 3.1

Lognormal Fragility Model for Limerick Generating Station Peactor Enclosure Structure $\left(\mathbf{S}_{4}\right)$ 


\subsection{SEISMIC HAZARD ANALYSIS}

The seismic hazard at a site is defined in terms of the maximum level of ground motion (or spectral acceleration) for which an engineered facility must be designed. Seismic hazard analysis should be viewed as a tool for decision-making, and the nature of the application determines the characteristics of the ground motion (or spectral) parameters sought (Reiter, 1990). Research in seismology and earthquake-resistant design during the past 20 years has enabled seismic hazard analysis and design ground motions for a particular site to be placed on a probabilistic basis (Cornell, 1968; Algermissen, et al, 1982; McGuire, 1976). Earthquake hazards in the Western United States generally can be associated with a series of capable faults. Such faults are not apparent in the Eastern United States, and the seismic hazard analysis there begins with an identification of postulated seismic source zones. These zones of potential future earthquake occurrence are determined from a review of local geology and historic seismicity. The mean rates of occurrence of earthquakes of various magnitudes (or intensities) within each zone are defined by,

$$
\log n(M)=A-B M
$$

in which $n(M)=$ mean annual number of earthquakes with magnitude $M$ and $A$ and $B$ are parameters obtained from historical seismicity data.

Attenuation functions are developed to propagate the earthquake ground motion parameter(s) from the source to the plant site. Such attenuation functions typically relate the site ground motion (acceleration or velocity) to magnitude and epicentral distance (Donovan, 1974; Campbell, 1985). A typical relation would be (Nuttli, 1979),

$$
A=A_{0}(f) R^{-5 / 6} \exp (-\gamma R)
$$

in which $R=$ epicentral distance, $A_{0}(f)$ is a frequency-dependent amplification factor, $R^{-5 / 6}$ represents spreading and $\gamma=$ an elastic attenuation factor.

Finally, a probability distribution of effective peak ground acceleration at the site is determined by summing (integrating) over all possible sources, magnitudes and distances consistent with each underlying source hypothesis. The result is usually presented as a complementary cumulative distribution function, $G_{A}(a)$, or seismic hazard curve, showing the annual probability of exceeding a specified ground acceleration, $a$, as a function of $a$. 
Typical seismic hazard curves for sites in the Western US and the Eastern US are compared in Figure 4.1. The curve in the Eastern US is much flatter than that in the Western US. This is because of the relatively larger uncertainty associated with Eastern seismicity due to the absence of large historical events during the period of modern instrumentation. The Western hazard curve may saturate at acceleration levels on the order of 1.2 to 1.8 times the design earthquake; in the Eastern US, the saturation level is unknown, but is believed to be on the order of at least 3 or 4 times the design earthquake.

Numerous sources of uncertainty affect the seismic hazard analysis. Some of these are inherently random, e.g., the magnitude and location of the next earthquake in the seismic source zone and characteristics of ground motion at the site. Other sources of uncertainty are due to lack of knowledge, and thus are reducible with additional data; identification of source mechanisms (seismotectonic provinces), maximum magnitude events associated with a source, and ground motion attenuation fall in this category of uncertainty. However, additional information to reduce this uncertainty may be costly and time-consuming to obtain, particularly at the time of decision-making.

Each postulated source hypothesis and attenuation function gives rise to a seismic hazard curve. The uncertainty in seismic hazard is displayed as a family of seismic hazard curves, each with an assigned probability that reflects its relative credibility. If there are numerous competing source hypotheses and attenuation models, the family can become quite large, and the families often are aggregated to reduce the number of seismic hazard curves to a manageable size. The method by which this aggregation is performed varies from PRA to PRA. The hazard curve family at a given peak ground acceleration often is modeled by a lognormal distribution.

During the 1980's, two research programs were conducted to estimate the seismic hazard at nuclear plant sites in the Eastern United States. One was funded by the U.S. Nuclear Regulatory Commission at Lawrence Livermore National Laboratory (LLNL). The other was undertaken by the Electric Power Research Institute (EPRI). Both programs drew upon elements of the basic approach described above and both utilized expert opinion to complement the limited data on historical seismicity in this region. However, there were some differences. In terms of seismicity, the original LLNL study considered earthquakes of magnitude 3.75 and above, while the EPRI study considered only earthquakes of magnitude 5.0 and above. The attenuation relations describing ground motion at the site were different. Finally, the method for aggregating the experts' opinion embodied in source hypotheses and attenuations differed. A comparison of these two approaches (Bernreuter, et al, 1987) showed that the fractiles 
of the LLNL hazard curves at a given peak ground acceleration could be as much as an order of magnitude higher at some sites than the corresponding fractiles of the EPRI hazard curves. However, the results were similar when the same basic ground motion models and lower bound magnitudes were used. Thus, the hazard methodology is relatively robust, but appears to be sensitive to the data on basic seismicity and to expert opinion.

Most engineers feel that small magnitude earthquakes are not capable of causing damage to well-engineered structures, and that it is appropriate to screen events smaller than a certain magnitude out of the historical seismicity data bank that is used to define Eqn 4.1. The lower bound magnitude becomes relatively more important at shorter epicentral distances because the high frequency acceleration peaks do not attenuate as much at short distances. The issue concerning the lower bound magnitude was resolved subsequently by setting the lower bound magnitude at 5.0 (Bernreuter, et al, 1989). At present, the median hazard curves obtained from the EPRI and LLNL methods are similar, but the uncertainty band on the hazard family using the LLNL method is somewhat larger.

Most seismologists agree that there should be an upper bound to the ground acceleration that can be generated near the earth's surface. However, the physical processes that determine the limit are not well understood and thus there is a lack of agreement as to what the upper limit should be. Some seismic hazard curves used in PRAs saturate at an upper limit; others do not, and the trend in the more recent seismic hazard analyses (Bernreuter, 1989; EPRI, 1989) is toward seismic hazard curves that are unbounded from above. The important issue then is whether the upper limit or lack of one has a significant impact on risk estimates. This issue is examined subsequently.

The seismic hazard and component fragility curves in each family are convolved to obtain a point estimate of component failure probability, as described subsequently in Section 5 . The hazard and fragility models must not only be dimensionally consistent but also must represent realistically the capability of the ground motion to damage engineered structures and equipment (hazard/fragility interface). It is well known that capability of ground motion to cause damage is reflected not only in the peak intensity of the ground motion but in its duration and frequency content as well. Instrumental peak acceleration is a poor measure of the capability of ground motion to cause damage in engineered facilities, particularly for near-field events. Large-magnitude events with a given peak ground acceleration are far more damaging to a component than a smaller event with the same peak ground acceleration but with a shorter duration of excitation and narrow distribution of energy in a relatively high frequency domain. The capacity of Eastern earthquakes to cause 
damage to structures and equipment is different from that indicated by Western accelerograms, which have been used in most of the laboratory and numerical studies of component response to earthquakes conducted to date (Kennedy, et al, 1984). Current seismic hazard analyses usually are based on a one-parameter characterization of ground motion (the effective peak acceleration, or EPA). The EPA encapsulates the effects of intensity, frequency content, duration and capability to cause damage in one parameter (Hall, 1982). Damageability of ground motion is treated in some seismic hazard analyses by reducing the instrumental peak acceleration for smaller-magnitude events. The median seismic fragilities for certain components also are sometimes adjusted. The procedure by which damagability is incorporated needs to be standardized; there is evidence that factors that account for damage potential may be double-counted in some PRAs.

For analytical studies of the sort performed herein, it is desirable to have closed-form representations of the seismic hazard curves in Figure 4.1. Elementary seismic hazard analysis (Cornell, 1968) indicates that at moderate to large values of ground acceleration, there is a logarithmic linear relation between annual peak ground acceleration, a, and the probability, $G_{A}(a)$, that specific values of acceleration are exceeded, i.e.,

$$
\log G_{A}(a)=\log (1-F(a)) \cong \alpha \log \mu-\alpha \log a
$$

in which $F_{A}(a)=$ cumulative distribution function (cdf) of acceleration and $\mu$ and $\alpha$ are parameters of the distribution. The implication of this relationship is that $A$ is described by a Type II distribution of largest values. These distribution parameters are related to the mean and coefficient of variation in annual acceleration by,

$$
\begin{aligned}
& \mathrm{m}_{\mathrm{A}}=\mu \Gamma\left(1 \frac{1}{\alpha}\right) \\
& \mathrm{v}_{\mathrm{A}}=\left[\Gamma\left(1 \frac{2}{\alpha}\right) / \Gamma^{2}\left(1-\frac{1}{\alpha}\right)-1\right]^{1 / 2}
\end{aligned}
$$

in which $\Gamma(\quad)=$ complete Gamma function.

Parameter $\alpha$ is related to the coefficient of variation in annual maximum peak acceleration. The seismic hazard analyses (Algermissen, et al, 1982) on which the NEHRP Recommended Provisions for Seismic Regulations (NEHRP, 1992) are based indicate that the factor $\alpha$ tends to be larger for sites in the Western US, decreasing from about 5.5 (c.o.v. $=0.28$ ) at San Francisco, CA to approximately 2.3 (c.o.v. $=138 \%$ ) at Boston, MA and Memphis, TN. 
When an upper bound to acceleration is postulated, the probability can be expressed by the following empirical relation (Kanda and Dan, 1987)

$$
G_{A}(a)=1-\exp \left[-\left(\frac{w-a}{\mu a}\right)^{\alpha}\right] ; a \leq w
$$

in which $\mu, \alpha$ and $w=$ scale and shape parameters and upper bound value, respectively.

\subsection{Limerick Generating Station}

The seismic hazard model used to evaluate risk at the Limerick Generating Station is described in Appendix A of the Limerick SARA (1983). It is based on the hazard model proposed by Cornell (1968) and later implemented by several others (McGuire, 1976).

Four source hypotheses were examined in the Limerick SARA; in two of these, however, two possible maximum body-wave magnitudes, $M_{b}$, were considered, bringing the total number of hypotheses to six. Only earthquakes with body-wave magnitudes of 4.5 or greater were considered, based on the assumption that "smaller earthquakes would not cause damage to engineered structures." An upper bound magnitude, $M_{\max }$, was assumed for each zone. The parameter B in Eqn. 4.1 was assumed to be deterministic and equal to 0.9 (a value believed to be suitable for the Eastern United States), while A was determined from historical seismicity. The uncertainty associated with the predictions of ground motion attenuation from Eqn 4.2 was assumed to be described by a lognormal distribution, with a logarithmic standard deviation of 0.6. Finally, the peak acceleration was transformed to an effective peak ground acceleration (EPA) by dividing the estimated instrumental peak ground acceleration by a factor of 1.23. This factor is intended to take into account the fact that instrumented peak ground acceleration may not be a good indication of damageabiity, particularly for earthquakes in the Eastern United States. Seismic hazard curves resulting from each of these six hypotheses were constructed and a weight was assigned to each, consistent with expert opinion on the credibility of the underlying hypothesis.

This family of hazard curves is illustrated in Figure 4.2 showing EPA vs annual probability of occurrence. There is a tendency for the curves to spread as the EPA increases. This family of hazard curves, with the liklihood assigned to each curve, describes the uncertainty in the hypotheses regarding earthquake source mechanisms and attenuation. The sources of uncertainty arise from the definition of the seismic source zones, maximum and minimum magnitudes associated with each hypothesis, 
and the ground motion attenuation. The peak accelerations used to construct these curves are tabulated in Table 5, Appendix A, of the LGS SARA (1983).

The distribution parameters used to model the seismic hazard curves in Figure 4.2 are given in Table 4.1. The symbols plotted on Figure 4.2 indicate the closeness with which Eqns 4.4 and 4.5 fit the acceleration fractiles tabulated in Appendix A of the SARA (1983).

\subsection{Millstone 3}

The seismic hazard model used in the Millstone 3 Probabilistic Safety Study (PSS) incorporates uncertainties due to alternate seismic source zonation, earthquake occurrence and upper bound magnitude, and attenuation. Eight sets of seismogenic zones were used, and a subjective weight was attached to each. Parameter B in Eqn 4.1 was assumed to be deterministic. Four different attenuation equations were used, equally weighted. Only events of magnitude 5.0 or greater were assumed to represent a potential for damage. The 10 hazard curves obtained from aggregrating the zone and attenuation hypotheses are illustrated in Figure 4.3. The parameters describing the individual seismic hazard curves, fitted to the tabulated annual frequencies of accelerations being exceeded, are summarized in Table 4.2. Six of these ten curves saturate at high accelerations. A magnitude-dependent spectrum rather than the usual broad-band spectrum was used in the response analysis, and thus the accelerations displayed are instrumental peak accelerations.

Subsequent to the PSS, a site-specific analysis of Millstone 3 was conducted as part of the seismic hazard characterization program, or SCHP, for selected plants in the Eastern United States (Bernreuter, et al 1984). In that study, events of magnitude 3.75 and greater were considered, and the attenuation functions were different. The SCHP curves are presented in Figure 4.5; they display a seismic hazard that is larger by a factor of 10 than that represented by the PSS curves. The differences appear to be due mainly to the different attenuation relations assumed in the two studies and, to a lesser extent, the inclusion of smaller events in the SCHP seismicity catalog. The impact of such differences on the estimated core damage probability will be considered subsequently.

\subsection{Maine Yankee}

The aggregated seismic hazard curves for Maine Yankee shown in Figure 4.5 are based on a consideration of earthquake magnitudes greater than 3.75 (LLNL) and 5.0 (EPRI), (Bernreuter, et al, 1987). The parameters to describe the $M=3.75$ curve using Eqn 4.4 are given in Table 4.3. In all 
cases, parameter $w$ in 4.5 was zero, meaning that the (aggregated) seismic hazard at Maine Yankee can be described by a Type II distribution of extreme values. The symbols plotted on Figure 4.5 show the closeness with which Eqn 4.4 fits the curves provided by LLNL and EPRI. 
TABLE 4.1

Seismic Hazard Curve Parameters - LGS

\begin{tabular}{|c|c|c|c|c|c|}
\hline Hypothesis & Maximum & weight & $\mu$ & $\alpha$ & $w$ \\
\hline 1. Piedmont, & $M_{b, \max }=5.8$ & 0.15 & 160.0 & 1.899 & 0.567 \\
\hline 2. Piedmont, & $M_{b, \max }=6.3$ & 0.15 & 834.9 & 1.446 & 0.810 \\
\hline 3. Northeast tectonic & $M_{b, \max }=5.0$ & 0.30 & 223.2 & 1.229 & 0.243 \\
\hline 4. Crustal block, & $M_{b, \max }=5.5$ & 0.15 & 333.9 & 1.937 & 0.405 \\
\hline 5. Crustal block, & $M_{b, \max }=6.8$ & 0.15 & 283.9 & 2.190 & 0.648 \\
\hline 6. Decollement & none & 0.10 & 0.0058 & 2.372 & 0.0 \\
\hline
\end{tabular}

TABLE 4.2

Seismic Hazard Curve Parameters - Millstone 3

\begin{tabular}{|c|c|c|c|c|}
\hline Curve No. & Weight & $\mu$ & $\alpha$ & $w$ \\
\hline 1 & 0.004 & 0.028 & 5.04 & 0 \\
\hline 2 & 0.163 & 0.0073 & 2.94 & 0 \\
\hline 3 & 0.127 & 0.0113 & 2.92 & 0 \\
\hline 4 & 0.084 & 0.0082 & 2.79 & 0 \\
\hline 5 & 0.129 & 2482.0 & 1.68 & 0.815 \\
\hline 6 & 0.074 & 365.5 & 1.88 & 0.815 \\
\hline 7 & 0.074 & 676.7 & 1.83 & 0.815 \\
\hline 8 & 0.168 & 494.8 & 2.03 & 0.612 \\
\hline 9 & 0.082 & 96.1 & 2.48 & 0.612 \\
\hline 10 & 0.095 & 431.9 & 1.86 & 0.612 \\
\hline
\end{tabular}

TABLE 4.3

Seismic Hazard Curve Parameters for Maine Yankee

\begin{tabular}{|c|c|c|c|c|}
\hline Curve No. & Weight & $\mu$ & $\alpha$ & $w$ \\
\hline 1 & 0.3 & 0.0110 & 3.463 & 0.0 \\
\hline 2 & 0.4 & 0.0125 & 2.846 & 0.0 \\
\hline 3 & 0.3 & 0.0161 & 2.401 & 0.0 \\
\hline
\end{tabular}




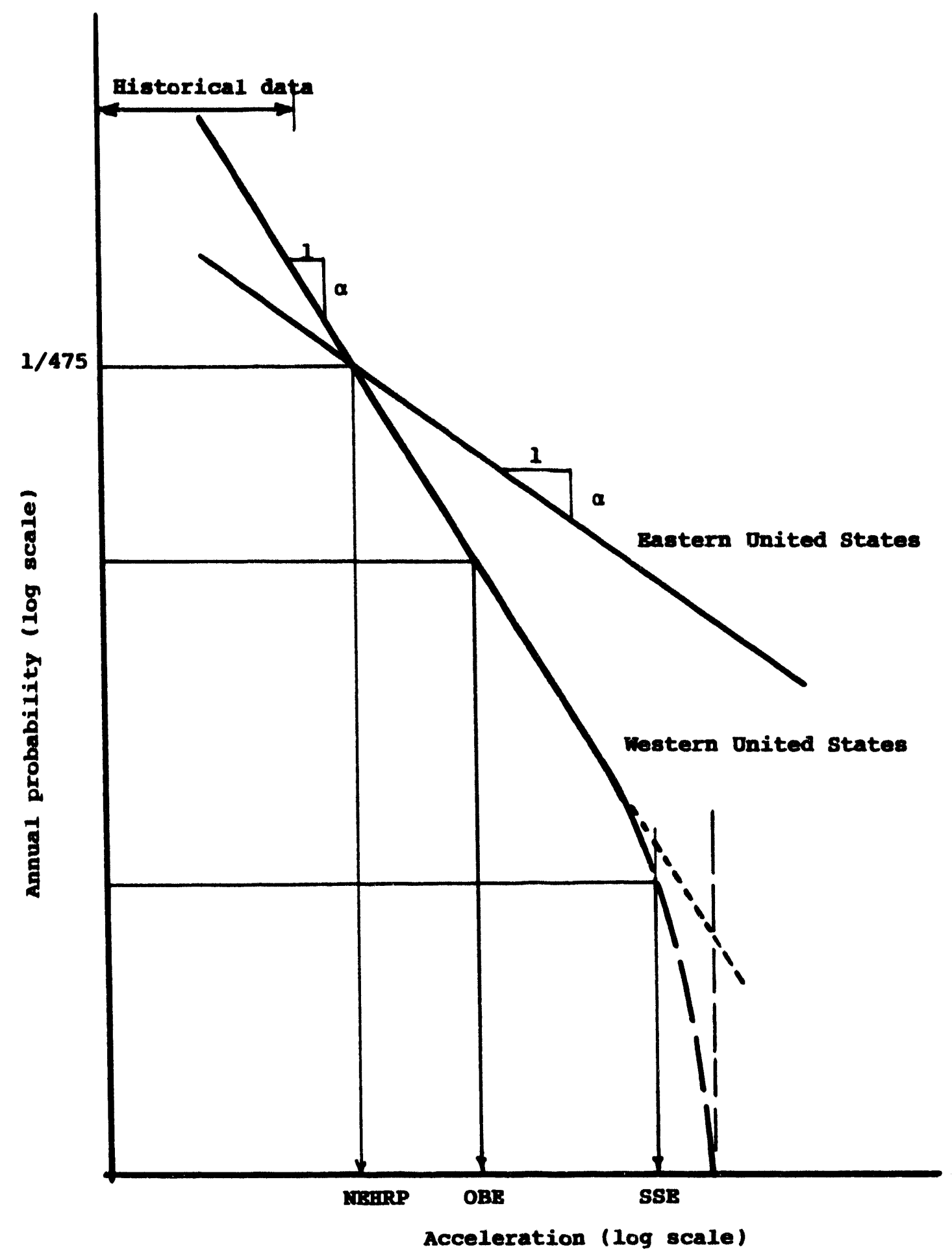

Figure 4.1

Typical Seismic Hazard Curve Showing Annual Probability that Acceleration is Exceeded 


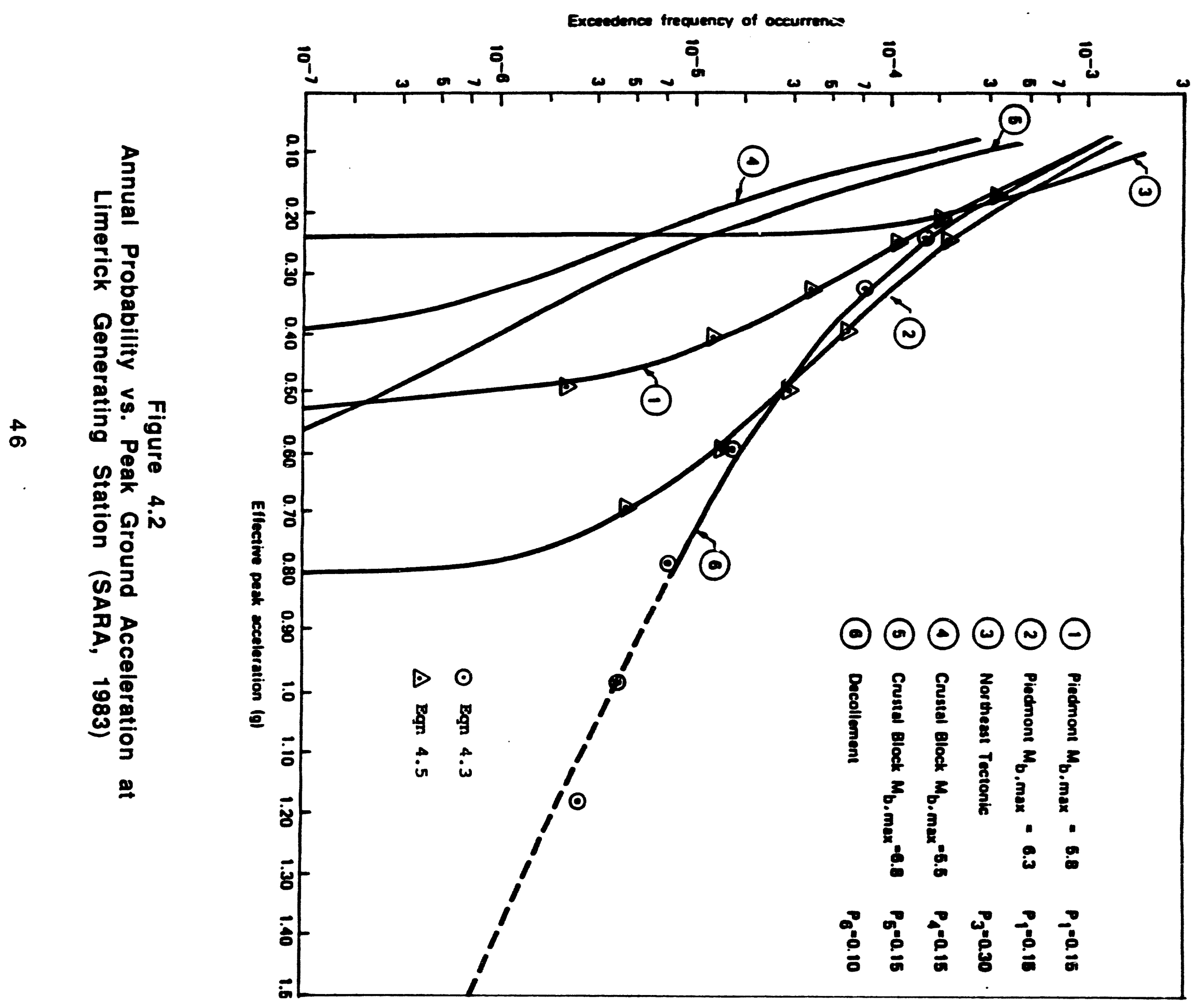




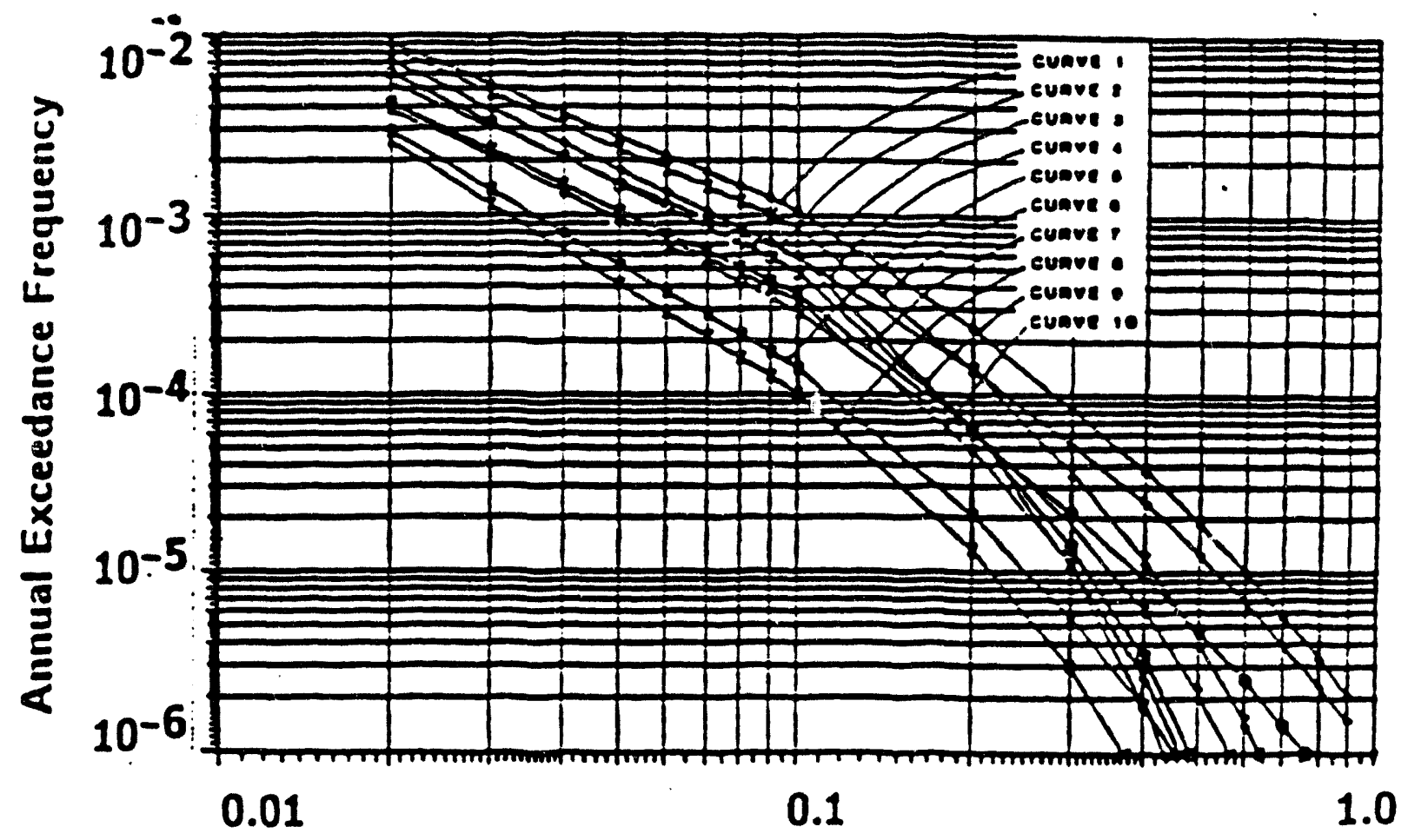

Peak Ground Acceleration (g)

Figure 4.3

Seismic Hazard Curves for Millstone Unit 3 (Dames \& Moore, 1983) 


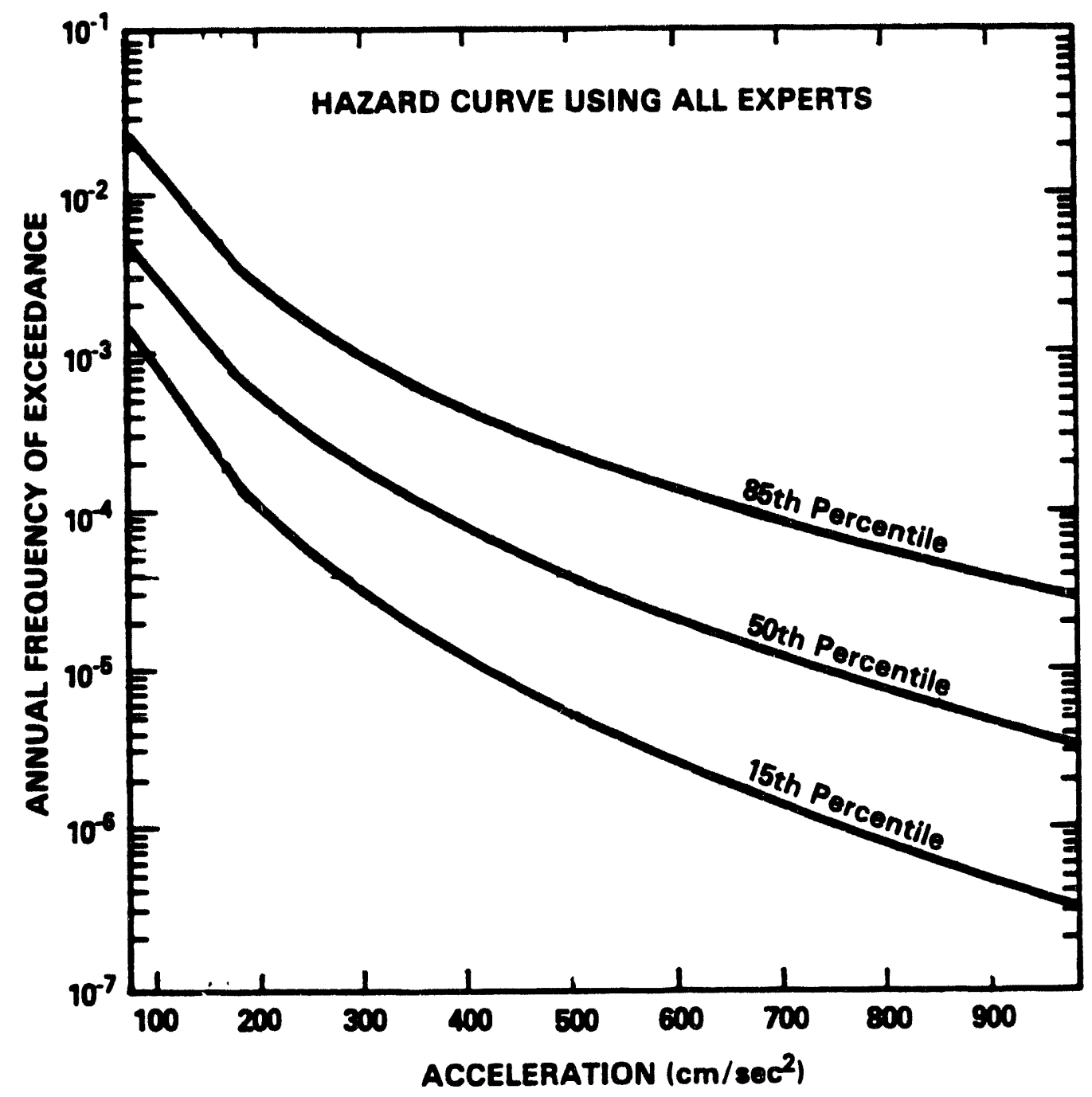

Figure 4.4

Seismic Hazard Curves for Millstone 3 (Bernreuter, et al, 1984) 


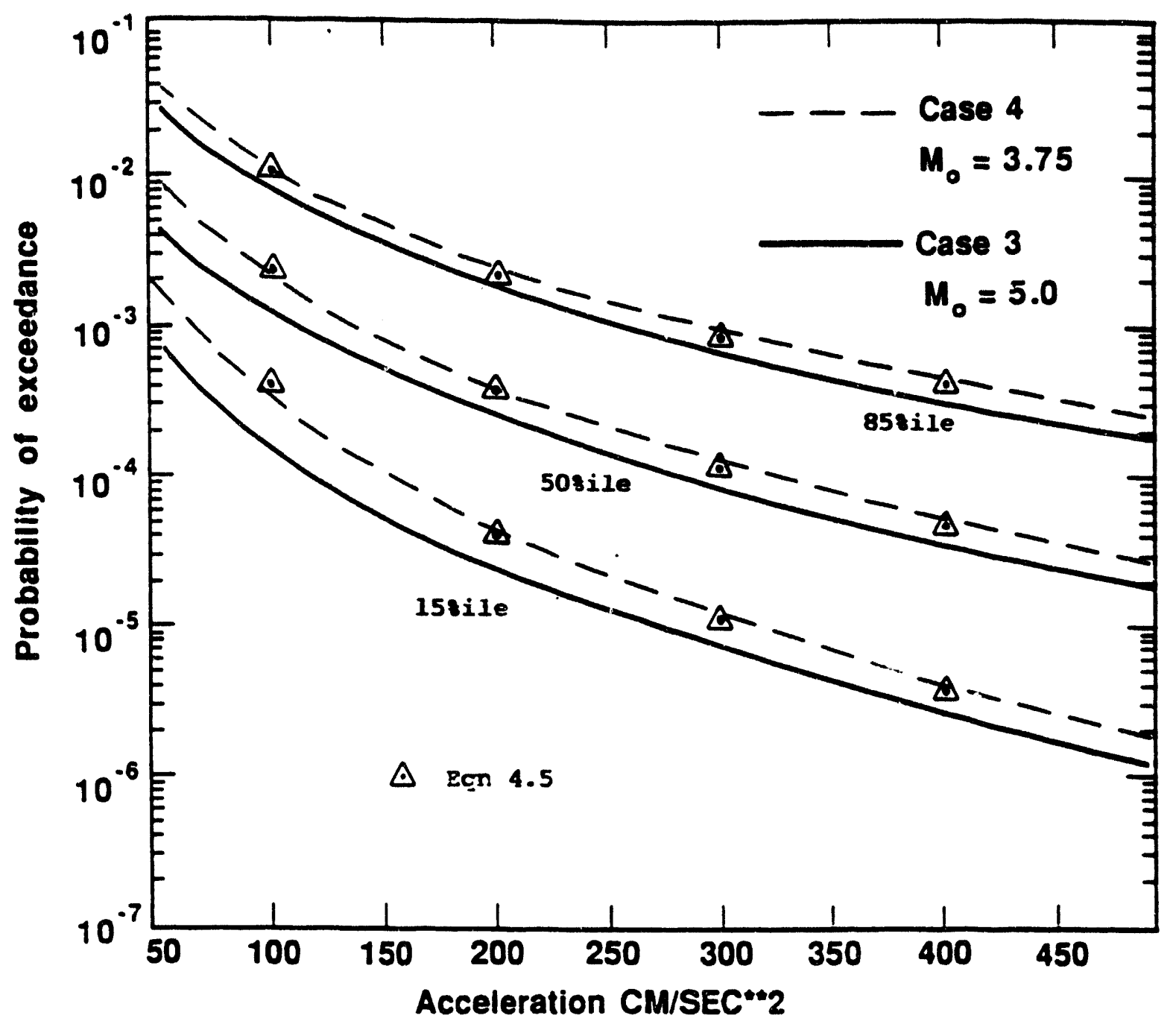

Figure 4.5

Seismic Hazard Curves for Maine Yankee (Bernreuter, et al, 1987) 


\subsection{ACCIDENi SEQUENCE PROBABILITIES AND SEISMIC MARGINS}

Core damage probabilities for the Limerick, Millstone 3 and Maine Yankee plants are evaluated using the sequences identified in Section 2 and the fragility and seismic hazard models summarized in Sections 3 and 4. The current analysis is validated by comparing the computed probabilities and HCLPF values to those published previously. The sensitivity of the frequency distribution of core damage probability to hazard and fragility modeling then is examined to determine the factors and uncertainties that are most significant in seismic PRA and seismic margin analysis. The Limerick Generating Station is the focus of the evaluation. The analyses of Millstone 3 and Maine Yankee serve to emphasize commalities and indicate differences across a range of plants.

\subsection{Method of Analysis}

The Latin Hypercube technique (Iman and Conover, 1980) was used to propagate the uncertainties in the seismic hazard analysis and fragility modeling and to determine the frequency distribution of core damage probabilities. This procedure is illustrated in Figure 5.1. For each component in the Boolean expression for a particular sequence, median fragilities are randomly selected consistent with the $\beta U$ and a sequence fragility, $F_{R}$, is computed using the Boolean expression for that sequence. By repeating the process, a family of sequence fragilities is generated; this family can be used to determine a plant level HCLPF, if desired. The plant level fragilities are randomly combined with the seismic hazard curves and are integrated by Gauss quadrature to obtain a set of accident sequence probabilities from,

$$
P_{i j}=-\int_{0}^{\infty} F_{R_{i}}(x) \frac{d G_{A j}(x)}{d x} d x
$$

in which $F_{R i}$ and $G_{A j}$ are sequence fragility $i$ and hazard curve j, respectively. The probabilities then are rank-ordered and plotted to describe the frequency distribution of core damage probability, $F_{P}(p)$. The 5-, 50- and 95-percentiles and mean sequence probability are taken from this frequency distribution. The mean and variance of the sequence probability are evaluated by,

$$
E[P]=\int_{0}^{1}\left[1-F_{P}(p)\right] d p
$$




$$
\operatorname{Var}[\mathrm{P}]=\int_{0}^{1} 2 \mathrm{p}\left[1-\mathrm{F}_{\mathrm{P}}(\mathrm{p})\right] \mathrm{dp}-(\mathrm{E}[\mathrm{P}])^{2}
$$

The standard deviation of $P, S D[P]$ is $\sqrt{\operatorname{Var}[P]}$.

Figures 5.2 and 5.3 illustrate this process for the condensed LGS sequence $T_{S} E_{S} \cup X$ (Eqn 2.11). Figure 5.2 shows the plant level fragility and the sequence HCLPF for a Latin hypercube sample of 20 . The sequence HCLPF is $0.33 \mathrm{~g}$, a factor of 2.2 times the SSE of $0.15 \mathrm{~g}$ for the plant. Figure 5.3 shows the frequency distribution of $P\left(T_{S} E_{S} U X\right)$ obtained by randomly combining the 20 plant fragilities with 6 hazard curves (120 points, obtained from the convolution in Eqn. 5.1), along with the $5 \%, 50 \%$ and $95 \%$ iles and mean values of core damage probability. The fractiles of $P\left(T_{s} E_{s} \cup X\right)$ can be obtained directly from this curve or from a smoothed version of it. Figures 5.4 and 5.5 show the sequence fragility and frequency distribution for LGS sequence $P(C D)$ (Eqn 2.17). Although it is not obvious from Figures 5.3 and 5.5, the frequency distributions of $P\left(T_{s} E_{s} \cup X\right)$ and $P(C D)$ are strongly positively skewed. The estimated mean core damage probability corresponds approximately to the 75th percentile of the frequency distribution and is nearly an order of magnitude higher than the median (50\%ile) estimate. The logarithmic standard deviation for $P(C D)$ is approximately 2.0. Similar results were observed for the other plants and core damage sequences in Section 2.

The reproducibility of the core damage estimates depends on the size of the Latin hypercube sample. To illustrate this point, 10 different Latin hypercubes of 20 each were generated for the component and sequence fragilities, randomly combined with the 6 hazard curves, and mean values of $P\left(T_{s} E_{s} \cup X\right)$ and $P(C D)$ were computed. The sampling distributions of $E\left[P\left(T_{S} E_{S} \cup X\right)\right]$ and $E[P(C D)]$ are plotted on normal probability paper in Figure 5.6; these sampling distributions represent the dispersion expected in estimates of the mean sequence probability based on Latin hypercubes of 20 . The linearity of these plots indicates that the sampling distributions are approximately normal. The standard deviations $S D\left[P\left(T_{s} E_{s} \cup X\right)\right]$ and $S D[P(C D)]$ are on the order of $0.08 \times 10^{-6}$, indicating that Latin hypercubes of 20 yield estimates within 1 to 2 percent of the actual (unknown) mean value 68 percent of the time and within 3 percent of the mean 90 percent of the time. This accuracy was judged sufficient for purposes of this study, and the remaining studies were conducted using Latin hypercubes of 20 for modeling uncertainty in the fragility functions. Differences on the order of 3 percent or less from the baseline cases will be assumed to be not statistically significant for purposes of sensitivity analysis. 


\subsection{Limerick Generating Station}

\subsubsection{Baseline Case}

In the baseline case to validate the present analyses, the component fragilities are modeled by lognormal distributions and component failures are assumed to be statistically independent. Two sets of Booleans were considered for Limerick, as described in Section 2 - an original form and a condensed form. The original form included doubleton and tripleton cut sets and a number of nonseismic random equipment failures. In the condensed form, the higher order cutsets were eliminated along with some of the "complementary" or "not" events and nonseismic random equipment failures. The nonseismic random failure rates were set equal to their mean values; it will be shown subsequently that this assumption has little impact on the sequence probabilities.

The fractiles and mean of core damage probability computed using the original form of the Booleans are summarized in Table 5.1 for the six dominant sequences. As noted previously, the frequency distributions for all sequences are highly positively skewed. The notation 1.7-6 denotes $1.7 \times 10^{-6}$. Note that the 5 to 95 percentile estimates of core damage probability range over three or more orders of magnitude. This range in the frequency distribution is a reflection of the uncertainties in the fragility modeling and in the seismic hazard analysis.

Table 5.2 compares the estimates of the mean seismic core damage probabilities for the six dominant accident sequences identified above with those obtained in the original SARA (1983) and in the SARA Peer Review (Azarm, et al, 1984). The agreement between these three analyses is quite close, with the exception of the sequences involving $\mathrm{C}_{\mathrm{m}}$, defined as the failure of the reactor to scram. The LGS SARA Peer Review noted that the expression for $C_{m}$ used in the original SARA (1983)

$$
P\left(C_{m}\right)=P\left(C_{R}\right)(1-0.2)+0.2 P\left(S_{3}+S_{5}+S_{7}\right)
$$

may not be justifiable. The term 0.2 is the probability that the scram system controls operate properly during a seismic event and was set subjectively. The revised expression in Eqn (2.10) was suggested by the SARA review and has the effect of lowering $P\left(T_{S} E_{S} \cup X\right)$ and increasing both $P\left(T_{s} E_{s} C_{m} C_{2}\right)$ and $P\left(T_{s} R_{b} C_{m}\right)$. Some idea of the magnitude of the increase in these two sequences can be obtained from the ratio,

$$
\frac{P\left(C_{m}\right) \text { new }}{P\left(C_{m}\right) \text { SARA }}=\frac{P\left(C_{R}\right)+\left(1-P\left(C_{R}\right)\right) P\left(S_{3}+S_{5}+S_{7}\right)}{0.8 P\left(C_{R}\right)+0.2 P\left(S_{3}+S_{5}+S_{7}\right)}
$$


in which $P\left(C_{R}\right)=1.5-5$ (see Table $(2.1(b)$ ). At low accelerations, $P\left(S_{3}+S_{5}+S_{7}\right)=0$ and this ratio is 1.25 . At high accelerations, $P\left(S_{3}+S_{5}+S_{7}\right)=1$, and the ratio approaches 5 . Similarly, one can show that $P\left(T_{s} E_{s} \cup X\right)$ would be lowered by a factor of about 2 using the revised expression for $P\left(C_{m}\right)$. Although the analyses summarized in Table 5.2 were conducted independently with different numerical approaches, they lead to essentially identical results when the differences in $\mathrm{C}_{m}$ noted above are taken into account.

The fractiles of core damage probability using the condensed expressions for the core damage sequence Booleans are given in Table 5.3. Also shown in this Table are the sequence or plant-level HCLPFs, defined as the lower 95-percent confidence interval estimate of the 5 percent exclusion limit of the sequence fragility. Because the condensed Booleans yielded comparable results for all damage sequences, they were used in the remainder of the studies, except where noted. Note from Tables 5.1 and 5.3 that rank ordering the importance of sequences on the basis of HLCPF, mean or median core damage probability may lead to different conclusions as to their relative importance.

There is a seventh sequence - Ts $E_{s} U V$, involving failure of the lowpressure injection system (V) - that was not included as a dominant sequence in the original SARA because it had a mean frequency of 5.9-9. This sequence was questioned in the SARA review (Azarm, et al, 1984), and it was suggested that the definitions of $V$ and the automatic depressurization function $(X)$ be revised. However, the revised sequence probabilities were not computed in the SARA review. These probabilities are presented in Tables 5.1 and 5.3. Although the revised sequence probabilities are nonnegligible, it was found that the $T_{s} E_{s} U V$ event is absorbed into the core damage event, $C D$, and thus the final core damage probability, $P(C D)$, listed in the last line of Table 5.3 is unchanged.

\subsubsection{Point Estimates of Core Damage Probability}

In some instances, a point estimate of core damage probability rather than a frequency distribution is desirable for decision-making (Lewis, 1985). The most commonly suggested point estimates are the mean, median, and the mode. For a skew-positive frequency distribution, mode $<$ median<mean. The mean contains information about skewness not contained in the median. The median is less sensitive to the presence of outliers. This is particularly important in seismic PRA or margin analyses, where the characteristics of the uncertainty band are determined to a large extent by judgement and expert opinion because of the lack of empirical data. If one expert's opinion is divergent with respect to other opinions but nontheless is given comparable weight in the aggregation leading to the construction of the uncertainty measures, that 
expert's opinion will elevate or decrease the estimate of the mean, and may unduly influence the risk analysis. Table 5.3 shows that the mean core damage probability provides a conservative point estimate of risk (with respect to the median) for a particular sequence or union of sequences. The ratio of mean to median estimates of $P(C D)$ is about 7 .

Frequently, point estimates of core damage probability are obtained in seismic PRAs by simply adding the point estimates for the individual contributing sequences; in fact, this was done in the original LGS SARA (1983) - see Table 5.2. If "success" states are not included in the Booleans (e.g., $T_{s} R_{b} C_{m}$ and $T_{s} R_{b} \bar{C}_{m}$ ), mutual exclusivity of sequences is not strictly preserved. If the core damage probability is expressed as the sum of accident sequence probabilities,

$$
P=P_{1}+P_{2}+\ldots
$$

in which the individual accident sequence probabilities are described by skew-positive distributions, then

$$
\begin{aligned}
& \text { median }(P)>\text { median }\left(P_{1}\right)+\text { median }\left(P_{2}\right)+\ldots+\text { median }\left(P_{n}\right) \\
& \text { mean }(P) \leq \text { mean }\left(P_{1}\right)+\text { mean }\left(P_{2}\right)+\ldots+\text { mean }\left(P_{n}\right)
\end{aligned}
$$

Summing the means provides an estimate of mean core damage probability that is conservative, while summing medians (or modes) results in an unconservative point estimate of median core damage probability. Means propagate consistently through unions and intersections in Booleans, whereas medians propagate only through intersections. However, the estimate of the mean is less robust than that of the median, particularly in the presence of large uncertainties. None of these point estimates gives a fully adequate picture of the risk for decision-making purposes.

\subsubsection{Fragility Modeling}

In most seismic PRAs conducted to date, the component fragilities have been modeled by a family of lognormal distributions described by three parameters - a median value, $A_{m}$, a logarithmic standard deviation, $\beta R$, describing randomness in capacity, and a logarithmic standard deviation, $\beta U$, describing modeling uncertainty (Kennedy and Ravindra, 1984). In this section, the effect of fragility modeling assumptions on core damage probability and on HCLPF values is considered.

In the first variation from the baseline case, the median capacity of the reactor enclosure structure $\left(S_{4}\right)$ was reduced from $1.05 \mathrm{~g}$ to $0.9 \mathrm{~g}$ and the uncertainty measure $\beta U 4$ was increased from 0.25 to 0.30 . This modification was suggested by the SARA review (Azarm, et al, 1984), 
which indicated that the modeling uncertainty may have been understated in the original SARA (1983). Component $S_{4}$ is the dominant singleton in the Boolean expression for $C D$. The results for core damage sequence $C D$ are compared in line 2 of Table 5.4. The increase in the median of $P(C D)$ is about $13 \%$, the increase in the mean of $P(C D)$ is about $15 \%$, and the reduction in the HCLPF is about $6 \%$. These changes are not believed to be significant for decision-making, considering the magnitude of the uncertainties involved. Similar variations (percentage-wise) in the fragilities of components appearing in doubletons or higher order cut sets in the sequence Booleans have less effect on the estimates of $P(C D)$.

The core damage Booleans $T_{s} E_{s} U X$ and $C D$ for the LGS are dominated by electrical equipment failures, i.e., components $S_{11}$ through $S_{15}$ in Table 2.1. Failure of such components can occur due to relay chatter or trip and be functional, or may be structural in nature (e.g., anchorage or support failures). In the LGS SARA (1983), the median fragilities of these components were determined assuming that relay chatter or trip meant component failure. The Boolean logic does not provide a means for modeling human intervention, partial failure or gradual degradation, or points of instability. This is an inherent problem in fault tree modeling. If such failures are assumed to be recoverable by appropriate operator action, the median fragilities would be substantially higher and would affect the plant HCLPF and risk. To determine the significance of this assumption on risk, the median fragilities for the electrical components were revised upward as follows:

Component

$\mathrm{S}_{11}$ - 440-V bus/SG breakers

$\mathrm{S}_{12}$ - 440-V bus transformer breaker

$S_{13}-125 / 250-V$ DC bus

$\mathrm{S}_{14}-4-\mathrm{kV}$ bus/SG

$S_{15}$ - Diesel generator circuit

$\begin{array}{ccc}A m & \beta R & \beta U \\ 3.95 \mathrm{~g} & 0.38 & 0.44 \\ 3.95 \mathrm{~g} & 0.38 & 0.44 \\ 4.43 \mathrm{~g} & 0.36 & 0.43 \\ 2.60 \mathrm{~g} & 0.36 & 0.43 \\ 2.60 \mathrm{~g} & 0.32 & 0.41\end{array}$

The revised values of $S_{11}, S_{13}$ and $S_{14}$ were taken from Table 4.3 of EPRI Report 4168 (Ravindra, Kennedy and Sues, 1985). The results are shown in line (3) of Table 5.4. The HCLPF increases to $0.37 \mathrm{~g}$, an increase of $16 \%$, while the mean decreases by 40 percent. Such changes may be significant, perhaps more so for margin studies than for seismic risk analysis.

In the LGS, failure of the control rods to insert is a result of seismically-induced distortions of the shroud and shroud support cylinder (component $S_{3}$ in Table 2.1). The median fragility for $S_{3}$ is $0.67 \mathrm{~g}$, which is relatively low. However, for this sequence to develop intn an ATWS sequence, the standby liquid control system also must fail (component $\mathrm{S}_{10}$ ). The significance of the operation of these systems in core damage 
sequence $C D$ was determined by revising the median fragilities for components $S_{3}$ and $S_{10}$ downward by 20 percent as follows:

$\begin{array}{rccc}\text { Component } & A m & \beta R & \beta U \\ S_{3}-\text { Reactor Internals } & 0.54 \mathrm{~g} & 0.28 & 0.32 \\ S_{10}-\text { SLC tank } & 1.06 \mathrm{~g} & 0.27 & 0.19\end{array}$

and recomputing the HCLPF and core damage fractiles with all other component fragilities unchanged. The results are presented in line (4) of Table 5.4. The fractiles and HCLPF are almost the same as in the base case. Since components $S_{3}$ and $S_{10}$ both must fail in order for core which appear as singleton cut sets in the expression for $C D$.

With the fragility of a component described by a lognormal distribution with three parameters $A_{m}, \beta R$ and $\beta U$, the HCLPF value for the component can be defined as (See Eqn 3.10)

$$
H C L P F=A_{m} \exp [-1.645(\beta R+\beta U)]
$$

It may be easier for fragility analysts to estimate the HCLPF directly from a so-called Conservative Deterministic Failure Margins (CDFM) analysis (Kennedy, 1985) rather than from Eqn 5.8. In a CDFM analysis a failure value is determined from conservative (deterministic) estimates of the response spectrum, damping, material strengths, structural behavior, and system ductility and energy-absorbing capacity. The procedure is similar to that traditionally followed by code committees in setting design requirements using code-specified minimum strengths, maximum loads and conservative models of structural behavior. Many engineers are more familiar with such methods than with modern reliability analysis tools which deal with uncertainty explicitly through the use of coefficients of variation, logarithmic standard deviations, or probability distributions.

Assuming that a fragility analyst can estimate the HCLPF from such a procedure directly, additional information would be required in order to describe the component fragility completely for use in a seismic PRA study. Equation 5.8 shows that knowledge of either $A m$ or $(\beta R+\beta U)$ is sufficient to define the relationship between the fragility parameters and the HCLPF. One might: (1) Assume a value for $(\beta R+\beta U)$, and then compute $A_{m}$; or (2) Assume $A_{m}$, and then compute $(\beta R+\beta U)$ to maintain a predetermined relation between the HCLPF and $A_{m}$.

Both approaches require a way of uncoupling $(\beta R+\beta U)$ into $\beta R$ and $\beta U$ in order to define the fragility family for risk anaiysis purposes. Occasionally, this can be done using supplementary clata. If such 
information is not available, the relation $\beta U=4 / 3 \beta R$ seems to hold, on average, for critical components tabulated in a number of published PRAs. Alternatively, it has been suggested that in lieu of determining $\beta R$ and $\beta U$ explicitly, it is (usually) conservative to assume that the sum $(\beta R+\beta U)$ is 0.7 to 0.8 (Prassinos, et al, 1986).

Two additional analyses were performed to determine the sensitivity of plant level HCLPF and core damage probabilities to these alternative methods of fragility parameter selection. In both analyses, the component HCLPF was assumed to be the known starting point and was the common factor. In the first analysis, the known quantities are:

Component HCLPF is known (Table 2.1)

Component $(\beta R+\beta U)=0.80$ and $\beta U=4 / 3 \beta R$

Values of $A m, \beta R$ and $\beta U$ then are determined to define the component fragility family. In the second analysis, the known quanties are:

Component HCLPF is known (Table 2.1)

Component $A_{m}$ is known and $\beta U=4 / 3 \beta R$

Lines 5 and 6 of Table 5.4 summarize the plant level HCLPF and core damage probabilities for these two cases. There is very little difference between the estimates. The common factor in these two analyses is the component HCLPF values, so the fact that the sequence HCLPF is essentially the same as in the baseline case, line 1 , is not surprising. Although the fragility parameter estimates $A_{m}, \beta R$ and $\beta U$ are different in all three cases, this parameter variation does not seem to have much effect on the core damage probabilities. The plant level HCLPF and core damage probability do not appear to be especially sensitive to the small variations in the fragility parameters $A_{m}, \beta_{R}$ and $\beta_{U}$ that would occur if different (but presumably competent) fragility analysts were asked to provide independent estimates of these parameters. Note that the estimates of the HCLPF are all less than the minimum HCLPF for any component appearing as a singleton in the bracketed expression multiplying $\mathrm{S}_{1}$ (Eqn 2.17).

The lognormal fragility model vests all modeling uncertainty in the estimate of the median fragility, $A_{m}$, associating with $A_{m}$ the uncertainty measure $\beta U$. The inherent variability measure, $\beta R$, is assumed to be a known constarit; thus, the fragility for a component is represented by a family of lognormal distributions which plot parallel to one another on lognormal probability paper. To examine the impact of uncertainty in $\beta_{R}$, both the median $A_{m_{i}}$ and the logarithmic standard deviation, $\beta R_{i}$ for each 
component were considered to be statistically independent lognormal random variables, both with logarithmic standard deviation $\beta U_{i}$. (There is no reason to believe that the measure of uncertainty in $A_{m_{i}}$ and $\beta R_{1}$ is the same; however, this assumption is convenient and will serve to determine whether it is sufficient to vest uncertainty solely in the median.) With $\beta R_{i}$ uncertain, the curves in the fragility family for components do not plot parallel on lognormal probability paper. The results of this analysis are summarized in Table 5.5. Comparison of these results with those in Table 5.3 indicates that the HCLPF values generally are reduced from those computed assuming that only the median is uncertain by about $18 \%$ for the dominant sequences while the core damage probabilities increase by about $30 \%$. One may conclude that the uncertainty in $\beta R$ might be significant in a seismic margin analysis but would be of secondary importance in a seismic PRA.

As a footnote to the treatment of uncertainty in fragility modeling, the effect on the HCLPF and fractiles of core damage probability of neglecting modeling uncertainty entirely (setting $\beta U$ equal to zero for all components in the sequence) was investigated for sequence CD. As additional information and experience becomes available, the modeling uncertainty generally would decrease and ultimately become negligible in comparison with the inherent variability. The effect of this assumption is to collapse the plant level fragility family into a single curve. The frequency distribution of $P(C D)$ then arises solely from the uncertainty in the seismic hazard itself. The results of this analysis are presented in the last line of Table 5.5. The elimination of modeling uncertainty is accompanied by a large increase in the HCLPF from $0.32 \mathrm{~g}$ in the base case to $0.54 \mathrm{~g}$ and by a reduction in the median and mean core melt probabilities from the base case by approximately a factor of 2 . It might be noted, however, that the frequency distribution of $P(C D)$ spans approximately the same range $\left(10^{-8}\right.$ to $\left.10^{-5}\right)$ as does $P(C D)$ when all component fragilities include the modeling uncertainty term $\beta U$. This result indicates that virtually all dispersion in the core damage probability estimates arises from the uncertainty in the basic seismic hazard rather than from uncertainties in the fragility modeling. We will return to this point later.

In most seismic PRA's conducted to date, the component fragilities have been modeled by a family of lognormal distributions. To test the sensitivity of the analysis to this assumption, the risk analyses were performed assuming that the fragility family is described by a family of Weibull distributions in which the lower limit is set at a fraction of the median value. To maintain consistency in the analysis, the Weibull parameters were determined assuming that the medians and coefficients of variation are the same for both lognormal and Weibull fragility models. As before, the medians were assumed to be lognormal to account for modeling uncertainty. 
Table 5.6 compares the results obtained for sequences $T_{s} E_{s} U X$ and $C D$ using the Weibull and lognormal fragility models. Parameter $k$ denotes the lower limit as a fraction of the median fragility. When $k=0$, the change in fragility model has a more pronounced effect on the 5percentile value of risk (by factor of 20) than on the 95-percentile value (by a factor of about 2). The median values of $P\left(T_{s} E_{s} \cup X\right)$ and $P(C D)$ increase by a factor of more than 12 when the Weibull model is used, while the means increase by a factor of about 3 . If the latter were used as a point estimate for risk, one would not expect this difference to have a significant impact on regulatory decision-making. On the other hand, the decrease in HCLPF by as much as one-third carries with it some implications for the selection of fragility models for seismic margin studies. This decrease results from differences in the characteristic of the lower tails of the Weibull and lognormal distributions. One might expect to see similar sensitivities of HCLPF values if other fragility models suggested in the literature (e.g., Goodman, 1985) were used. Such differences may be important in a seismic margins study such as that for the Maine Yankee Plant (Prassinos, et al, 1987), where the estimated plant HCLPF was close to the review earthquake level.

When the non-zero lower limit is included in the Weibull distribution (see Eqn 3.6), the HCLPF increases moderately, as illustrated in Table 5.6. However, the sensitivity of the HCLPF to plausible variations in the lower fragility limit is not as great as the sensitivity to whether a lognormal or Weibull fragility model is selected.

\subsubsection{Random Nonseismic Equipment Failures}

Random Failures of Diesel Generators

The random (nonseismic) failure of the diesel generators enters the expression for A (see Eqn 2.9) as a singleton, and thus might impact the supply of emergency power following a seismic event. Some risk assessments (Wells, et al. 1987), have indicated that random nonseismic failures and, in particular, the diesel generator common mode failure, were significant contributors to core damage. Accordingly, P(DGR) was varied from its base value of 1.25-3 to determine the extent to which random equipment failures might overshadow seismic failures in a seismic PRA. The results are summarized in Table 5.7. Increasing P(DGR) from 0 to 0.125 affects the lower fractiles of $P\left(T_{s} E_{s} U X\right)$ and $P(C D)$ more than the upper fractiles, the 5\%ile value increasing by a factor of 150 while the $95 \%$ tile value increases by a factor of about 5 . The nonseismic failure rate of the diesel generators must increase above 0.01 year before the impact of the mean core damage probability becomes significant. 
The original form of accident sequence $T_{s} E_{s} U X$ contains several other nonseismic random failures: $X_{R}=$ failure to depressurize the reactor manually; $H_{R}=$ random failure of high pressure coolant injection; $R_{R}=$ random failure of reactor core isolation cooling; and $G=$ combined random failure of the high pressure system and failure to transfer to the suppression pool source of water given the unavailability of the conderisate storage tank. The SARA review (Azarm, et al, 1984) suggested the following revised mean values for these random nonseismic failures:

$\begin{array}{ccc}\text { Function Failure } & \text { SARA (1983) } & \text { Review (1984) } \\ X_{R} & 0.002 & 0.006 \\ H_{R} & 0.088 & 0.116 \\ R_{R} & 0.076 & 0.070 \\ G & 0.014 & 0.130\end{array}$

These terms do not appear in the condensed $T_{s} E_{s} U X$ of Eqn. 2.11. A comparison of fractiles of $P\left(T_{S} E_{S} \cup X\right)$ assuming these two sets of mean random equipment failures is given in lines 1 and 2 of Table 5.8. The change in random nonseismic equipment failure rates has only a marginal effect on the frequency distribution of $P\left(T_{s} E_{s} U X\right)$ because all random equipment failures, with the exception of the diesel generator failures, occur only in fourth-order cut sets. Variations in nonseismic component failure rates in this circumstance will have little effect on point estimates of risk or regulatory decisions. Indeed, it was partly on this basis that the condensed Boolean expressions for $T_{S} E_{S} U X$ were derived.

In the preceding analyses (Tables $5.1-5.7$ ), the random (nonseismic) equipment function failure rates were set equal to their respective mean values, as specified in Table 2.1(b). However, these failure rates can be described by lognormal distributions with error factors, defined as the ratio of the $95 \%$ ile to the $50 \%$ ile of the estimated failure rate, which are tabulated in Table 2.1(b). To determine whether there is any significant effect of neglecting this source of uncertainty, the frequency distribution for $P\left(T_{s} E_{s} U X\right)$ was recomputed with the random failure rates included. The results in line (3) of Table 5.8 show that the impact on sequence probability is negligible. One arrives at a similar conclusion if the condensed forms of the system Booleans are used, as summarized in lines (4) through (7) of Table 5.8. In all cases examined, the neglect of randomness in nonseismic equipment failure rates has a negligible effect on the accident sequence probabilities and HCLPF values. It may be concluded that it is sufficient to use "best estimate" values (mean, median or mode) in a seismic PRA or margin study. This approach will be taken in subsequent analyses of the Millstone 3 and Maine Yankee plants. 


\subsubsection{Dependent (Common Cause) Failures}

Seismic PRA and margin studies customarily are conducted assuming that failures of different components are statistically independent (Collins and Hudson, 1981; Reөd, 1985, Budnitz, et al, 1985; Prassinos, et al, 1987). This assumption is reasonable provided that the components are dissimilar in nature and are not subjected to coherent external forces. However, stochastic dependence in component failures may occur when the initiating event, such as an earthquake, is external to the plant and affects many systems simultaneously (McCann, et al, 1985). Adjacent components excited by a common earthquake would have highly correlated responses. In other cases, frontline systems may share components in support systems, and a support system fault may affect more than one frontline system. Common manufacturing and fabrication processes may lead to dependence when several components are supplied by one vendor and all are consistently strong or weak. Operator actions and human errors associated with design, testing and maintenance may be common to more than one system.

Suppose that a core damage sequence consists of the union of component failure events. Each component fragility is given as the conditional probability,

$$
F_{R_{i}(x)}=P\left(F_{i} \mid x, \theta_{i}\right)
$$

in which $F_{i}$ is the failure event, $x=$ effective peak ground acceleration or spectral acceleration, and $\theta_{i}=$ vector of fragility parameters. The sequence fragility is,

$$
F_{\text {seq }}(x)=P\left(F_{i}+F_{j}+\ldots . \mid x, \theta_{i}, \theta_{j} \ldots\right)
$$

If the failure events $F_{i}$ and $F_{j}$ are perfectly dependent, one failure event is predictable from another, and

$$
F_{\text {seq }}(x) \approx \max _{i=1}^{n} P\left(F_{i} \mid x, \theta_{i}\right)
$$

whereas if they are statistically independent,

$$
\mathrm{F}_{\text {seq }}(\mathrm{x})=1-\prod_{i=1}^{\mathrm{n}}\left(1-\mathrm{P}\left(\mathrm{F}_{i} \mid \mathrm{x}, \theta_{i}\right)\right) \approx \sum_{i=1}^{\mathrm{n}} \mathrm{P}\left(\mathrm{F}_{i} \mid \mathrm{x}, \theta_{i}\right)
$$

the latter sum holding if the individual probabilities are small. In general,

$$
\max _{i=1}^{n} P\left(F_{i} \mid x, \theta\right) \leq F_{s e q}(x) \leq \sum_{i=1}^{n} P\left(F_{i} \mid x, \theta_{i}\right)
$$


Suppose that the damage sequence consists of the intersection of component failure events. The sequence fragility then is,

$$
F_{s e q}(x)=P\left(F_{i}^{*} F_{j} \ldots \mid x, \theta_{i}, \theta_{j}\right)
$$

If failure events are perfectly dependent,

$$
F_{\text {seq }}(x)=\min _{i=1}^{n} P\left(F_{i} \mid x, \theta_{i}\right)
$$

whereas if the events are statistically independent,

$$
\mathrm{F}_{\mathrm{seq}}(\mathrm{x})=\prod_{i=1}^{\mathrm{n}} \mathrm{P}\left(\mathrm{F}_{i} \mid \mathbf{x}, \theta_{i}\right)
$$

In general,

$$
\prod_{i=1}^{n} P\left(F_{i} \mid x, \theta_{i}\right) \leq F_{s e q}(x) \leq \min _{i=1}^{n} P\left(F_{i} \mid x, \theta_{i}\right)
$$

Unfortunately, there are few data available to describe dependence in component behavior. One must, instead, evaluate the potential significance of statistical dependence by assuming the component capacities to be perfectly correlated and comparing the results to the case where they are statistically independent. When the core damage sequences are expressed as unions or intersections of component failure events, respectively, the assumption of perfect correlation yields the following approximations:

$$
\begin{aligned}
& \text { For } F=F_{1}+F_{2}+\ldots+F_{m}, P(F)=\max P\left(F_{i}\right) \\
& \text { For } F=F_{1} * F_{2}{ }^{*} F_{m}, P(F)=\min P(F i)
\end{aligned}
$$

The role of dependence in component fragility can be illustrated in a simple way by comparing the system fragilities of a series and parallel system, each consisting of two components. This is illustrated in Figures 5.7 and 5.8. The solid lines in both figures represent system fragilities when the component fragilities are statistically independent for two cases, one in which $A_{m 2}=A_{m 1}=4 S S E$ and the second when $A_{m 2}=2 A_{m 1}=$ 8 SSE. The dashed lines represent system fragilities when component fragilities are fully dependent, computed using Eqns 5.18 and 5.19 , as appropriate. When system failure involves the union of component failure events (Figure 5.7), dependence has only a small effect on sequence fragility in the lower tail, less than $10 \%$ at the $5 \%$ ile (HCLPF) level. The effect is most pronounced when the sequence contains two (or more) components that are both of approximately equal strength (equally weak, 
in a broad sense). If the Boolean contains only one weak component, the difference in the HCLPF is on the order of $5 \%$ regardless of the assumption concerning dependence. When the core damage Boolean is dominated by an intersection of failure events (Figure 5.8), assuming dependent failures leads to a lower HCLPF. Again, the difference is most pronounced if there are two "equally weak" components in the core damage expression, about $17 \%$ in this example. This suggests that common cause failures are particularly important in highly redundant systems consisting of components each of which has high reliability. In both cases, when the medians differ by a factor of 2 (with $\beta_{R}$ constant), Eqns 5.18 and 5.19 differ at the $5 \%$ ile level by less than $10 \%$ from the values computed assuming component strengths are statistically independent.

Two cases were considered using sequences $T_{s} E_{s} U X$ and $C D$. In the first case, it was assumed that fragilities of: (1) components $S_{11}, S_{12}$, $S_{13}$ and $S_{14}$ which are all located in the reactor enclosure, are perfectly correlated; (2) components $S_{15}$ and $S_{16}$ located in the diesel generator building are perfectly correlated; and (3) components in different buildings are statistically independent. In the second case, all components in $T_{S} E_{S} U X$ and $C D$ were assumed to be perfectly correlated irrespective of their location in the plant. Equations 5.18 and 5.19 above were used to evaluate the sequence fragilities, HCLPFs and core damage probabilities. The results of these analyses are compared to the base case in Table 5.9. The fractiles of $P\left(T_{s} E_{S} \cup X\right), P(C D)$ and the HCLPF show a negligible reduction when correlation in component capacities is considered. When the core damage Boolean is dominated by a union of single failure events (singleton cut sets), the assumption of independence leads to a smaller HCLPF than one would obtain assuming perfect correlation. In sequences such as $T_{s} E_{s} \cup X$ which are dominated by unions of cut sets, none of which is especially weak (see Table 2.1), correlation has a relatively small impact on the sequence fragility in its lower tail.

Although the effecis of correlation on sequence fragility are more pronounced at the higher fractiles, these are less likely to be important in the convolution with the seismic hazard to determine failure probability. Thus, dependence in component failures seems to have a relatively minor effect on HCLPF and mean core damage probability in plants such as LGS where the dominant accident sequences can be described as a union of events. By inference, this also suggests that if a few dominant contributors to risk can be identified, a simplified Boolean containing only those components will lead to a close estimate of the HCLPF and mean risk. However, in plants with core damage sequences dominated by intersections rather than unions of events, correlation would be relatively more important. 


\subsubsection{Seismic Hazard}

The basic seismic hazard at the LGS site is described by a family of hazard curves relating effective peak ground acceleration to annual probability (Section 4). The most conservative of these hazard curves (based on the so-called Decollement model) is unbounded, while the remaining curves have an upper limit on the ground acceleration. The existence (of lack therenf) of an upper bound on ground motion is the object of some controversy. The seismic hazard curve families developed in more recent studies (e.g., Bernreuter, et al, 1987) generally do not contain an upper bound.

The sensitivity of core damage probability estimates to seismic hazard modeling was evaluated by three analyses. In the first, the 5 hazard curves in the family that are bounded from above were modified to be unbounded by using a Type II distribution to extrapolate to higher fractiles. The curve associated with the Decollement hypothesis was left unchanged, as were the weights assigned to each hypothesis. The resulting fractiles of $P\left(T_{S} E_{S} U X\right)$ and $P(C D)$ are compared in Lines (2) of Table (5.10). The $95 \%$ ile is essentially unchanged while the means increase by less than a factor of 2 . The most pronounced effect is seen in the increase in the lower fractiles, causing the scatter in $P\left(T_{S} E_{S} \cup X\right)$ and $P(C D)$ to decrease.

In the second, the Decollement curve was truncated successively at $0.6 \mathrm{~g}$ and $0.9 \mathrm{~g}$ and renormalized, but the weights on the curves were left unchanged. The resulting core damage fractiles are shown in Lines (3) and (4) of Table (5.10). The differences in the fractiles frorll the base case are negligible. This is consistent with the observation made in previous studies (Ravindra, et al, $1984 ; 1985)$ that the dominant contribution to core damage probability arises from accelerations in the range 2 to 4 SSE; for LGS, this range would be $0.3 \mathrm{~g}$ to $0.6 \mathrm{~g}$, below the above levels of truncation. Truncating the seismic hazard curve generally has little impact on plant damage frequencies because plausible levels of truncation fall above the range contributing most to core damage. This point is addressed further in Addendum A5.

Finally, in the third, the effect of the Decollement hypothesis was examined by leaving the hazard curves unchanged but varying the weights assigned to each The weight assigned to the Decollement hypothesis $\left(P_{6}\right.$ in Figure 4.2) was increased, first from 0.10 to 0.30 and second from 0.30 to 1.0 while the other weights were decreased in proportion. In the latter case, the Decollement model is assumed to represent the only credible seismogenic hypothesis, and the frequency distribution of core damage probability reflects solely uncertainty in the component fragility modeling. Lines (5) and (6) of Table (5.10) summarize the results of this 
analysis for sequences $T_{s} E_{s} U X$ and $C D$. The seismic hazard curve resulting from the Decollement model is the determining factor for the upper fractiles of the frequency distributions for $P\left(T_{S} E_{S} \cup X\right)$ and $P(C D)$. This is reflected in the relatively small change in the 95 percentile value of both $P\left(T_{s} E_{s} \cup X\right)$ and $P(C D)$. However, the differences are significant in the lower frequency range. As the uncertainty in the seismic hazard modeling is reduced, the family of curves is collapsed into a single hazard curve (here, the Decollement), and the spread in core damage probability is reduced from three (or more) orders of magnitude to less than one. In the baseline case, the ratio of mean to median risk is approximately 7; when $P_{6}=1.0$, the ratio is 1.2. This shows that the mean seismic risk is dominated by the more conservative hazard curves in the family. The logarithmic standard deviation in estimates $P\left(T_{S} E_{S} U X\right)$ and $P(C D)$ in lines (6) are 0.52 and 0.40 respectively. These arise solely from the fragility modeling uncertainties, $\beta U$, and are of the same order of magnitude as the maximum $\beta_{u} i$ for components in each sequence. No other uncertainty in the seismic PRA has as great an impact on the results as that in the basic seismic hazard. Moreover, there does not seem to be any way to reduce this large uncertainty (and thus its impact on seismic PRA results) given the current state of the art of seismic hazard analysis.

\subsection{Millstone 3}

The analysis of Millstone 3 was intended to determine the degree of consistency between PRAs conducted for a BWR and PWR plant and to identify any apparently significant differences. In all cases, the seismic fragilities were described by a lognormal model, with parameters given in Table 2.2. Two competing seismic hazard analyses were available, as outlined in Section 4.2, and were used in the comparative evaluation.

The plant level fragilities for the four plant damage states are illustrated in Figures 5.9 - 5.12. Table 5.11 summarizes the results of the analyses of the four dominant sequences. Line (1) under each sequence was developed using the "PSS" seismic hazard curves developed by Dames and Moore as part of the PRA for the plant. In line (2) under each sequence, components $S_{29}, S_{30}, S_{31}, S_{32}$ and $S_{35}$, which had component HCLPF values greater than $3 \times$ SSE (see Table 2.2) were eliminated from the sequence Booleans, but all other parameters were unchanged. In line (3), median fragilities for components $\mathrm{S}_{6}, \mathrm{~S}_{9}$ and $\mathrm{S}_{17}$ were reduced in line with suggestions made during the external events peer review (Garcia, et al, 1986): 
Component

S6 - core geometry

S9 - control rod drive

$\mathrm{S}_{27}$ - containment crane wall
Am

$0.87 \mathrm{~g}$

$0.88 \mathrm{~g}$

$1.82 \mathrm{~g}$
$\beta_{R}$

$\beta u$

0.33

0.38

0.38

In line (4), the alternative "SCHP" seismic hazard curves developed as part of the seismic hazard characterization project were used in lieu of the PSS curves, but all fragility parameters were unchanged from those in line (2). Finally, in line (5), the HCLPFs reported in Table B-9 of Appendix $B$ of NUREG/CR-4334 (Budnitz, et al, 1985) for damage states TE, AE, SE, and $V 3$ are summarized.

A comparison of lines (1) and (2) under each sequence indicates that the inclusion of components in the accident sequences with HCLPF values greater than 3SSE has a negligible effect on core damage probability distributions or plant HCLPF. Accordingly, such components can be culled from the plant logic Booleans to simplify the analysis without affecting the risk estimates significantly. The decrease in median fragility for components $S_{6}, S_{9}$ and $S_{27}$ has a negligible impact on core damage probability for all sequences except $V_{3}$, where the component affected is one of two components in series. The sequence HCLPF values reported in line (5) are consistent with those obtained in this study, with the exception of that for V3. Since $V_{3}=S_{27}+S_{29}$ and $S_{29}$ has a HCLPF of 0.52 (see Table 2.2(a)), the reported HCLPF of 0.60 is believed to be in error.

The probabilities in line (4) obtained using the SHCP hazard curves are an order of magnitude higher than those in lines (1) - (3) at the higher fractiles of the core damage probability, and two (or more) orders of magnitude higher at the lower fractiles. As with LGS, the mean core damage probability occurs at approximately the 75th percentile of the frequency distribution in all cases. It is clear that the uncertainty in the basic seismic hazard at the Millstone 3 site is the dominating factor in the PRA, as it was at Limerick. The difference between seismic hazard curves obtained using the LLNL and EPRI approaches to hazard analysis are similar to the differences between the PSS and SHCP curves illustrated in Figure 4.2. One might expect that similar differences in core damage risk would be observed at other plants if the LLNL and EPRI curves were used.

The interfacing systems LOCA is most significant to offsite risk, but contributes only about $1 \%$ to core damage probability. Thus dominent core damage sequences may not be the same as those dominating risk. 


\subsection{Maine Yankee}

Maine Yankee was selected to demonstrate the seisnic margins approach to plant safety evaluation (Prassinos, et al, 1987). The basic objective of margins analysis is to determine a HCLPF value of ground motion for the plant that can be compared with a review level earthquake that has been determined independently. A margins analysis of a plant provides "risk insight" without directly estimating risk by identifying potentially vulnerable components within the plant in terms of their contribution to the HCLPF. For PWR plants such as Maine Yankee, the focus is on two critical plant safety functions: reactor subcriticality and early emergency core cooling and heat removal. To simplify the analysis, the seismic margins review focuses on systems related to these essential functions. Two such accident sequences were identified for Maine Yankee, as summarized in Section 2.3.

The results of the seismic PRA of Maine Yankee using the two sequences identified above are summarized in Table 5.12. The plant level fragilities for these two sequences are illustrated in Figures 5.13 and 5.14. These are not combined as the walkdown within the containment needed to validate the core damage sequence could not be performed. Three different fragility models were used in the analysis for comparative purposes. Notations LN, W and JS refer to the fragility model selected; the JS model (Eqn 3.8) had a minimum fragility equal to 0.25 times the median while the other two had a minimum value equal to 0 . The HCLPF computed using the three fragility models are close to one another, in contrast to the HCLPFs computed for the LGS sequences with the $\mathrm{LN}$ and $\mathrm{W}$ models, and the fractiles of the core damage sequence probabilities generally differ by less than a factor of two (cf Table 5.6). Thus, the fragility modeling issue appears to be relatively unimportant for this particular plant. For comparison, the sequence HCLPFs computed in the Maine Yankee margins review (using the lognormal fragility model) were $0.21 \mathrm{~g}$ and $0.32 \mathrm{~g}$ for sequences $A_{1}$ and $A_{2}$, respectively (Prassinos, et al, 1987).

NUREG/CR-4482, section 4.8.2 (Prassinos, et al, 1986) describes a simple method to compute a plant-level HCLPF from the HCLPF values of the individual components in the dominant accident sequences. This method can be explained in a simple way by considering a two-component system. If

$$
F_{\text {sys }}=F_{1}{ }^{*} F_{2}
$$

then

$$
\mathrm{HCLPF}_{\text {sys }}=\max \left(\mathrm{HCLPF}_{1}, \mathrm{HCLPF}_{2}\right)
$$

Similarly, if

$$
F_{\text {sys }}=F_{1}+F_{2}
$$


then

$$
\mathrm{HCLPF}_{\text {sys }}=\min \left(\mathrm{HCLPF}_{1}, \mathrm{HCLPF}_{2}\right)
$$

These simple formulas can be applied in a stepwise fashion to sequences involving more complicated unions and interactions of component failures. Applying them to the Maine Yankee Sequences $A_{1}$ and $A_{2}$, one obtains

$$
\begin{aligned}
& \mathrm{HCLPF}_{1}=0.21 \mathrm{~g} \\
& \mathrm{HCLPF}_{2}=0.30 \mathrm{~g}
\end{aligned}
$$

as was reported in NUREG/CR-4826 Prassinos, et al, 1986). When compared to the "exact" HCLPF determined from Figures 5.13 and 5.14 and reported in Table 5.12, the error is less than $5 \%$ on the unconservative side for both sequences.

On the other hand, if the same methodology is applied to the LGS core damage sequence $C D$, one obtains $H C L P F=0.37 \mathrm{~g}$, greater than the "exact" HCLPF of $0.32 \mathrm{~g}$ by $16 \%$. A comparison of this approach for the Millstone 3 plant damage states is summarized below:

$\begin{array}{ccc}\text { Sequence } & \text { HCLPF simple } & \text { HCLPF exact } \\ \text { TE } & 0.30 \mathrm{~g} & 0.28 \mathrm{~g} \\ \text { SE } & 0.31 \mathrm{~g} & 0.41 \mathrm{~g} \\ \text { AE } & 0.31 \mathrm{~g} & 0.45 \mathrm{~g} \\ \text { V3 } & 0.52 \mathrm{~g} & 0.51 \mathrm{~g}\end{array}$

This simple calculation procedure is reasonable as long as the failure sequence is dominated by a union of singleton cut sets. It is not as good when intersections are important. It results in errors that are dependent on the plant logic and are unpredictable in magnitude. Since it may err on the unconservative side, it is not recommended for general margin evaluations without a supporting probabilistic analysis of plant level fragility.

Addendum A5. Seismic Hazard - Fragility Interactions

\section{A5.1 Introduction}

The seismic hazard curve in Section 4 expresses the annual probability of exceeding a specified effective peak ground acceleration (EPA) or of exceeding a specified spectral acceleration. A seismic fragility is defined as the probability of failure of a structural, mechanical or electrical component, conditioned on the EPA being equal to 
$x$. The fragility and hazard curves must be expressed in physically and dimensionally consistent units.

The limit state or functional failure probability is expressed as,

$$
P_{f}=\int_{0}^{\infty} F_{R}(x) f_{A}(x) d x
$$

in which $F_{R}(x)=$ cumulative distribution function (c.d.f.) modeling the seismic fragility of the component., and $f_{A}(x)=$ density function of effective peak ground acceleration (EPA). This density function is related to the seismic hazard curve, $G_{A}(x)$, described in Section 4 by,

$$
f_{A}(x)=-d G_{A}(x) / d x
$$

The convolution integral in Eqn A5.1 is illustrated conceptually in Figure A5.1. It might be observed that only a relatively small range of accelerations contributes significantly to $\mathrm{Pf}$. Questions arise as to what range of accelerations is important and whether this information can be used to simplify seismic PRA or margin studies, develop simplified point estimates of core damage probability, and devise accelerated testing or in- service testing procedures to confirm expectations of plant performance. Some studies have concluded that the dominant contributors to estimates of core damage probability come from EPAs in the range of 2 - 4 times the SSE (Ravindra, et al, 1985). This information is anecdotal, coming from risk evaluations of a few specific plants. In the following, a more general approach is taken.

In the following analysis, the effects of modeling uncertainty will be neglected unless otherwise noted. This is tantamount to assuming that the fragility and hazard curves each can be collapsed to one "best estimaten curve. However, different fragility models are considered.

\section{A5.2 Method of Analysis}

The seismic hazard is assumed to be modeled by a Type II distribution of extreme values,

$$
G_{A}(x)=1-\exp \left[-(x / u)^{-\alpha}\right]
$$

in which $u$ and $\alpha=$ parameters of the distribution. This assumption is consistent with elementary seismic hazard analysis (Cornell, 1968). A review of recent seismic hazard analyses for a number of nuclear power plants shows that the slope parameter $\alpha$ varies from approximately 2.3 to 4.4, the smaller values being associated with plants in the Eastern United States where the seismic hazard curve is relatively flat. The parameter $u$ 
is determined by relating the SSE to a specific annual probability of its being exceeded. This probability varies from site to site, but a typical value might be about $4 \times 10^{-4} / \mathrm{yr}$ (Reiter, 1990), corresponding to a mean recurrence interval of 2500 years. This assumption is reasonable for purposes of sensitivity analysis, which is is not tied to any specific plant. The corresponding value of $u$ increases from 0.033 SSE when $\alpha=2.3$ to 0.169 SSE when $\alpha=4.4$.

The probability of component failure is expressed as,

$$
\begin{aligned}
P_{f} & =-\int_{0}^{\infty} F_{R}(x) \frac{d G_{A}}{d x} d x \\
& =\int_{0}^{\infty} I(x) d x
\end{aligned}
$$

in which $F_{R}(x)$ denotes the particular fragility chosen. Through a transformation of variables, Eqn A5.4 can be evaluated numerically to any degree of accuracy desired by Gauss-Laguerre quadrature (Abramowitz and Segun, 1968). Examination of the characteristics of the integrand, I(x), indicates the accelerations that contribute most to failure probability.

\section{A5.3 Results}

\section{A5.3.1 Lognormal Fragility Model}

The seismic fragility is modeled by a lognormal c.d.f.,

$$
F_{R}(x)=\Phi\left(\frac{\ln \left(x / A_{m}\right)}{\beta_{R}}\right)
$$

in which $\Phi=$ standard normal probability c.d.f. and $A_{m}, \beta_{R}$ are the median and logarithmic standard deviation of the seismic capacity of the component. Parameter $\beta_{R}$ is a convenient measure of uncertainty or variability, related to the coefficient of variation in capacity, $V_{R}$, by,

$$
\beta_{R}=\sqrt{\ln \left(1+V_{R}^{2}\right)}
$$

When $V_{R}<0.30$, as is typical for most component seismic fragilities, $\beta_{R} \approx$ $V_{R}$. The lognormal distribution is positively skewed toward larger values of acceleration, with a skewness coefficient equal to $V_{R}\left(3+V_{R}{ }^{2}\right)$.

Substitute Eqn A5.5 into Eqn A5.4, differentiate $I(x)$ and set equal to zero, and assume that,

$$
G_{A}(x) \approx(x / u)^{-\alpha}
$$


This approximation is reasonable if $(x / u)-\alpha$ is less than about 0.10 , corresponding to accelerations above approximately 0.2 SSE. This focuses attention on that portion of the seismic hazard curve where the probability is 0.05 or less that the acceleration is exceeded in a given year. Current seismic regulations for buildings and NPPs result in components with capacities well above this level. The modal (maximum) value, $x_{0}$, of $I(x)$ is found to be, ,

$$
x_{0}=A_{m} \exp \left[-\beta_{R}^{2}(1+\alpha)\right]
$$

The implications of this analysis are displayed in Table A5.1 for a range of fragility parameters that are typical of those found in nuclear plant construction. The tabulated parameters indicate the modal value $x_{0} /$ SSE of $I(x)$ in the limit state probability integral, $P_{f}$. For c.o.v.s in the range of 0.2 to 0.3 and relatively flat hazard curves the major contribution to $\mathrm{Pf}_{\mathrm{f}}$ comes from accelerations in the range of 75 to 90 percent of the median fragility. Tables $2.1-2.3$ show that the majority of component fragilities have a $\beta_{R}$ in the range of 0.2 to 0.4 .

A typical case might be when $\alpha=2.7$ (c.o.v. of $85 \%$ in annual EPA), $A_{m}=4$ SSE and $V_{R}=0.30$ (see, e.g., component $S_{4}$, the reactor enclosure structure, in the Limerick plant). Figure A5.2 illustrates $I(x)$ for this case. The mode of $I(x)$ is 2.905 SSE $\left(73 \%\right.$ of $\left.A_{m}\right)$ and $P_{f}=1.3 \times 10-5 / y r$. Of this $\mathrm{Pf}_{\mathrm{f}}, 90 \%$ comes from accelerations between 1.95 and 5.05 times the SSE $\left(0.49 A_{m}-1.26 A_{m}\right) ; 95 \%$ come from accelerations between 1.75 and 5.50 times the SSE $(0.44 \mathrm{Am}-1.38 \mathrm{Am})$. There is essentially no contribution to $\mathrm{Pf}_{\mathrm{f}}$ from accelerations below the SSE. Figure A5.3 illustrates the 5-to-95 percent scatterband on the contribution to $P_{f}$ as a function of $A_{m} / S S E$ when $\alpha=2.7$ and $V_{R}=0.30$. These limits are virtually linear as long as the slope of the hazard curve is flat (say, less than 3.8). The maximum contribution to $P_{f}$ is always centered around accelerations that are less than the median fragility.

It might be noted from Table A5.1 that $x_{0} / S S E$ is relatively insensitive to parameter $\alpha$. However, as $\alpha$ increases and the basic variability in the annual EPA decreases, the region contributing significantly to $P_{f}$ shifts leftward in Figure A5.1. In such cases, the behavior of the lower tail of the fragility model becomes relatively more important, particularly when the variability in fragility, $V_{R}$, is relatively large. As the variability in fragility increases to $0.40, x_{0} / S S E$ decreases to about 60 percent of $A_{m}$. This result implies that correct modeling of the lower tail of the fragility is relatively more important for plants in the Western US than for plants in the Eastern US where the seismic hazard curve is flat. 


\section{A5.3.2 Modified Lognormal Fragilities}

Several cases were evaluated in which the lower tail of the fragility was modified.

Some have suggested arbitrarily truncating the fragility at 2 or 3 logarithmic standard deviations below In $A_{m}$. If $V_{R}=0.30$, for example, this is equivalent to truncating the fragility at $0.56 \mathrm{~A}_{\mathrm{m}}$ or $0.42 \mathrm{~A}_{\mathrm{m}}$, respectively. If $\alpha=2.7,90$ percent of $\mathrm{Pf}_{\mathrm{f}}$ comes from accelerations from $0.49 A_{m}-1.26 A_{m}$, and truncating the fragility would have little impact on $P_{f}$ in this case. Only when $V_{R}>0.3$ does truncating the lower tail of the fragility model have a significant effect on $P_{f}$; the truncation effect becomes more pronounced as hazard slope, $\alpha$, increases. Truncating the seismic hazard curve above 5 SSE or $1.25 \mathrm{~A}_{m}$ has little effect on $\mathrm{Pf}$ for the range of $V_{R}$ and $\alpha$ in Table A5.1.

The lognormal fragility model can be shifted rather than truncated so that there is a minimum value $x_{\min }$ below which the fragility is zero. This operation, of course, modifies the shape of the lower tail above $x_{\min }$ as well. Substituting this modified fragility model in Eqn A5.4 and differentiating results in a nonlinear equation in $x$ that must be solved for the mode, $x_{0}$ :

$$
x=x_{\min }+\left(A_{m}-x_{\min }\right) \exp \left[-\beta_{R}^{2}\left(1+\alpha\left(\frac{x-x_{\min }}{x}\right)\right)\right]
$$

Suppose that $\alpha=2.7, A_{m} / S S E=4$ and $x_{\min } / S S E=2$. If $V_{R}=0.20, x_{0} / S S E=$ 3.49 , while if $V_{R}=0.30, x_{0} / S S E=3.17$. The comparable values for the basic lognormal fragility are 3.46 and 2.91 (see Table A5.1). Thus, the lower tail shaping effect is more important when the inherent variability in the fragility is relatively large.

\section{A5.3.3 Weibull Fragility Model}

The two-parameter Weibull fragility is defined by,

$$
F_{R}(x)=1-\exp \left[-(x / w)^{\gamma}\right] ; x, \gamma, w>0
$$

in which $w, \gamma$ are parameters of the distribution related to the median and c.o.v. by,

$$
\mathrm{w}=\mathrm{A}_{\mathrm{m}} /(\ln 2)^{\frac{1}{\gamma}}
$$




$$
V_{R}=\left[\Gamma\left(1+\frac{2}{\gamma}\right) / \Gamma^{2}\left(1+\frac{1}{\gamma}\right)-1\right)^{\frac{1}{2}}
$$

The Weibull model is positively skewed if $\gamma<3.6$. Substituting Eqn A5.10 into Eqn A5.4, differentiating the integrand and setting it equal to zero, and making the assumption of Eqn A5.7, as before, we obtain,

$$
x_{0} \approx w\left[\frac{(\gamma-1)-\alpha}{\gamma}\right] \frac{1}{\gamma}
$$

This approximation is valid provided that $\gamma-1>\alpha$, which usually is is the case if the hazard curve is flat; e.g., if the c.o.v. in fragility is $0.3, \gamma=3.7$.

A comparison of the values $x_{0} / S S E$ for lognormal and Weibull fragility models with a coefficient of variation of 0.20 is presented in Table A5.2. The impact of the relative shape of the lower fragility tail can be seen by reading horizontally in Table A5.2 and noting that $x_{0} / S S E$ decreases at a faster rate for the Weibull fragility model as the slope of the hazard curve increases. For plants in the Western US, then, where $\alpha$ would tend to be relatively larger, the dominant contribution to risk using this fragility model would come from accelerations that are relatively closer to the SSE.

\section{A5.4 Simplified Estimates of Core Damage Probability}

A simplified procedure for estimating the mean and coefficient of variation in core damage probability can be developed expanding a procedure suggested by Cornell and Newmark (1979).

Assume that the seismic hazard is described by a Type II distribution of largest values and that the component fragility is described by a lognormal distribution. The hazard curve can be approximated by,

$$
G_{A}(x) \approx(x / u)^{-\alpha}
$$

which is a valid approximation for accelerations greater than about 0.2 SSE when $2.3<\alpha<4.4$. Modeling uncertainty in the fragility and the seismic hazard would be represented by assigning $A_{m}$ and $u$ logarithmic standard deviations $\beta_{U}$ and $\beta_{H}$, thus defining two families of curves.

If there is no modeling uncertainty in either fragility or hazard, each can be described by a single curve and the failure probability, $\mathrm{P}_{\mathrm{f}}$, becomes,

$$
P_{f}=\int_{0}^{\infty} G_{A}(x) f_{R}(x) d x
$$




$$
=u^{\alpha} \int_{0}^{\infty} \frac{1}{\sqrt{2} \pi \beta_{R} x^{\alpha+1}} \exp \left[\frac{1}{2}\left(\frac{\ln \left(x / A_{m}\right.}{\beta_{R}}\right)^{2}\right] d x
$$

Performing the indicated integrations and using Eqn A5.14, one obtains,

$$
\begin{aligned}
P_{f} & =u^{\alpha} A_{m}^{-\alpha} \exp \left[\beta_{R}^{2} \alpha^{2} / 2\right] \\
& =G_{A}\left(A_{m}\right) \exp \left[\left(\alpha \beta_{R}\right)^{2 / 2}\right]
\end{aligned}
$$

With no parametric uncertainty in $u$ or in $A_{m}$, the seismic hazard is evaluated at the median fragility. The exponential term in Eqn A5.16 represents the effect of randomness in seismic capacity on $P_{f}$; if the fragility is deterministic, modeled by a step function at $A_{m}, \beta_{R}=0$ and this second term is unity.

Modeling uncertainty is addressed by treating $H=u^{\alpha}$ and $A_{m}$ as lognormal random variables, with medians $u_{m}^{\alpha}$ and $A_{m}$ and logarithmic standard deviations $\beta_{U}$ and $\beta_{H}$. The expected value of $P_{f}$ is computed as,

$$
E\left[P_{f}\right]=\int_{0}^{\infty} \int_{0}^{\infty} P\left(F \mid H, A_{m}\right) f_{H}(h) f_{a_{m}}(a) d h d a
$$

in which the conditional probability is determined from Eqn A5.16 and $f_{H}$ and $f_{A_{m}}$ are the lognormal density functions of $H$ and $A_{m}$. Performing the integrations,

$$
\begin{aligned}
E\left[P_{f}\right] & =\widehat{G}_{A}\left(A_{m}\right) \exp \left[\left(\beta_{\mathrm{H}}^{2}+\alpha^{2}\left(\beta_{\mathrm{R}}^{2}+\beta_{\mathrm{u}}^{2}\right) / 2\right]\right. \\
& =\bar{G}_{A}\left(A_{m}\right) \exp \left[\alpha^{2}\left(\beta_{R}^{2}+\beta_{u}^{2}\right) / 2\right]
\end{aligned}
$$

in which $\widehat{\mathrm{G}}_{\mathrm{A}}\left(\mathrm{A}_{\mathrm{m}}\right)=$ median hazard curve evaluated at the median fragility and $\bar{G}_{A}\left(A_{m}\right)=$ mean hazard curve. The coefficient of variation in $P_{f}$ is,

$$
\text { c.o.v. }\left(\mathrm{P}_{\mathrm{f}}\right)=\left[\exp \left[\beta_{\mathrm{H}}^{2}+\alpha^{2} \beta_{\mathrm{u}}^{2}\right]-1\right]^{\frac{1}{2}}
$$

Consider for illustrative purposes the Limerick sequence $T_{S} R_{B}$, with fragility parameters defined in Table 2.1. Assuming that the Decollement curve (Section 4) represents the seismic hazard; the Type II parameters describing this curve are $\alpha=2.6$ and $u=0.00825 \mathrm{~g}$. The estimate of sequence probability from Eqn A5.16 is, 


$$
\begin{aligned}
P_{f} & =(1.05 / 0.00825)^{-2.6} \times \exp \left[(0.31 \times 2.6)^{2 / 2}\right] \\
& =\left(3.37 \times 10^{-6}\right) \times(1.384) \\
& =4.67 \times 10^{-6}
\end{aligned}
$$

Taking into account the uncertainty in fragility modeling $(\beta U=0.25)$ and in seismic hazard modeling $\left(\beta_{H}=0.6\right.$ if the uncertainty band on the hazard family is one order of magnitude), we obtain from Eqns A5.18 and A5.19,

$$
\begin{aligned}
& E\left[P_{f}\right]=6.9 \times 10^{-6} \\
& \text { c.o.v. }\left[P_{f}\right]=1.1
\end{aligned}
$$

The mean sequence probability calculated for this particular case from the PRA hazard curve and fragility families is $1.1 \times 10^{-6}$ (cf Table 5.3) and the logarithmic standard deviation is approximately 2.4. The differences arise mainly from the assumption that the slope, $\alpha$, of the hazard curve equals 2.6 for all curves in the family and that the uncertainty is vested simply in the position of the hazard curves. The actual hazard curves did not exhibit this property (cf Figure 4.2).

A similar analysis can be performed for fragilities modeled by the Weibull or Johnson distributions.

\section{A5.5 Estimating Core Damage Probability from the HCLPF}

In a seismic margin study, the seismic hazard issues are decoupled from the plant logic and fragility modeling. The core damage probability is not estimated through this procedure, and in fact the seismic hazard curve(s) may not even be available if the review earthquake has been selected by fiat. However, in cases where some idea of the seismic hazard exists, it might be of interest to attempt an orderof-magnitude estimate of the core damage probability from the margin results.

Interestingly, such an estimate can be obtained from the results presented earlier in this Addendum. If the seismic hazard curves are described by a Type II distribution of largest values, the probabilities at large acceleration levels are related by (cf Eqn A5.7),

$$
G_{A}\left(x_{1}\right) / G_{A}\left(x_{2}\right)=\left(x_{2} / x_{1}\right)^{\alpha}
$$

The slope $\alpha$ typically varies from 2.3 to 3.5 for plants in the Eastern United States. The fragilities presented in Section 3 and the results presented in Table A5.1, as well as previous work indicate that major contributions to core damage come from accelerations in the range of 4 SSE. Further, the plant HCLPF typically is about 2 SSE for plants in the 
Eastern United States. Assuming that the variability in fragility is small with respect to the uncertainty in seismic hazard (cf. Eqn A5.16), the ratio

$$
\begin{aligned}
G_{A}(2 \text { SSE }) / G_{A}(4 \text { SSE }) & =2^{2.3} \text { to } 2^{3.5} \\
& =4.9 \text { to } 11.3
\end{aligned}
$$

suggests that $P(C D)$ equals approximately 0.1 to 0.2 times the probability that the EPA exceeds the HCLPF.

This observation was tested for several sequences at the Limerick and Millstone 3 plants. The expected value of the probability that $A$ exceeds the sequence HCLPF was computed using the probabilities or weights, $W_{1}$, assigned to the various seismic hazard curves used in the PRA (see, e.g., Tables 4.1 and 4.2):

$$
E[P(A>H C L P F)]=\Sigma P_{i}(A>H C L P F) w_{i}
$$

The results of this analysis are presented in Table A5.3. It might be observed that in almost all cases in this limited sample, the means fall in the range indicated above, and it is tempting to conclude that $P($ Seq $) \approx P(A>H C L P F) / 10$. Obviously, further studies are required to generalize this conclusion.

\section{A5.6 Summary}

In the Eastern US and other sites where the seismic hazard curve is relatively flat $(2.3<\alpha<3.5)$, the choice of fragility model and the characteristics of the lower fragility tail are relatively less important for $P_{f}$ than when $\alpha>4$. Simply truncating the fragility at an arbitrary 2 or 3 logarithmic standard deviations below $\ln \left(A_{m}\right)$ is not recommended. Instead, a more comprehensive investigation of the characteristics of the lower fragility tail should be undertaken, especially for use in seismic margin studies where these characteristics are particularly important.

Accident sequence probabilities can be estimated, with accuracy to less than an order of magnitude, by relatively simple analyses, as illustrated in Section A5.4. An evaluation of a limited number of sequences at Limerick and Millstone 3 plants suggests that an even simpler estimate of accident sequence probability can be obtained as 10 times the probability that the HCLPF for that sequence is exceeded. 
TABLE 5.1

Fractiles and Mean Values of Core Damage Probability - LGS

$\begin{array}{ccccc}\text { Sequence } & 5 \% & 50 \% & \text { Mean } & 95 \% \\ T_{s} E_{s} U X & 1.7-8 & 4.6-7 & 1.7-6 & 8.4-6 \\ T_{s} R_{b} & 1.5-12 & 8.2-9 & 9.4-7 & 6.2-6 \\ T_{s} R P V & 2.6-16 & 4.1-10 & 5.4-7 & 4.4-6 \\ T_{s} E_{s} C_{m} C_{2} & 2.1-11 & 3.5-8 & 2.7-6 & 1.5-5 \\ T_{s} R_{b} C_{m} & 9.0-18 & 5.5-10 & 5.3-7 & 3.2-6 \\ T_{s} E_{s} W & 2.2-9 & 5.2-8 & 1.2-7 & 3.1-7 \\ T_{s} E_{s} U V & 2.0-11 & 2.5-9 & 3.9-7 & 2.5-6\end{array}$

TABLE 5.2

Comparison of Mean Core Damage Sequence Probabilities - LGS

$\begin{array}{cccc}\text { Sequence } & \text { LGS-SARA } & \text { Peer Review } & \text { This study } \\ T_{s} E_{s} U X & 3.1-6 & 2.8-6 & 1.7-6 \\ T_{s} R_{b} & 9.6-7 & 9.5-7 & 9.4-7 \\ T_{s} R P V & 8.0-7 & 4.4-7 & 5.4-7 \\ T_{s} E_{s} C_{m} C_{2} & 5.4-7 & 6.0-7 & 2.7-6 \\ T_{s} R_{b} C_{m} & 1.4-7 & 3.5-7 & 5.3-7 \\ T_{s} E_{s} W & 1.1-7 & 1.1-7 & 1.2-7 \\ \text { CM (Summed) } & 5.7-6 & 5.3-6 & 6.5-6\end{array}$

TABLE 5.3

HCLPF and Core Damage Probability Fractiles Using Condensed Booleans. LGS

$\begin{array}{lccccc}\text { Sequence } & \text { HCLPF } & 0.05 & 0.50 & \text { Mean } & 0.95 \\ \mathrm{~T}_{s} E_{s} U X & 0.33 \mathrm{~g} & 1.8-8 & 5.0-7 & 3.4-6 & 2.0-5 \\ \mathrm{~T}_{s} R_{b} & 0.42 \mathrm{~g} & 2.0-13 & 6.6-9 & 1.1-6 & 7.3-6 \\ \mathrm{~T}_{s} R P V & 0.55 \mathrm{~g} & 1.5-16 & 1.9-10 & 4.7-7 & 3.5-6 \\ \mathrm{~T}_{s} \mathrm{E}_{s} \mathrm{C}_{m} \mathrm{C}_{2} & 0.42 \mathrm{~g} & 4.7-12 & 1.0-8 & 1.5-6 & 8.6-6 \\ \mathrm{~T}_{s} R_{b} C_{m} & 0.54 \mathrm{~g} & 3.7-17 & 2.9-10 & 6.0-7 & 4.4-6 \\ \mathrm{~T}_{s} E_{s} W & 0.37 \mathrm{~g} & 2.1-9 & 5.2-8 & 1.2-7 & 3.8-7 \\ \mathrm{~T}_{s} E_{s} U V & - & 1.5-14 & 3.2-9 & 1.3-6 & 7.9-6 \\ \mathrm{CD} \text { (Union) } & 0.32 \mathrm{~g} & 2.7-8 & 7.2-7 & 5.0-6 & 2.4-5\end{array}$


TABLE 5.4

Effect of Structural Fragility Parameters on $P(C D)$ - LGS

Case considered HCLPF $5 \% \quad 50 \%$ Mean $95 \%$
(1) Baseline Case
$0.32 \mathrm{~g}$
$2.7-8 \quad 7.2-7$
5.0-6 2.4-5
(2) Reactor encl. structure
$0.30 \mathrm{~g} \quad 3.2-8 \quad 8.2-7$
5.8-6 2.9-5
(3) Recoverable Elect.
$0.37 \mathrm{~g} \quad 1.4-8 \quad 5.0-7$
3.0-6 $\quad 1.5-5$
(4) Reactor Internals
$0.32 \mathrm{~g}$
$2.6-8$
8.0-7
5.0-6
2.5-5
(5) $\beta \mathrm{R}+\beta_{\mathrm{U}}=0.80$
$0.32 \mathrm{~g} \quad 2.2-8 \quad 7.7-7$
4.6-6 2.4-5
(6) $A_{m}$ known
$0.31 \mathrm{~g} \quad 2.5-8 \quad 5.9-7$
4.8-6
2.6-5

TABLE 5.5

Effect of Uncertainty in $\beta_{R}$ on Sequence Probabilities - LGS

\begin{tabular}{lcclll}
\multicolumn{1}{c}{ Sequence } & HCLPF & $5 \%$ & $50 \%$ & Mean & $95 \%$ \\
$T_{s} E_{s} U X$ & $0.27 \mathrm{~g}$ & $1.7-8$ & $9.1-7$ & $4.8-6$ & $2.5-5$ \\
$T_{s} R_{b}$ & $0.40 \mathrm{~g}$ & - & $1.3-8$ & $1.2-6$ & $8.0-6$ \\
$T_{s} R P V$ & $0.54 \mathrm{~g}$ & - & $1.8-10$ & $4.9-7$ & $3.5-6$ \\
$T_{s} E_{s} C_{m} C_{2}$ & $0.44 \mathrm{~g}$ & $1.2-11$ & $9.0-9$ & $1.5-6$ & $8.0-6$ \\
$T_{s} R_{b} C_{m}$ & $0.50 \mathrm{~g}$ & - & $9.0-11$ & $6.8-7$ & $4.8-6$ \\
$T_{s} E_{s} W$ & $0.33 \mathrm{~g}$ & $2.4-9$ & $1.0-7$ & $1.8-6$ & $1.1-5$ \\
$\infty$ & $0.26 \mathrm{~g}$ & $4.9-8$ & $1.3-6$ & $6.5-6$ & $2.8-5$ \\
$C D($ Baseline $)$ & $0.32 \mathrm{~g}$ & $2.7-8$ & $.2-7$ & $5.0-6$ & $2.4-5$ \\
$C D(\beta U \approx 0)$ & $0.54 \mathrm{~g}$ & $1.9-8$ & $4.2-7$ & $1.9-6$ & $9.2-6$
\end{tabular}

TABLE 5.6

Effect of Fragility Mudeling on Sequence Probabilities - LGS

\begin{tabular}{|c|c|c|c|c|c|c|}
\hline \multirow{5}{*}{$\begin{array}{c}\text { Sequence } \\
T_{s} E_{s} U X\end{array}$} & Model & HCLPF & $5 \%$ & $50 \%$ & $95 \%$ & Mean \\
\hline & LN & $0.33 \mathrm{~g}$ & $1.8-8$ & $5.0-7$ & $2.0-5$ & 3.4-6 \\
\hline & $W(k=0.0)$ & $0.23 \mathrm{~g}$ & $3.6-7$ & $6.1-6$ & $3.9-5$ & 1.1 .5 \\
\hline & $W(k=.05)$ & $0.24 \mathrm{~g}$ & & na & & \\
\hline & $W(k=.25)$ & $0.25 \mathrm{~g}$ & & na & & \\
\hline \multirow[t]{4}{*}{$\infty$} & LN & $0.32 \mathrm{~g}$ & $2.7-8$ & $7.2-7$ & $2.4-5$ & $5.0-6$ \\
\hline & $W(k=0.0)$ & $0.21 \mathrm{~g}$ & $7.9-7$ & $1.3-5$ & $5.2-5$ & $1.7-5$ \\
\hline & $W(k=.05)$ & $0.22 \mathrm{~g}$ & & na & & \\
\hline & $W(k=.25)$ & $0.24 \mathrm{~g}$ & & na & & \\
\hline
\end{tabular}


Random Failures of Diesel Generators - LGS

Sequence $T_{s} E_{s} U X$

$\begin{array}{cccccc}\text { P(DGR) } & \text { HCLPF } & 5 \% & 50 \% & \text { Mean } & 95 \% \\ 0 & & & & & \\ 1.25-4 & 0.32 \mathrm{~g} & 2.3-9 & 1.5-7 & 3.2-6 & 2.0-5 \\ 1.25-3 & 0.33 \mathrm{~g} & 1.8-8 & 5.0-7 & 3.4-6 & 2.0-5 \\ 1.25-2 & 0.32 \mathrm{~g} & 1.2-7 & 3.4-6 & 5.9-6 & 2.1-5\end{array}$

Sequence CD

$\begin{array}{cccccc}\text { P(DGR) } & \text { HCLPF } & 5 \% & 50 \% & \text { Mean } & 95 \% \\ 0.0 & 0.32 g & 6.8-9 & 3.0-7 & 4.5-6 & 2.2-5 \\ 1.25-4 & 0.32 g & 7.7-9 & 3.6-7 & 4.7-6 & 2.6-5 \\ 1.25-3 & 0.32 g & 2.8-8 & 7.2-7 & 5.0-6 & 2.4-5 \\ 1.25-2 & 0.29 g & 9.7-8 & 3.6-6 & 7.7-6 & 2.7-5 \\ 1.25-1 & 0.13 g & 9.1-7 & 2.6-5 & 3.3-5 & 9.8-5\end{array}$

TABLE 5.8

Effect of Random Equipment Failures - LGS

Sequence $T_{s} E_{S} U X($ Eqn. 2.1) $\quad$ HCLPF $\quad 5 \% \quad 50 \% \quad$ Mean $95 \%$
(1) Original
$0.32 \quad 1.7-8$
4.6-7 1.7-6
8.4-6
(2) Revised means
$0.32 \quad 1.8-8$
4.7-7 1.8-6
9.5-6
(3) Random rates
$0.32 \quad 1.6-8$
5.2-7 1.8-6
9.7-6

Sequence $T_{s} E_{s} \cup X$ (Eqn 2.11)
(4) Original
$0.33 \mathrm{~g} \quad 1.8-8$
$5.0-7$
3.4-6
2.0-5
(5) Random Rates
$0.32 \mathrm{~g} \quad 1.9-8$
$5.1-7$
3.4-6
2.1-5

Sequence CD (Eqn. 2.17)
(6) Original
$0.32 \mathrm{~g}$
2.8-8
$7.2-7$
5.0-6 2.4-5
(7) Random rates
$0.32 \mathrm{~g}$
2.5-8
$7.6-7$
5.1-6 2.4-5 
TABLE 5.9

Effect of Correlation on $P\left(T_{S} E_{S} \cup X\right)$ and $P(C D)$ - LGS

Case HCLPF $5 \% \quad 50 \%$ Mean $95 \%$

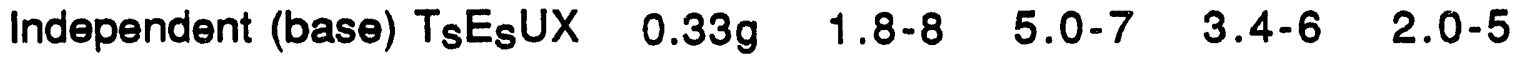

CD $\quad 0.32 \mathrm{~g} \quad 2.7-8 \quad 7.2-7 \quad 5.0-6 \quad 2.4-5$

$\begin{array}{llllll}\text { Correlated (bldg) } T_{s} E_{s} \cup X & 0.34 \mathrm{~g} & 2.0-8 & 4.5-7 & 3.0-6 & 1.7-5\end{array}$

CD $\quad 0.32 \mathrm{~g} \quad 2.7-8 \quad 5.8-7 \quad 4.5-6 \quad 2.1-5$

$\begin{array}{llllll}\text { Correlated (plant) } T_{S} E_{S} \cup X & 0.32 g & 2.1-8 & 4.3-7 & 2.9-6 & 1.6-5\end{array}$

$C D \quad 0.32 \mathrm{~g} \quad 2.8-8 \quad 5.4-5 \quad 4.2-6 \quad 1.9-5$

TABLE 5.10

Role of Uncertainty in Seismic Hazard - LGS

Sequence

$T_{s} E_{s} U X$
(1)

(6)

$\infty$
Seismic

Baseline

Unbounded

$A_{\max }=0.6$

$A_{\max }=0.9$

$$
P_{6}=0.3
$$$$
P_{6}=1.0
$$

\section{$5 \%$}

1.8-8

6.5-8

1.8-8

2.0-8

2.2-8

4.7-6
$50 \%$

5.0-7

2.8-6

5.0-7

5.3-7

1.6-6

$1.1-5$
Mean $\quad 95 \%$

3.4-6 2.0-5

5.4-6 1.6-5

2.6-6 1.4-5

3.4-6 2.1-5

5.9-6 2.3-5

1.3-5 2.6-5
(1)

(6)

\section{Baseline}

Unbounded

$A_{\text {max }}=0.6$

$A_{\max }=0.9$

$P_{6}=0.3$

$P_{6}=1.0$
2.7-8

1.0-7

3.4-8

2.5-8

3.1-8

7.5-6
7.2-7

4. 4-6

7.3-7

7.8-7

3.1-6

1.9-5
5.0-6

7.3-6

4. 0-6

5.1-6

8.5-6

1.8-5
2.4-5

2.5-5

2.3-5

2.8-5

2.7-5

2.8-5 
TABLE 5.11

Plant damage state probabilities for Millstone 3

\begin{tabular}{|c|c|c|c|c|c|c|}
\hline $\begin{array}{l}\text { Sec } \\
\text { TE }\end{array}$ & $\begin{array}{l}\text { ence } \\
(1) \\
(2) \\
(3) \\
(4) \\
(5)\end{array}$ & $\begin{array}{l}\text { HCLPF } \\
0.28 \\
0.25 \\
0.28 \\
0.29 \\
0.26\end{array}$ & $\begin{array}{c}5 \% \\
1.2-8 \\
1.1-8 \\
2.5-8 \\
6.5-7\end{array}$ & $\begin{array}{c}50 \% \\
1.6-6 \\
1.8-6 \\
1.7-6 \\
2.1-5 \\
\text { not repol }\end{array}$ & $\begin{array}{l}\text { Mean } \\
4.3-6 \\
5.1-6 \\
4.3-6 \\
6.7-5\end{array}$ & $\begin{array}{l}95 \% \\
1.8-5 \\
2.3-5 \\
1.8-5 \\
3.4-4\end{array}$ \\
\hline$A E$ & $\begin{array}{l}(1) \\
(2) \\
(3) \\
(4) \\
(5)\end{array}$ & $\begin{array}{l}0.45 \\
0.41 \\
0.45 \\
0.43 \\
0.45\end{array}$ & $\begin{array}{c}1.9-10 \\
1.2-10 \\
1.6-10 \\
4.0-8\end{array}$ & $\begin{array}{r}1.2-7 \\
7.4-8 \\
9.4-8 \\
2.7-6 \\
\text { not repor }\end{array}$ & $\begin{array}{l}6.7-7 \\
5.0-7 \\
6.3-7 \\
1.1-5\end{array}$ & $\begin{array}{l}3.3-6 \\
2.5-6 \\
3.1-6 \\
2.3-5\end{array}$ \\
\hline SE & $\begin{array}{l}(1) \\
(2) \\
(3) \\
(4) \\
(5)\end{array}$ & $\begin{array}{l}0.41 \\
0.42 \\
0.36 \\
0.40 \\
0.40\end{array}$ & $\begin{array}{c}3.8-9 \\
7.0-10 \\
1.8-9 \\
7.1-7 \\
\text { not }\end{array}$ & $\begin{array}{r}3.6-7 \\
2.9-7 \\
6.3-7 \\
1.4-5 \\
\text { rep }\end{array}$ & $\begin{array}{l}1.5-6 \\
1.1-6 \\
2.0-6 \\
3.4-5\end{array}$ & $\begin{array}{l}5.9-6 \\
5.0-6 \\
8.1-6 \\
1.2-4\end{array}$ \\
\hline V3 & $\begin{array}{l}(1) \\
(2) \\
(3) \\
(4) \\
(5)\end{array}$ & $\begin{array}{l}0.51 \\
0.63 \\
0.49 \\
0.63 \\
0.60\end{array}$ & $\begin{array}{c}1.3-10 \\
1.9-13 \\
9.0-10 \\
1.6-8\end{array}$ & $\begin{array}{r}5.2-8 \\
2.8-9 \\
9.7-8 \\
8.2-7 \\
\text { not repor }\end{array}$ & $\begin{array}{l}3.5-7 \\
1.1-7 \\
4.8-7 \\
3.8-6\end{array}$ & $\begin{array}{l}1.6-6 \\
5.5-7 \\
2.1-6 \\
1.8-5\end{array}$ \\
\hline$\infty$ & $\begin{array}{l}(1) \\
(2) \\
(3) \\
(4)\end{array}$ & $\begin{array}{l}0.29 \\
0.27 \\
0.28 \\
0.27\end{array}$ & $\begin{array}{l}7.6-8 \\
4.0-8 \\
4.5-8 \\
2.5-6\end{array}$ & $\begin{array}{l}2.3-6 \\
1.8-6 \\
2.1-6 \\
2.9-5\end{array}$ & $\begin{array}{l}5.3-6 \\
7.9-6 \\
5.3-6 \\
8.6-5\end{array}$ & $\begin{array}{l}2.1-5 \\
1.9-5 \\
2.2-5 \\
2.9-4\end{array}$ \\
\hline
\end{tabular}


TABLE 5.12

Core Damage Probabilities for Maine Yankee

Sequence $A_{1}$

$\begin{array}{cccccc}\text { Model } & \text { HCLPF } & 5 \% & 50 \% & \text { Mean } & 95 \% \\ \text { LN } & 0.22 \mathrm{~g} & 2.1-6 & 5.1-5 & 1.7-4 & 7.0-4 \\ \text { W } & 0.18 \mathrm{~g} & 4.6-6 & 9.0-5 & 2.3-4 & 8.2-4 \\ \text { JS } & 0.21 \mathrm{~g} & 1.7-6 & 5.0-5 & 1.6-4 & 6.6-4\end{array}$

Sequence $A_{2}$

$\begin{array}{cccccc}\text { Model } & \text { HCLPF } & 5 \% & 50 \% & \text { Mean } & 95 \% \\ \text { WN } & 0.31 \mathrm{~g} & 6.3-7 & 1.7-5 & 6.7-5 & 2.8-4 \\ \text { W } & 0.28 \mathrm{~g} & 9.6-7 & 2.4-5 & 8.2-5 & 3.2-4 \\ \text { JS } & 0.31 \mathrm{~g} & 6.5-7 & 1.9-5 & 6.6-5 & 2.8-4\end{array}$

TABLE A5.1

Modal value, $x_{0} /$ SSE, of risk integrand, $I(x)$

\begin{tabular}{ccccccc} 
Fragility & parameters & \multicolumn{6}{c}{ Seismic hazard } \\
Am/SSE & $V_{R}$ & 2.3 & 2.7 & 3.3 & 3.8 & 4.4 \\
& & & & & & \\
2.0 & 0.2 & 1.757 & 1.730 & 1.690 & 1.657 & 1.618 \\
2.0 & 0.3 & 1.504 & 1.453 & 1.379 & 1.321 & 1.254 \\
2.0 & 0.4 & 1.226 & 1.156 & 1.057 & 0.982 & 0.898 \\
& & & & & & \\
4.0 & 0.2 & 3.515 & 3.460 & 3.379 & 3.314 & 3.237 \\
4.0 & 0.3 & 3.007 & 2.905 & 2.758 & 2.642 & 2.508 \\
4.0 & 0.4 & 2.453 & 2.311 & 2.115 & 1.964 & 1.797 \\
& & & & & & \\
8.0 & 0.2 & 7.029 & 6.920 & 6.757 & 6.628 & 6.474 \\
8.0 & 0.3 & 6.015 & 5.810 & 5.516 & 5.284 & 5.016 \\
8.0 & 0.4 & 4.905 & 4.623 & 4.231 & 3.927 & 3.593
\end{tabular}


TABLE A5.2

$x_{0} / S S E$ contributing most to $\mathrm{Pf}_{\mathrm{f}}$

\begin{tabular}{|c|c|c|c|c|c|c|}
\hline \multirow[b]{2}{*}{$A_{m} / S S E$} & \multirow[b]{2}{*}{ Fragility } & \multicolumn{5}{|c|}{ Seismic hazard parameter $\alpha$} \\
\hline & & 2.3 & 2.7 & 3.3 & 3.8 & 4.4 \\
\hline 2 & $\begin{array}{l}\mathbf{W} \\
W\end{array}$ & $\begin{array}{l}1.757 \\
1.842\end{array}$ & $\begin{array}{l}1.730 \\
1.788\end{array}$ & $\begin{array}{l}1.690 \\
1.687\end{array}$ & $\begin{array}{l}1.657 \\
1.573\end{array}$ & $\begin{array}{l}1.618 \\
1.343\end{array}$ \\
\hline 4 & $\begin{array}{l}\text { W } \\
W\end{array}$ & $\begin{array}{l}3.515 \\
3.685\end{array}$ & $\begin{array}{l}3.460 \\
3.576\end{array}$ & $\begin{array}{l}3.379 \\
3.375\end{array}$ & $\begin{array}{l}3.314 \\
3.147\end{array}$ & $\begin{array}{l}3.237 \\
2.687\end{array}$ \\
\hline 8 & $\begin{array}{l}\text { WN } \\
\text { W }\end{array}$ & $\begin{array}{l}7.029 \\
7.371\end{array}$ & $\begin{array}{l}6.920 \\
7.153\end{array}$ & $\begin{array}{l}6.759 \\
6.750\end{array}$ & $\begin{array}{l}6.628 \\
6.294\end{array}$ & $\begin{array}{l}6.474 \\
5.374\end{array}$ \\
\hline
\end{tabular}

TABLE A5.3

Calculation of $P(C D)$ from $P(A>$ HCLPF $)$

Plant, sequence HCLPF $\quad E[P(A>$ HCLPF $)] \quad P(S e q) \quad$ Ratio

Limerick

$\begin{array}{lllll}\mathrm{T}_{s} E_{s} U X & 0.33 \mathrm{~g} & 3.0 \times 10-5 & 3.4 \times 10-6 & 8.8 \\ \mathrm{~T}_{s} R_{b} & 0.42 \mathrm{~g} & 1.5 \times 10-5 & 1.1 \times 10-6 & 13.6 \\ \mathrm{~T}_{s} \mathrm{E}_{s} \mathrm{C}_{m} \mathrm{C}_{2} & 0.42 \mathrm{~g} & 1.5 \times 10-5 & 1.5 \times 10-6 & 10.0 \\ & & & & \\ \mathrm{~T}_{s} R P V & 0.55 \mathrm{~g} & 4.4 \times 10-6 & 4.7 \times 10-7 & 9.4 \\ \mathrm{~T}_{s} R_{b} C_{m} & 0.55 \mathrm{~g} & 4.4 \times 10-6 & 6.0 \times 10-7 & 7.3\end{array}$

Millstone 3

$\begin{array}{lllll}\text { TE } & 0.26 \mathrm{~g} & 4.0 \times 10-5 & 4.2 \times 10-6 & 9.5 \\ \text { AE } & 0.45 \mathrm{~g} & 7.6 \times 10-6 & 6.7 \times 10-7 & 11.3\end{array}$



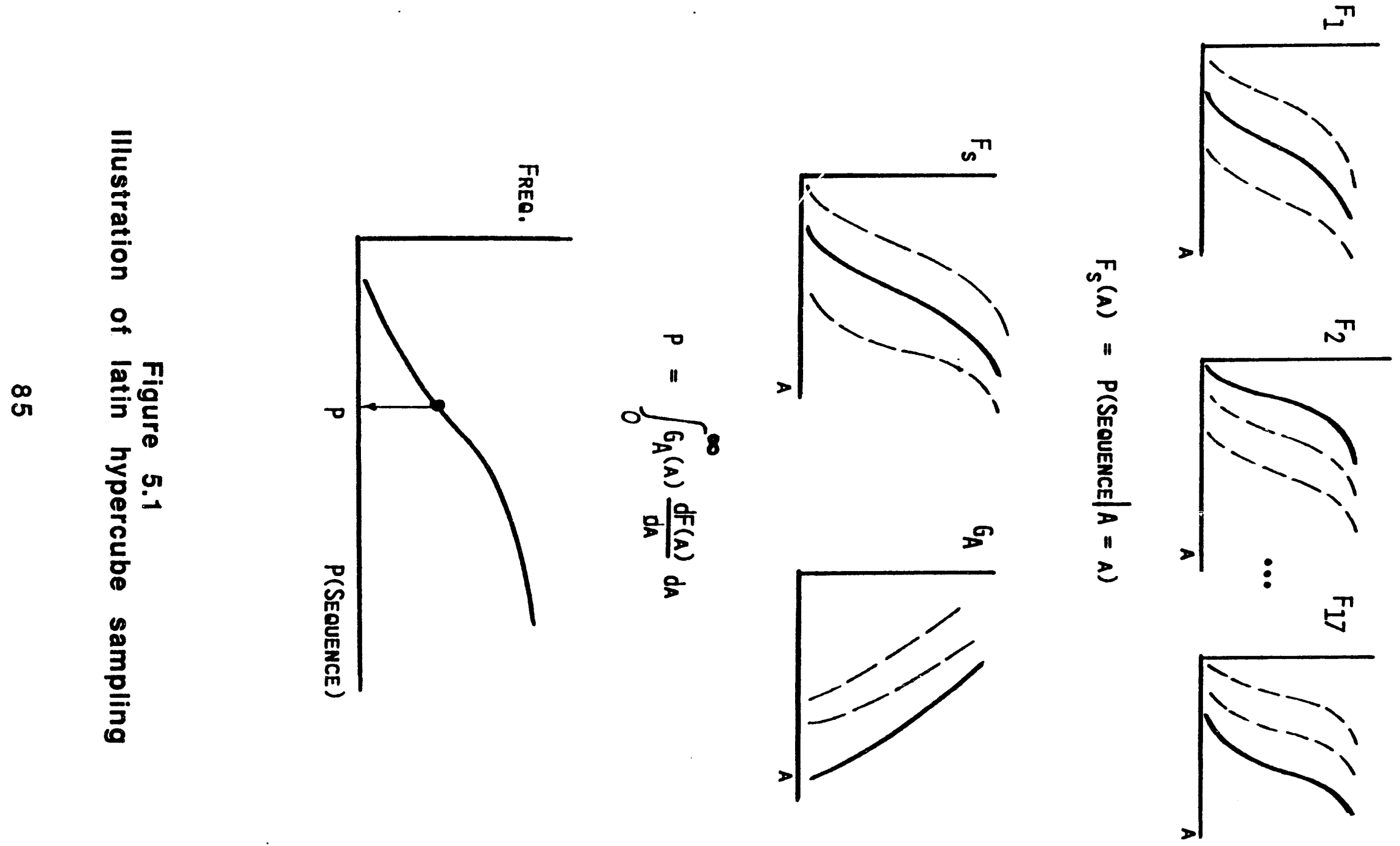


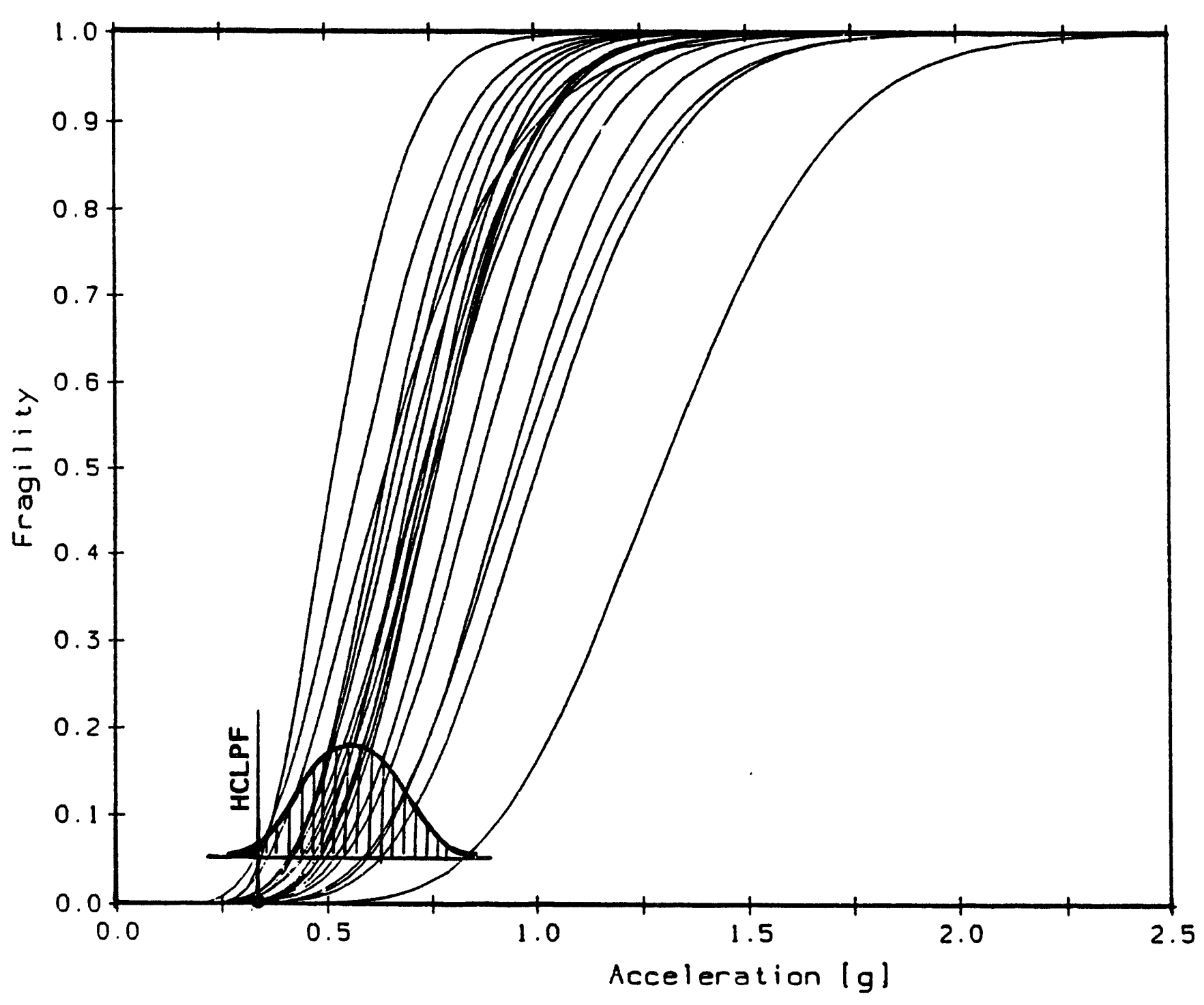

Figure 5.2

Limerick - Fragility for sequence $T_{s} E_{s} U X$ 


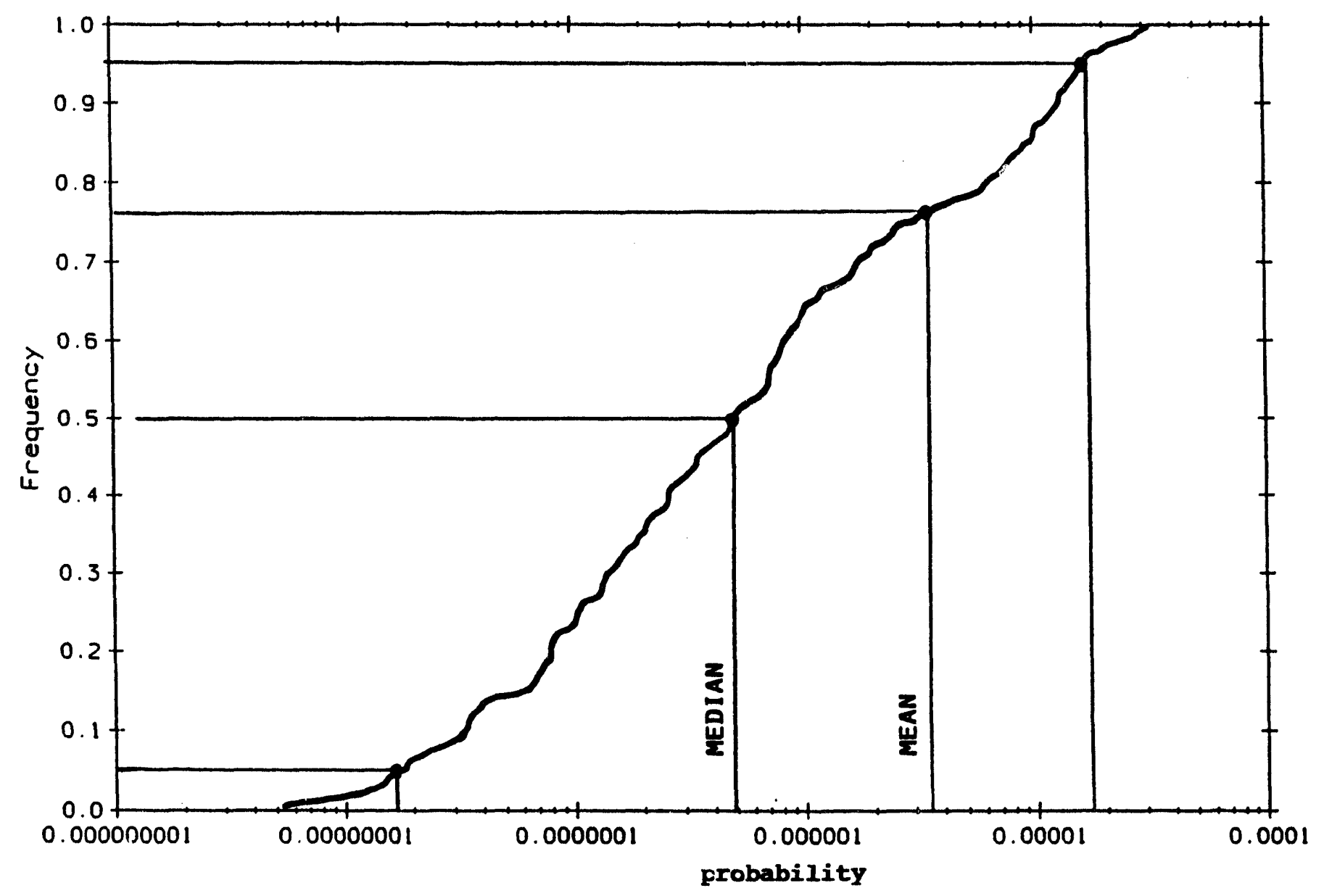

Figure 5.3

Limerick - Frequency distribution of core damage probability for sequence $T_{s} E_{s} U X$ 


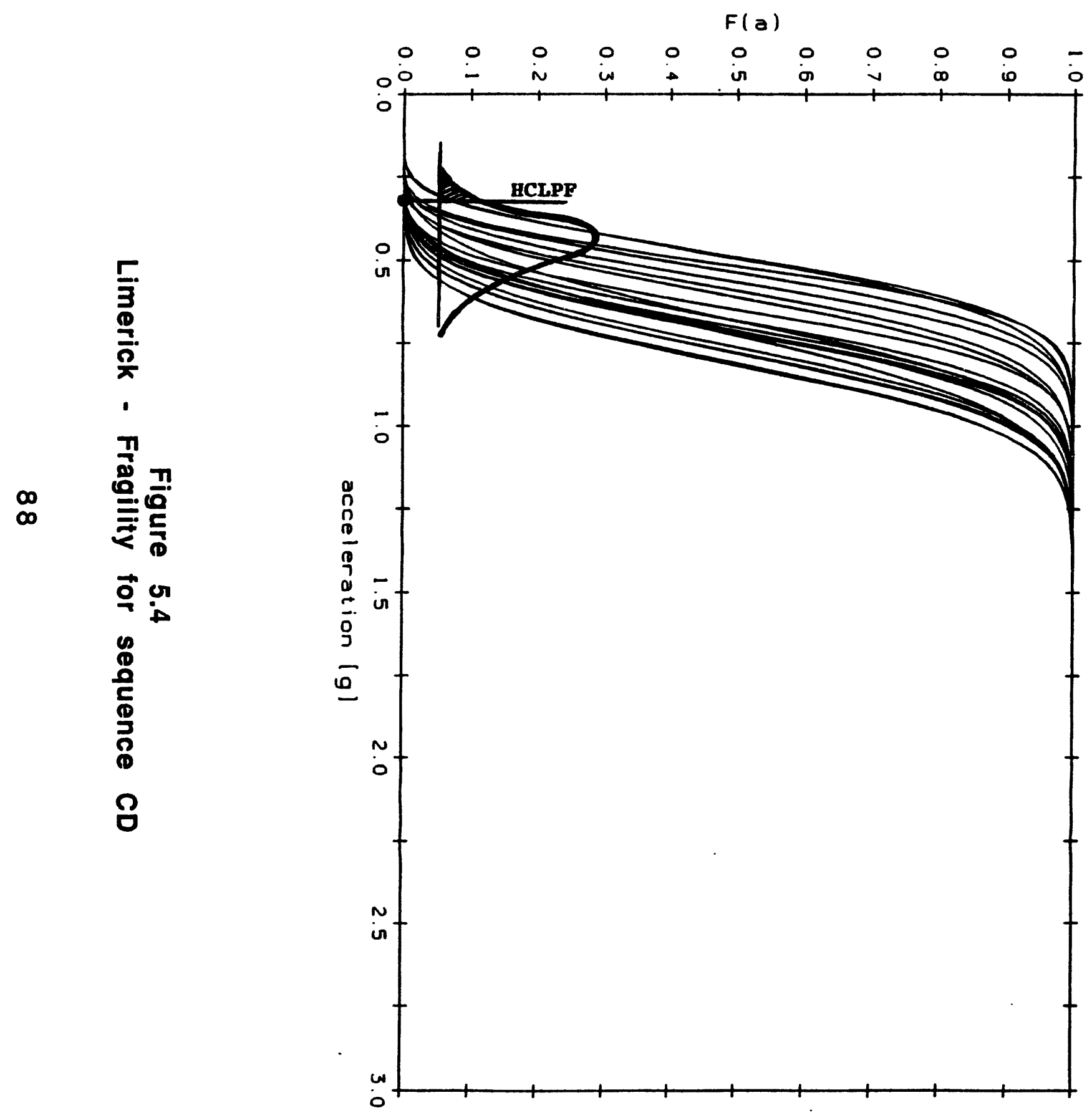




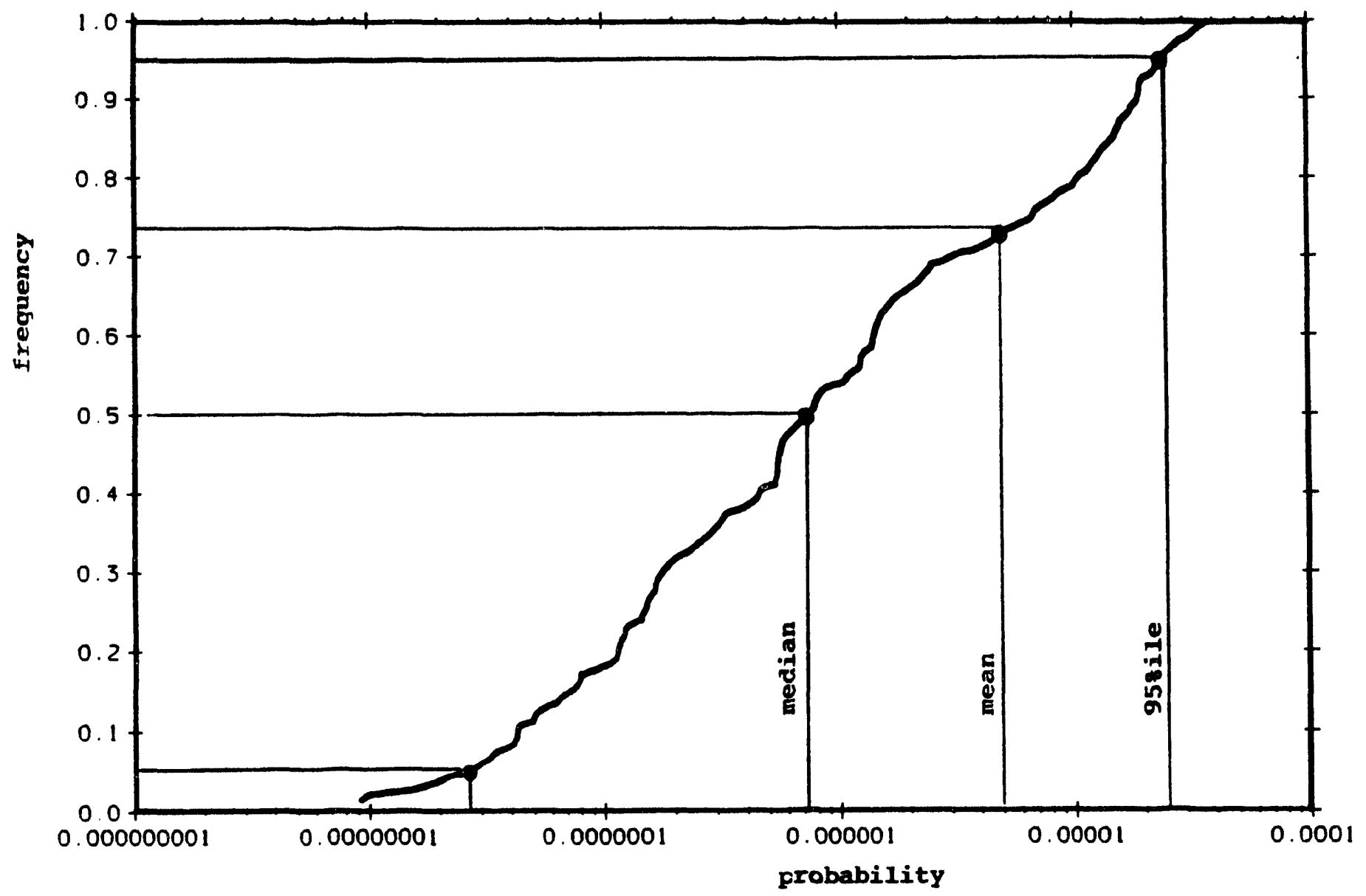

Figure 5.5

Limerick - Frequency distribution of core damage probability for sequence $C D$ 

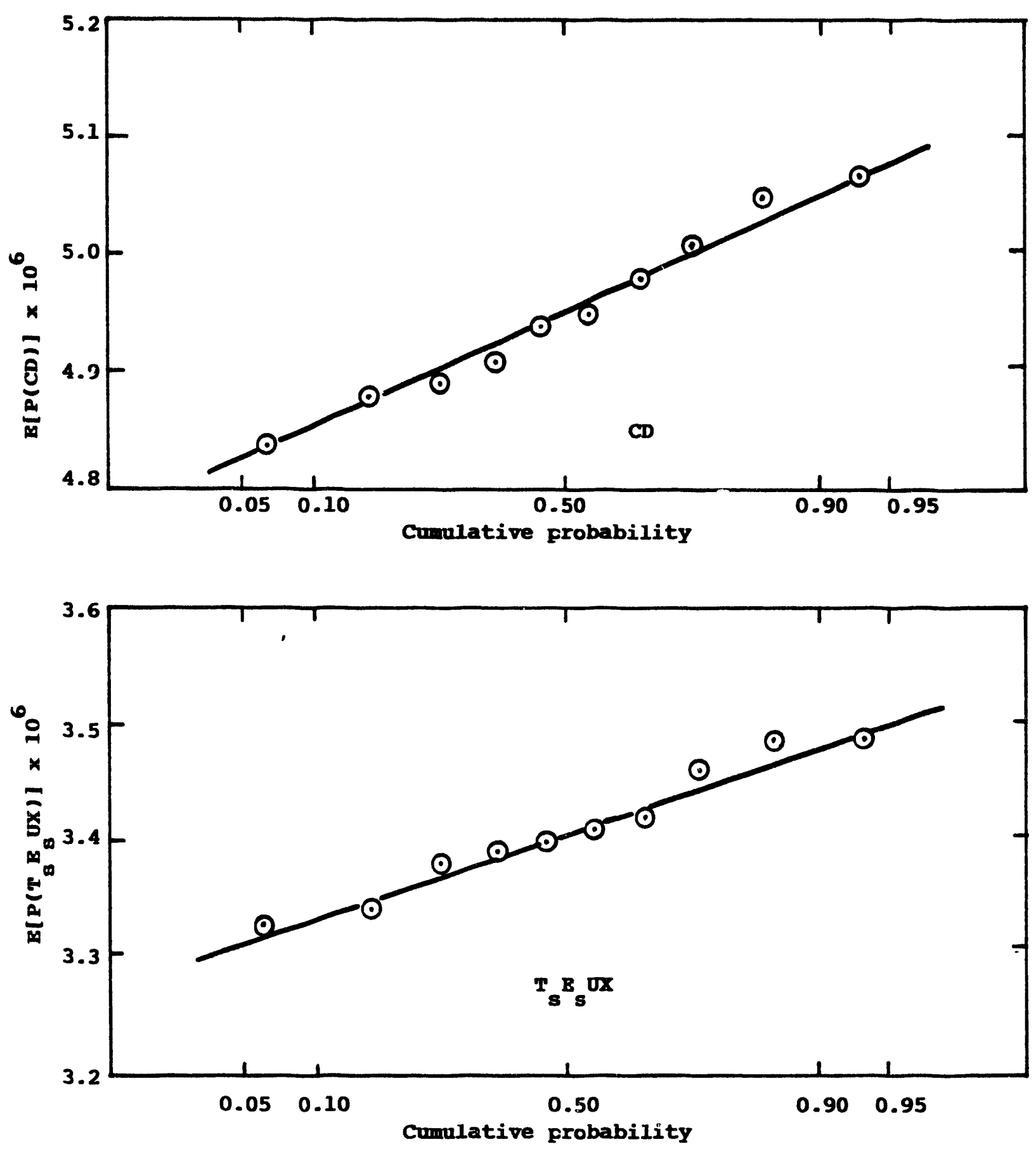

Figure 5.6

Limerick - Sampling distributions for $E\left[P\left(T_{s} E_{s} \cup X\right)\right]$ and $E[P(C D)]$ 


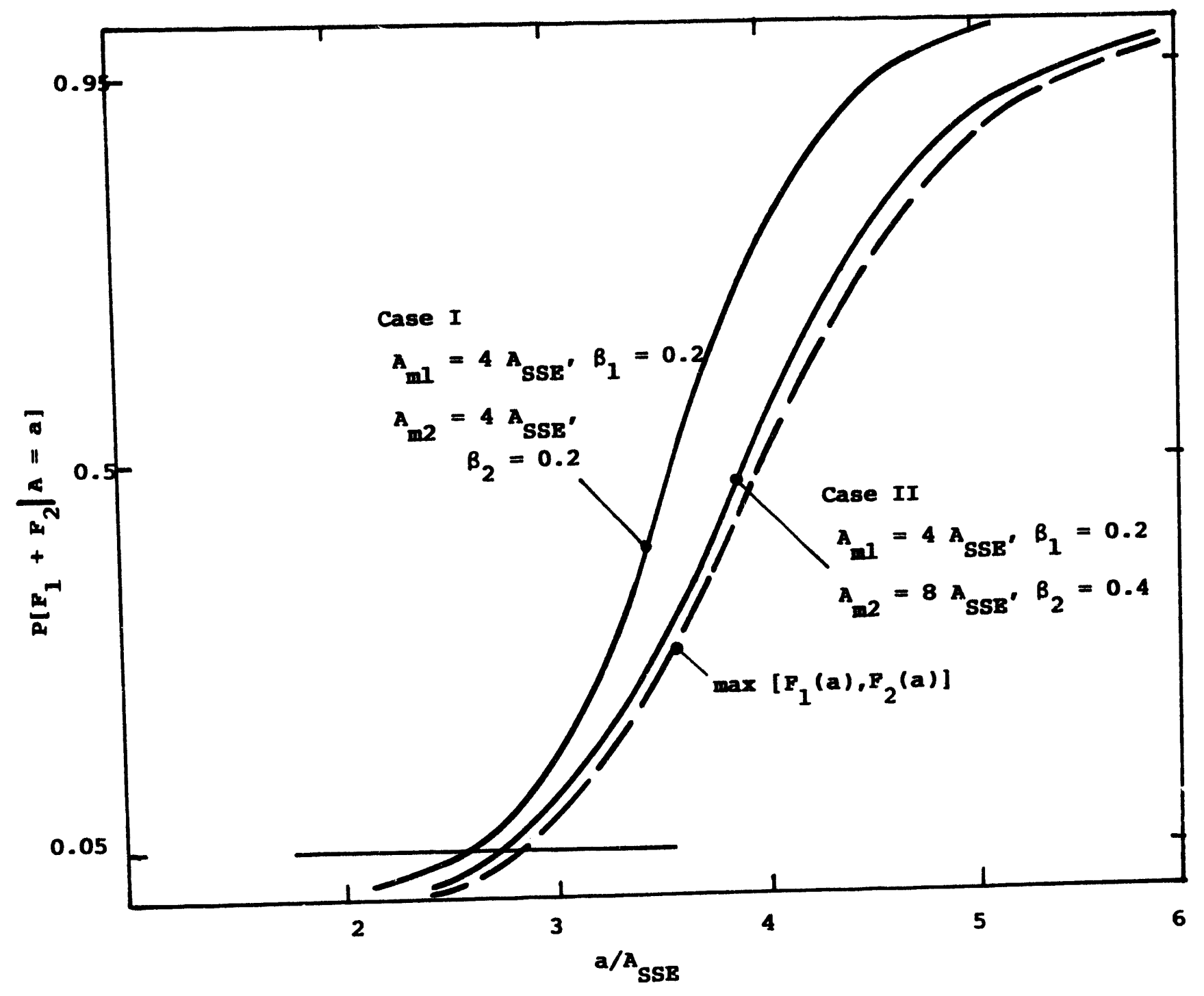

Figure 5.7

System Fragility - FSYS $=F_{1}+F_{2}$ 

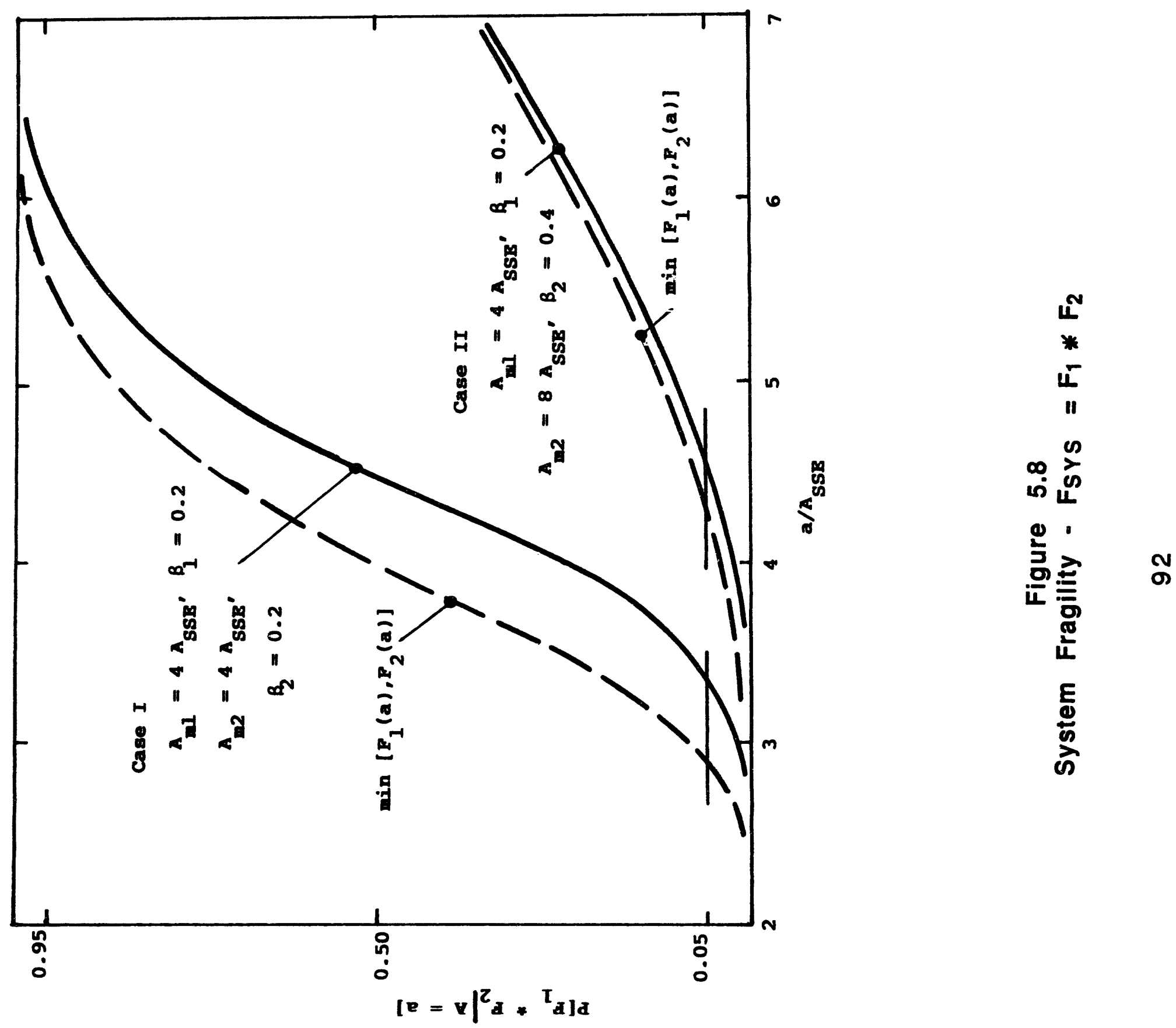


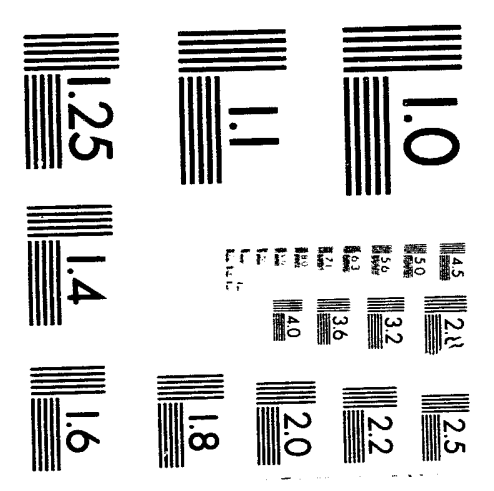



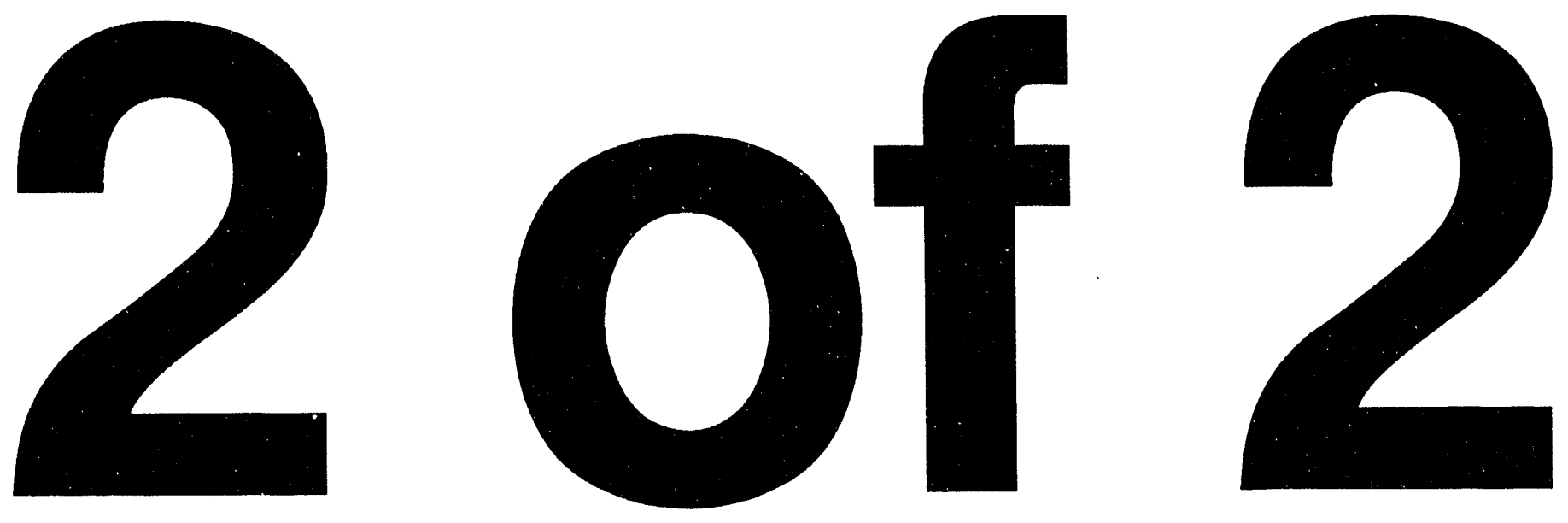


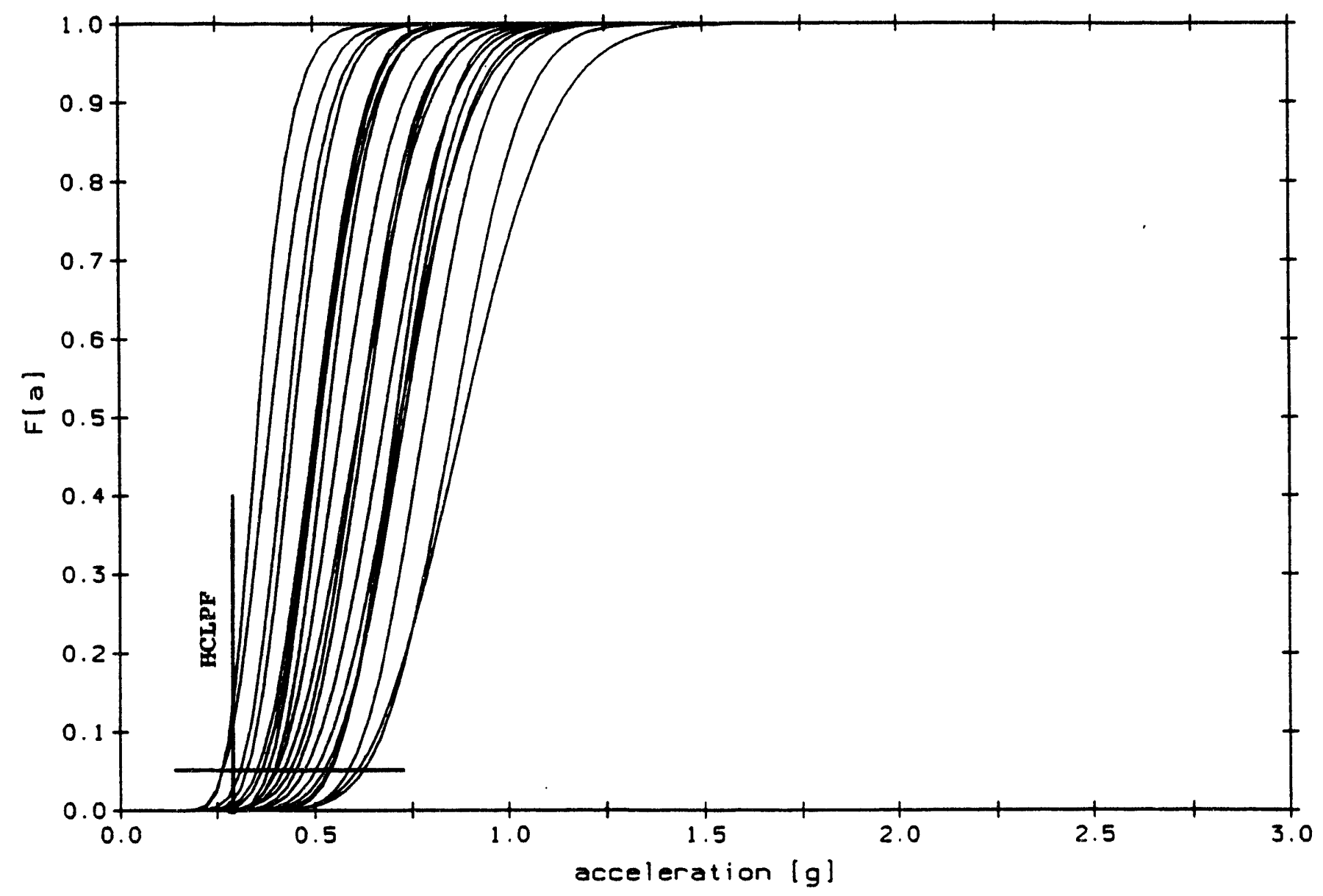

Figure 5.9

Millstone 3 - Fragility Family for Plant Damage State TE 

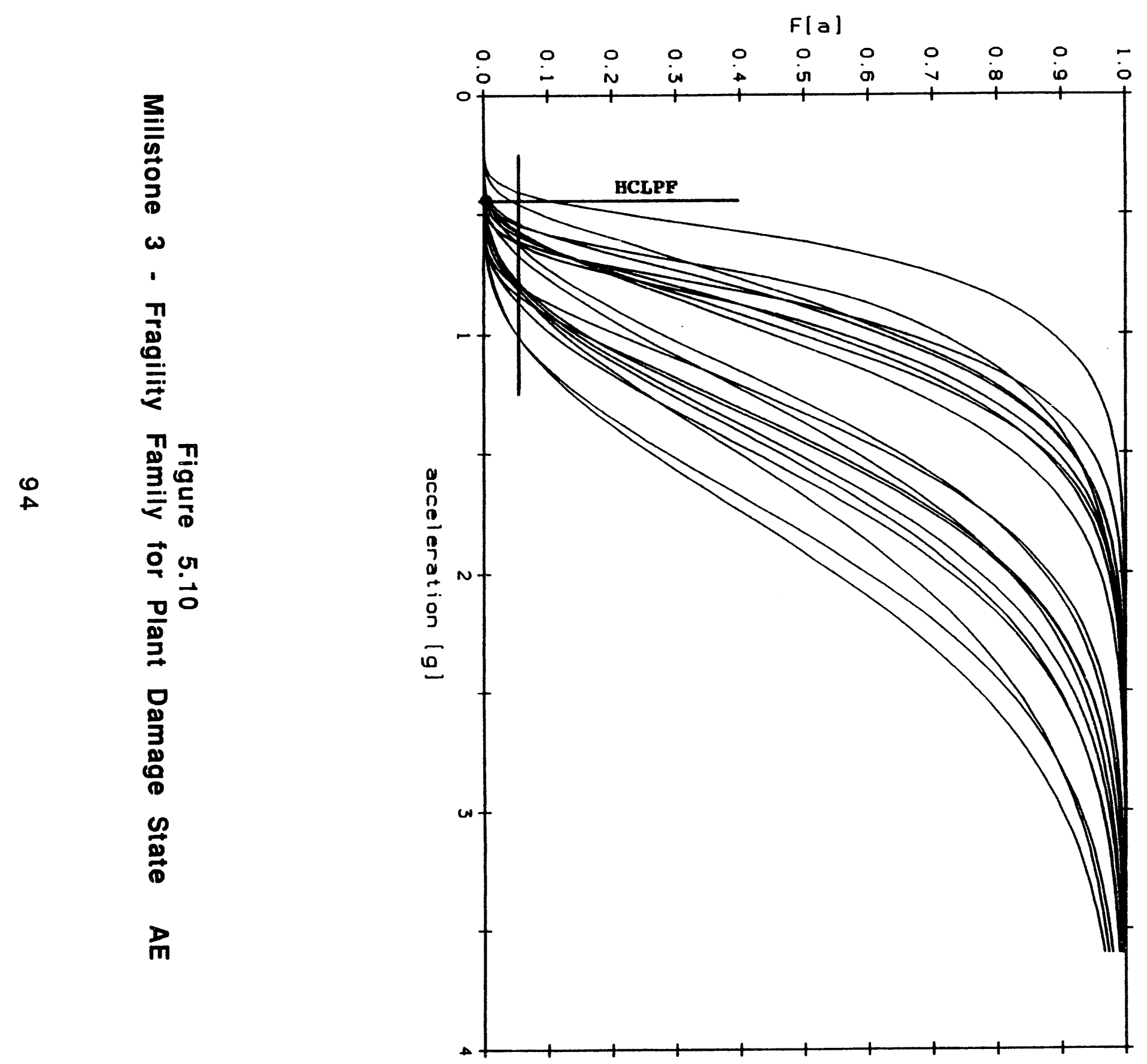

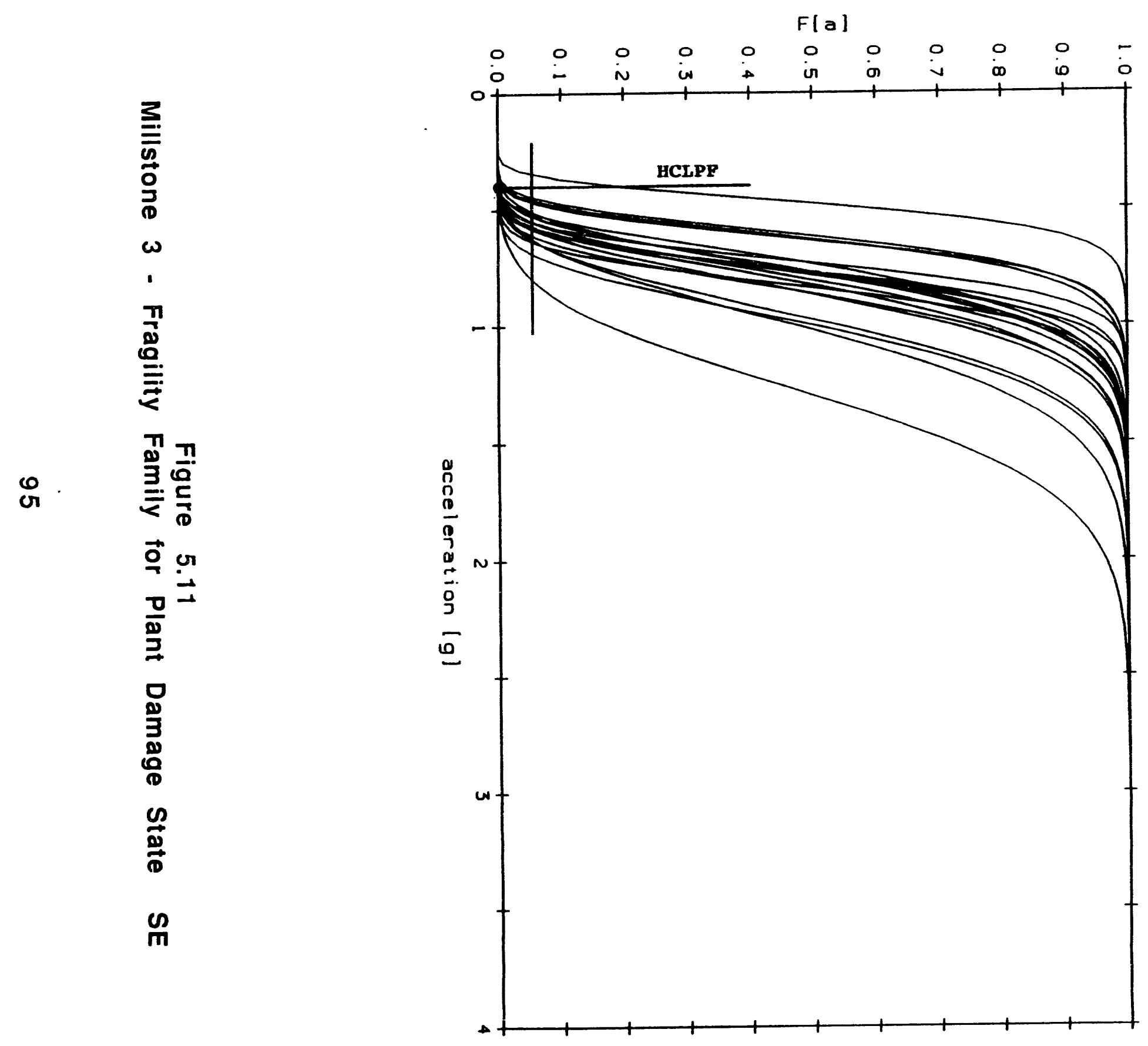


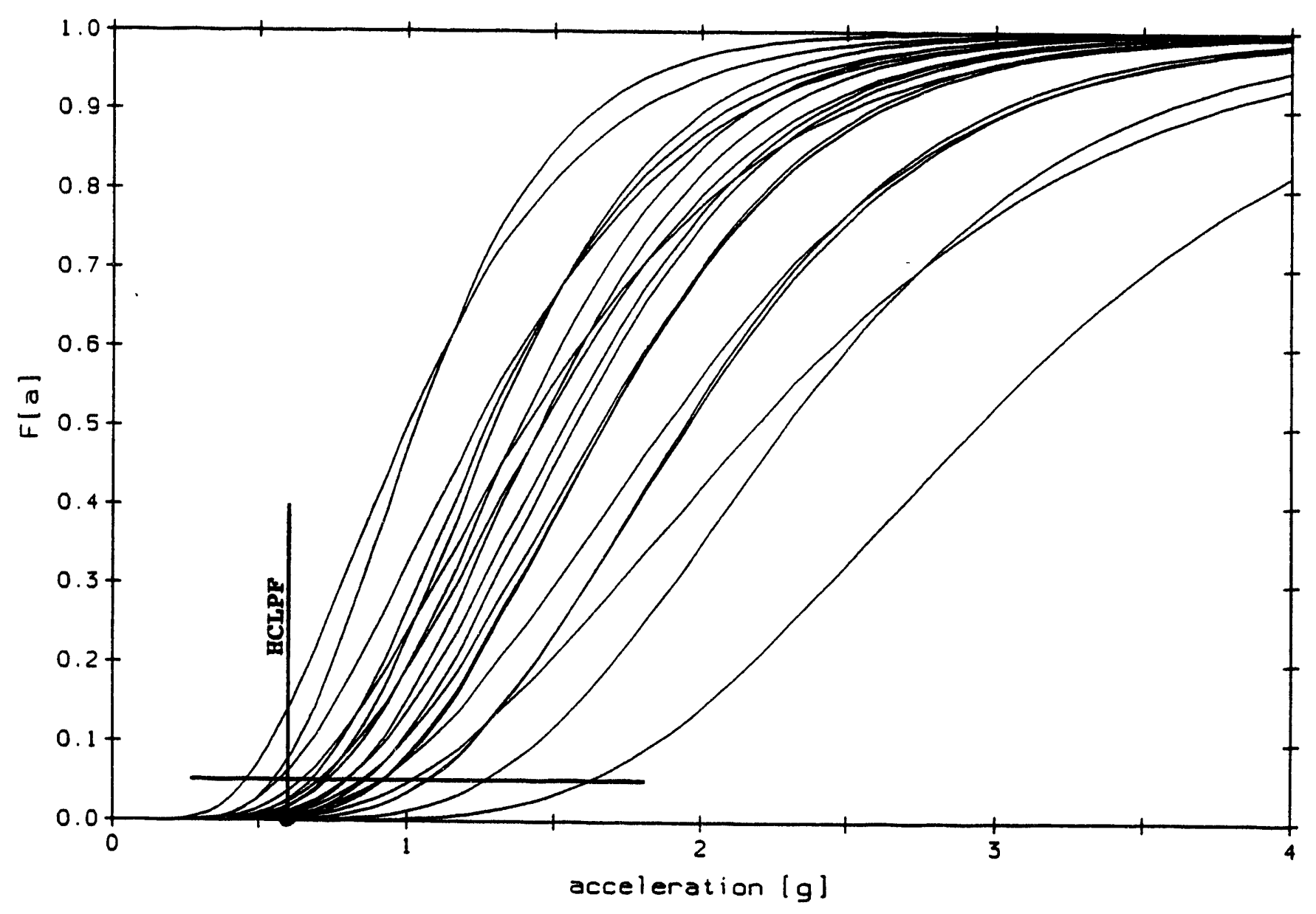

Figure 5.12

Millstone 3 - Fragility Family for Plant Damage State V3 


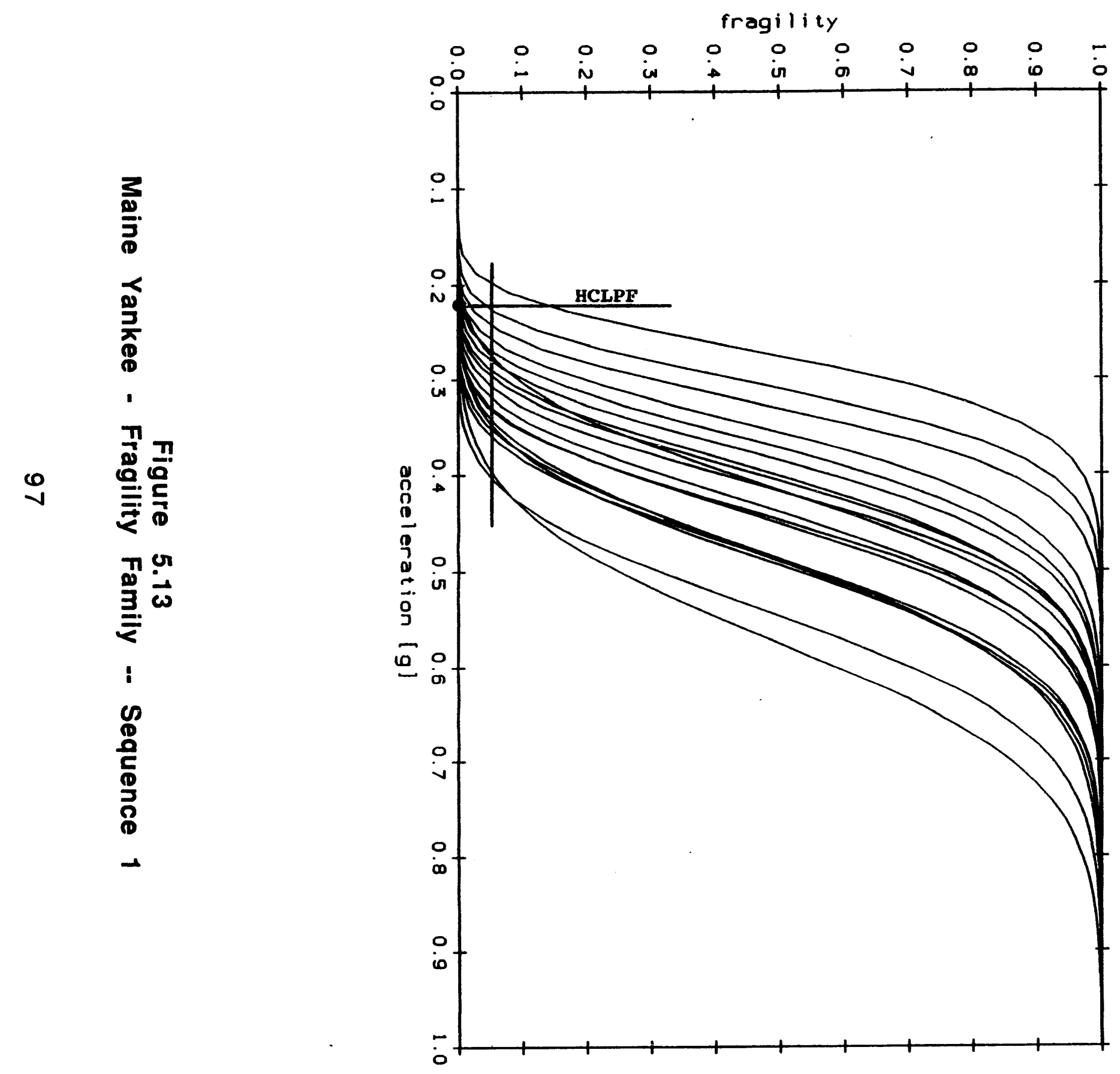




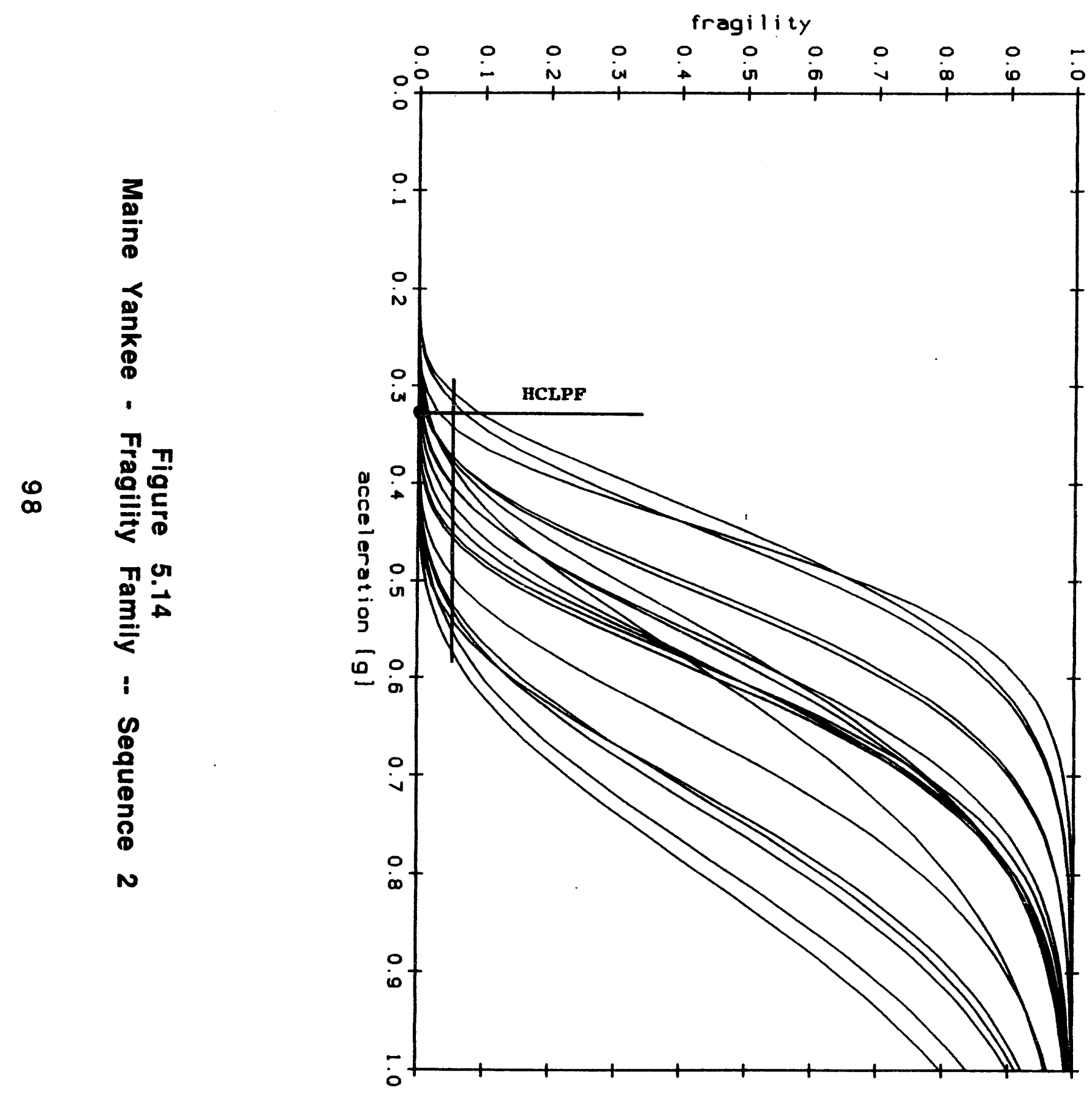




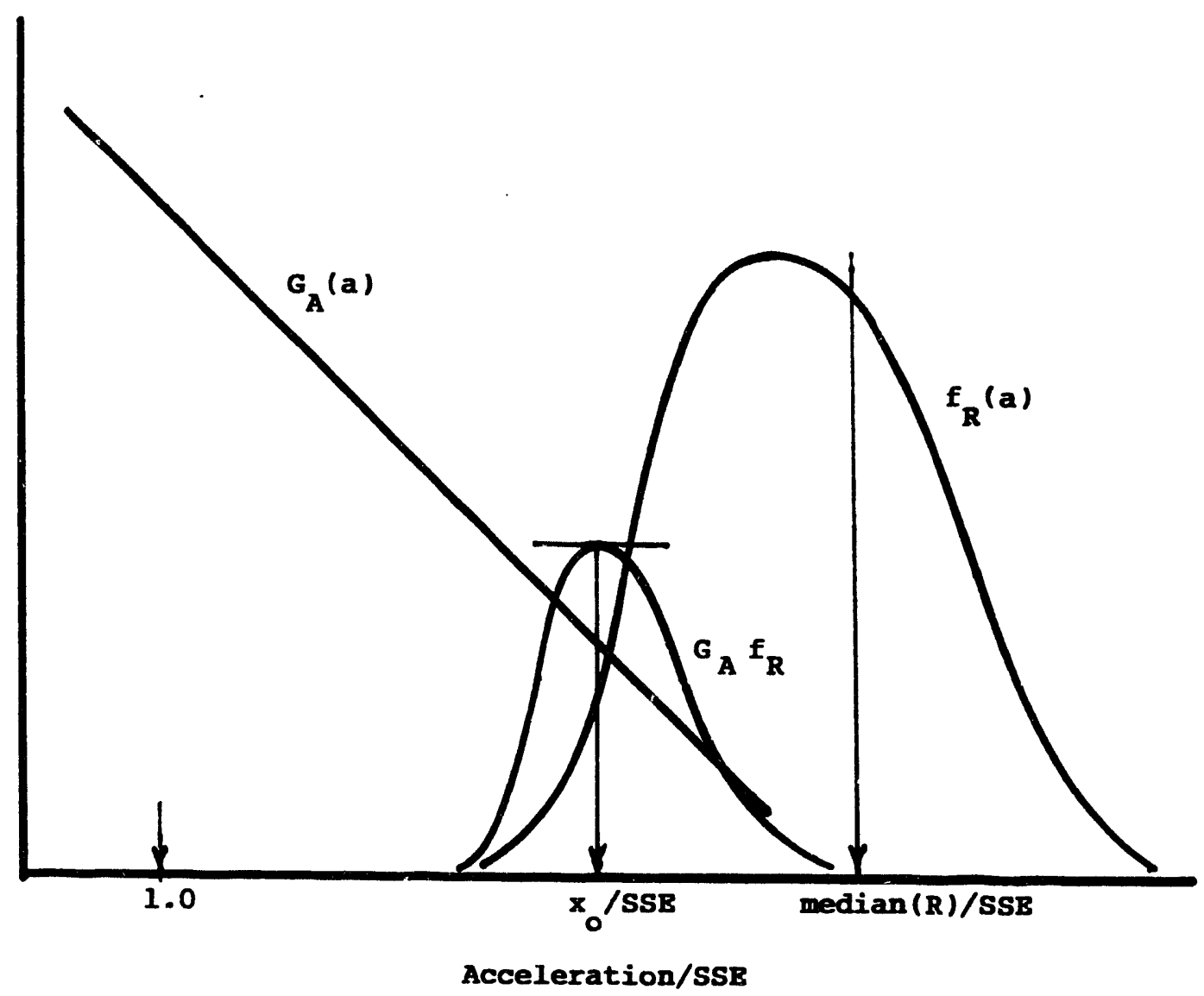

Figure A5.1

Illustration of Seismic Hazard - Fragility Interface and Convolution

99 


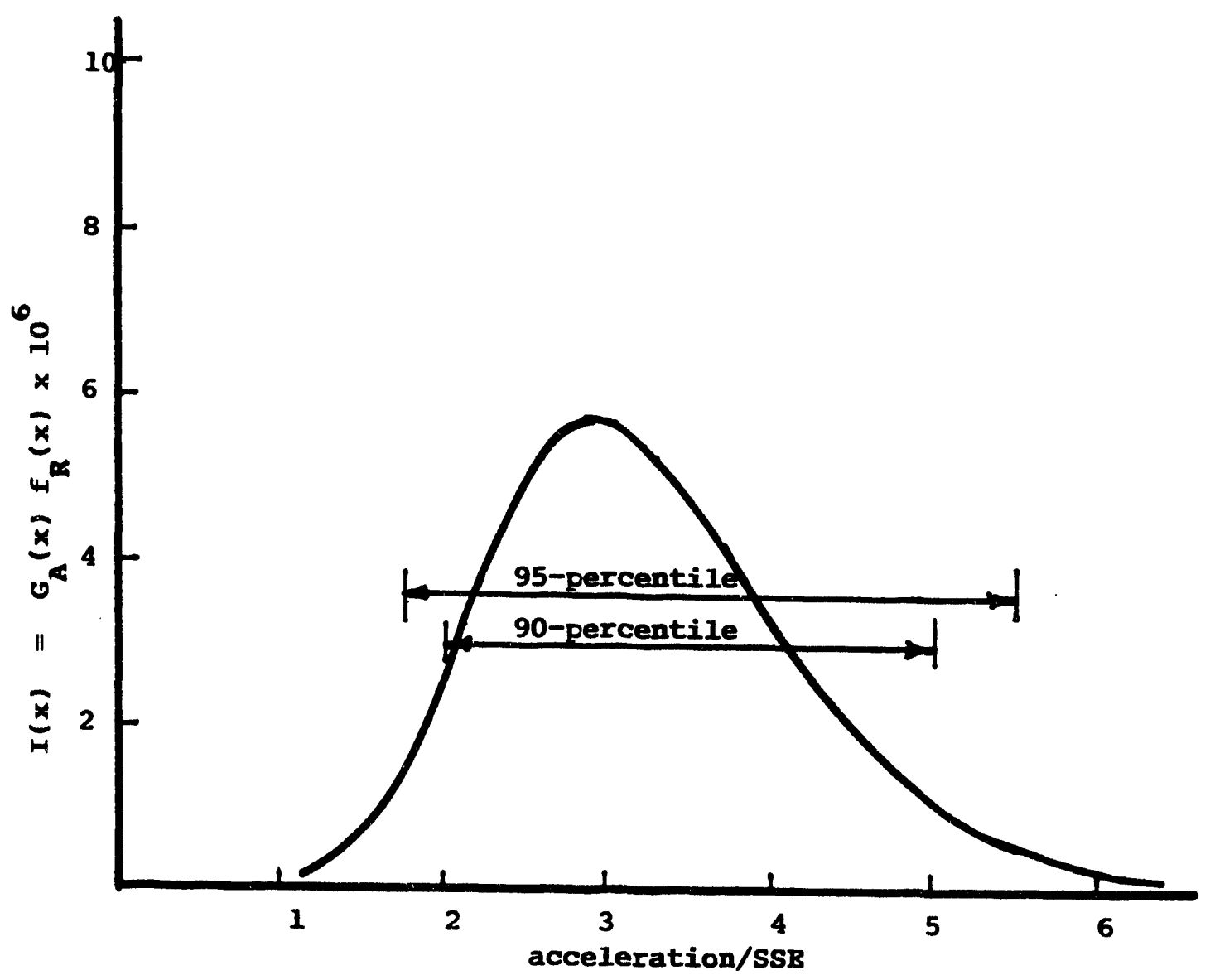

Figure A5.2

Relative Contribution of Accelerations to Core Damage Probability

$$
\left(A_{m}=4 \text { SSE, } V_{R}=0.30 \text { and } \alpha=2.7\right)
$$

100 

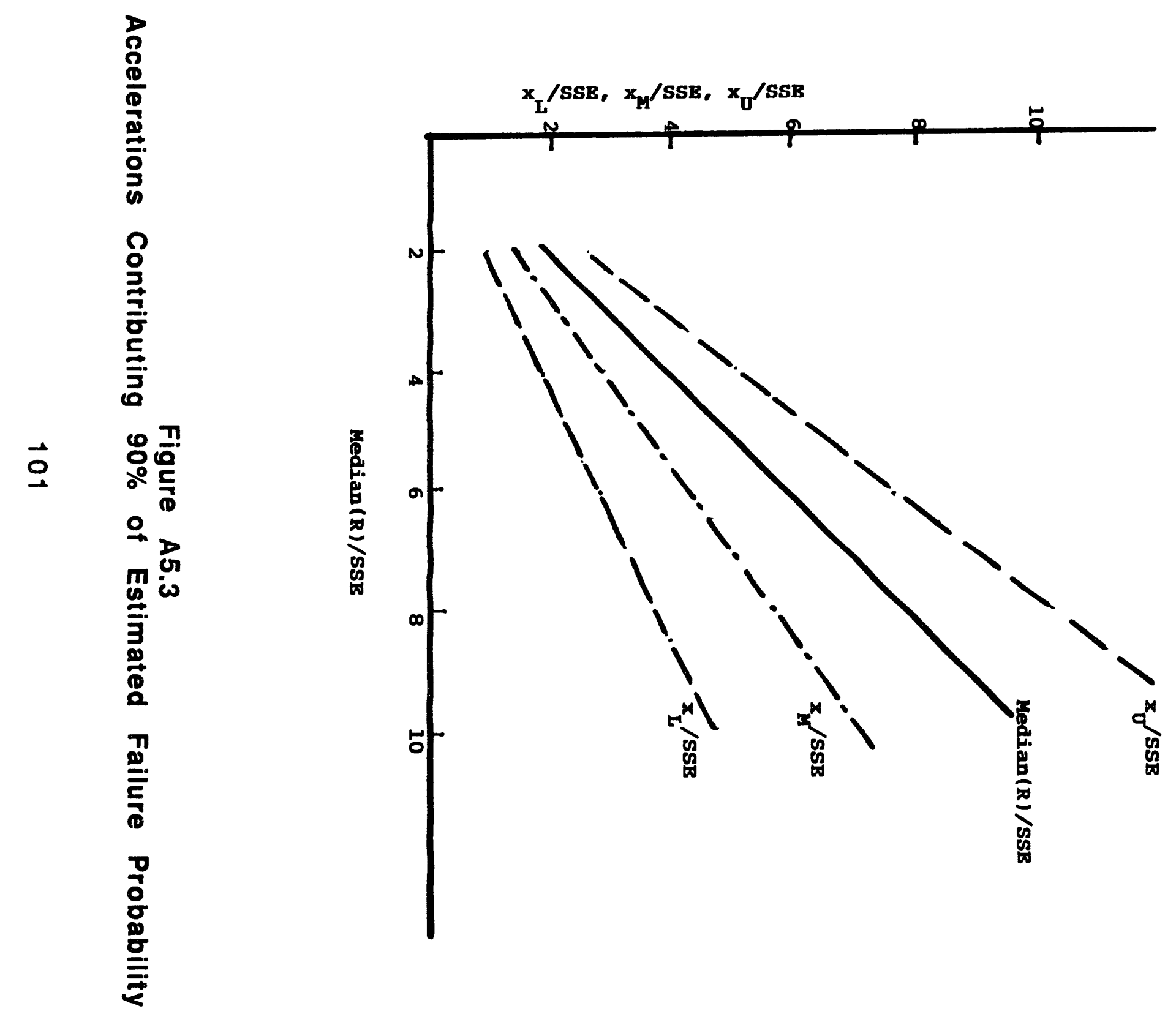


\subsection{ROLE OF ERROR IN SAFETY EVALUATION}

\subsection{Design/Construction Errors}

Engineered facilities are designed to tolerate minor deviations from the design envelope. Errors may enter the building process and impact structural performance and reliability. There are errors in concept, in execution or in intention. An even simpler taxonomy identifies errors of omission and errors of commission. Minor errors are part of stochastic variability. Structural design practice addresses the problem of design and construction (D/C) error through a combination of safety factors and quality assurance and control programs. Structural effects of many errors are effectively screened through this practice. Nontheless, gross D/C errors do occur and have been found to contribute to overall failure rates in ordinary building and bridge construction. Although it is difficult to define what is "gross" in this context, the central notion is that the error lies outside the normal range of variation and should have been recognized and circumvented by a professionally competent and properly trained individual. in other words, it represents an unintended departure from accepted practice or a fundamental avoidable mistake.

Several reviews of the role of $D / C$ error in structural reliability have been published recently (e.g., Blockley, 1977; Melchers and Harrington, 1984; Nowak and Carr, 1985; Ellingwood, 1987; Ravindra, 1987; Ravindra and Ellingwood, 1989). Some of the sources of design and construction errors are listed below. The list is not exhaustive, but serves to indicate errors that are known to have been significant in the past.

\section{Design errors:}

Conceptual misunderstandings of mechanics

Selection of improper loads, omission of certain loads

Modeling and approximations, including computer codes

Use of incorrect material properties

Incorrect use of design aids - specifications, table lookup

Numerical errors - addition, multiplication, etc.

Errors in detailing, particularly connections and anchorages

Errors in preparation of project specifications and drawings

\section{Construction errors:}

Mistakes in reading working drawings 
Improper member and fastener sizes

Placement of reinforcement in concrete structures

Placement and curing of concrete

Defective installation of equipment, equipment anchorages.

A mathematical model for analyzing the effect of error on structural safety should include the following elements: (1) Identification of likely error scenarios; (2) Likelihood of detection and correction of error by QA/AC program; and (3) Likelihood that undetected error(s) lead to structural damage or failure (Ellingwood, 1987). The probability of failure for an engineered facility can be expressed as,

$$
\begin{aligned}
P(F) & =P[F \bar{E}]+P[F E] \\
& =P[F \mid \bar{E}] P[\bar{E}]+P[F \mid E] P[E]
\end{aligned}
$$

in which $E$ = event that error occurs, $P[F \mid E]=$ the conditional probability of failure, given that error occurs, and $\bar{E}$ denotes the complement of $E$. If $n$ identifiable sources of error exist, then

$$
P[F E]=\sum_{i=1}^{n} P\left[F \mid \bar{D}_{i} O_{i}\right] P\left[\bar{D}_{i} \mid O_{i}\right] P\left[O_{i}\right]
$$

in which $\mathrm{P}\left[\mathrm{O}_{\mathrm{i}}\right]=$ probability of occurrence of error, $\mathrm{P}\left[\overline{\mathrm{D}}_{\mathrm{i}} \mid \mathrm{O}_{\mathrm{i}}\right]=$ probability that error is not detected, given that it occurs, and $P\left[F \mid \bar{D}_{i} O_{i}\right]=$ conditional probability of failure, given the presence of an undetected error. Eqn 6.2 encompasses the important notions of error occurrence, detection and consequences. Surveys of failures in ordinary building construction suggest that failures due to stochastic variability in strengths and loads account for only about $10 \%$ of failures. Thus, $\mathrm{P}[\mathrm{FE}]$ in Eqn 6.1 may be as much as 10 times greater than $P[F \bar{E}]$ (Allen, 1979).

\subsection{Significance of Error for Nuclear Plant Safety}

The quality assurance and control programs in nuclear plant construction are strict, and errors are less likely to occur in NPPs than in ordinary building construction. Most $D / C$ errors that might reduce the seismic capacity of components and systems likely are eliminated through design review and inspection during construction. Seismic PRAs and margin studies conducted to date have not included the effects of human error on component fragilities. 
Even a highly regulated design and construction process can produce poor results, however, (Turkstra, et al, 1983). Some believe that undiscovered $D / C$ errors may seriously compromise the safety of plant systems during or following the occurrence of a large earthquake. Others believe that the inferences drawn from previous seismic PRAs or margin studies, in which the plant was assumed to be error-free, might have been different if $D / C$ errors had been included in the analysis. A gross error may render an otherwise noncritical component critical in a PRA or margin analysis. Moreover, errors may affect several systems simultaneously. For example, a design error involving defective structural analysis may affect the responses of several components and reduce any benefit of redundancy.

Design/construciion errors affect mainly the fragility of structures or mechanical or electrical equipment. The presence of $D / C$ errors rnay cause the fragility family for a component to be repositioned toward smaller ground (or spectral) accelerations. Only limited data are available to describe the effect of such errors on seismic fragility. Component fragilities may be rendered statistically dependent by common- cause errors.

A statistically significant data base on design/construction errors does not exist. Although some information can be obtained from Construction Deficiency Reports or Inspection and Enforcement Bulletins, systematic data collection on gross errors is impractical. One early survey of malfunctions identified in abnormal occurrence reports for NPPs in the United States concluded that about $36 \%$ could be attributed to design error and $12 \%$ to faulty installation, fabrication and maintenance (Taylor, 1975). Unfortunately, causes for the remaining $52 \%$ were not identified. Design/construction deficiencies tend to be similar, percentagewise, from plant to plant; in one recent study, it was found that (Gonzales-Cuesta and Okrent,1986) errors occurred according to:

$\begin{array}{ll}\text { Design } & 27 \% \\ \text { Procurement } & 14 \% \\ \text { Construction } & 59 \%\end{array}$

In terms of the components affected, it was found that $22 \%$ of the errors occurred in structural components, while $78 \%$ occurred in mechanical and electrical components. Piping supports were the components most affected by D/C errors (Gonzales-Cuesta and Okrent, 1986). Welding problems were involved in $24 \%$ of construction deficiency reports reviewed, and bolt installation problems also were common. D/C errors tend to be repetitive in nature, e.g., deficient installation of anchorages, bolts, and other repetitive tasks, and thus may affect several plant systems simultaneously. Later studies identified construction 
deficiencies due to inadequate document controls and review during design or plant modification. Most of these deficiencies would not have been identified by normal plant testing programs. Instances of distress also have been observed in concrete structures. Many of these involved chemical reactivity of the concrete or degradation of the post-tensioning systems. Other design errors involved improper consideration of shrinkage or detailing. Construction errors have included improper placement of reinforcement and concreting. The degree to which these errors impact seismic capacity is unknown.

In addition to design/construction errors, the possibility of operator error in initiating or mitigating an accident condition needs to be considered. Certain plant systems depend on operator action to maintain availability during a design-basis event. In other industries such as chemical or commercial aviation, operator error is estimated to be involved in as many as 90 percent of failures. Cognitive errors dominate over procedural errors. Cognitive errors tend to occur in clumps, particularly if tasks are repetitive in nature. Human errors associated with operations, testing or maintenance may introduce common mode failures since more than one system may be affected by faulty intervention. Moreover, some human actions exert a positive influence, but the PRA generally does not take this into account.

One means for investigating the impact of error on safety is to identify plausible errors, and determine what impact such errors have on component fragility and on core damage probability. This approach presumably allows a subsequent data collection exercise to be more efficient. In one such study (Ravindra, et al, 1985), the fragility parameters were modified to account for "plausible" errors, and it was found that they had a negligible effect on core damage. This approach is consistent with the current state-of-the-art (it is applied to Limerick and Millstone 3 in Section 6.3), but has some limitations insofar as assessing the impact of error on plant safety is concerned. In a sense, the term, "plausible gross error" is a contradiction in terms, since by definition gross errors represent an unintended (and thus unpredictable) departure from accepted engineering practice. More generally, D/C errors cannot be dealt with by simply arbitrarily increasing fragility parameter $\beta U$ or decreasing $A_{m}$. Moreover, potential changes to the core damage Booleans are not considered in this approach.

Expanding on the formulation in Eqns 6.1 and 6.2, the seismic fragility of a component can be modeled as,

$$
\mathrm{P}[\mathrm{F} \mid \mathrm{A}=\mathrm{x}]=\mathrm{P}[\mathrm{FE}+\mathrm{FDC}+\mathrm{FR} \mid \mathrm{A}=\mathrm{x}]
$$


in which events $\overline{F E}=$ failure when system and its operation are error-free, $F D C=$ failure due to $D / C$ error and $F R=$ failure due to unavailability upon demand (maintenance, replacement, operator error). Such an approach might indicate the kinds of errors that are important for certain systems and that dominate plant risk.

\subsection{Sensitivity of Risk Estimates to Postulated Errors}

The significance of design/construction error or operator error in seismic PRA or seismic margin analysis must be evaluated in terms of its impact on plant risk, measured by the core damage frequency distribution or the margin of the plant level HCLPF above the review earthquake.

In this section, the impact of several postulated errors on the core damage probability and HCLPF values for Limerick Generating Station and Millstone 3 is evaluated. It is assumed that the presence of the error causes the fragility family to be repositioned toward lower accelerations. This approach identifies those components where design/construction errors are most significant to plant risk. The plant logic models are unchanged. Errors that may reside in the conceptual system modeling and construction of plant logic would lead to changes in the system Booleans used to compute core damage probability and HCLPF values, as well in the fragility models themselves.

Both the Limerick and Millstone 3 seismic PRAs identified a relatively small group of critical components, the failure of which could lead to severe core damage. The analysis in this section draws upon a study performed independently by EQE as part of the research on validation of seismic PRAs (Ravindra, 1987). However, the critical components, fragility models and plant Booleans were defined somewhat differently in the EQE study than in the original SARA and SARA review that were used in Section 5, and the HCLPF values were not computed. Consequently, the numerical results were not directly comparable to those in Section 5 . The following results were obtained using the same seismic hazard curves and fragility models as in Section 5, modified, as appropriate, for the effects of error.

A series of error scenarios are postulated as occurring in selected critical components in the plant, the component fragilities are modified accordingly, and the core damage probability frequency distribution and sequence HCLPF are recomputed and compared to the baseline results presented in Chapter 5 . It is assumed that the error causes the median fragility to be decreased by a set amount, but that the inherent variability and modeling uncertainty, $\beta R$ and $\beta U$, remain unchanged. An independent study of error effects (Ravindra, 1987) showed that uncertainties in error magnitude, modeled by increasing $\beta U$ to account for uncertainty in the 
impact of error on the median fragility, had a negligible effect on core damage probabilities.

\subsubsection{Limerick Generating Station}

Several postulated error scenarios are considered, in order of descending importance to plant safety (SARA, 1983). The components considered are identified in Table 2.1.

\section{Beactor Pressure Vessel (S6)}

The reactor pressure vessel is the most important component in preserving the integrity of the reactor pressure boundary and core. The RPV fails as a result of failure in the upper support bracket welds, which allows the top of the vessel to oscillate back and forth during an earthquake. This leads to failure of steam lines and creates a large LOCA. It is assumed that as a result of defective welding, the median fragility $\left(S_{6}\right)$ is reduced 50 percent from $1.25 \mathrm{~g}$ to $0.63 \mathrm{~g}$.

\section{Beactor Enclosure Building $\left(\mathrm{S}_{4}\right)$}

The reactor enclosure structure houses the emergency core cooling systems and control systems, and is next in importance to the reactor pressure vessel. Failure of the enclosure structure is caused by flexural failure of shear walls, which damages the emergency core cooling systems and makes them unavailable for accident mitigation. Flexural capacity is not strongly dependent on concrete strength; it is assumed that defective installation of reinforcement causes the median fragility (S4) to be reduced 25 percent from $1.05 \mathrm{~g}$ to $0.79 \mathrm{~g}$.

\section{Beactor Internals $\left(\mathrm{S}_{3}\right)$}

If the reactor pressure vessel and enclosure structure maintain their integrity, the reactor scram system is the next line of accident prevention. Failure of the reactor to scram occurs if any of the following fail: shroud support $\left(S_{3}\right)$, control-rod-drive tubes $\left(S_{5}\right)$, or hydraulic control unit (S7). Failure of the shroud is caused by seismically-induced yielding or distortion of the shroud support cylinder. The median fragility of the shroud is $50 \%$ of the other two. It is assumed that inadequate tolerances due to improper installation reduces its median fragility 25 percent from $0.67 \mathrm{~g}$ to $0.50 \mathrm{~g}$.

\section{Electrical Equipment $\left(S_{11}-S_{14}\right)$}

A systematic error might arise from the use of an incorrect floor response spectrum in designing equipment or improper installation of 
equipment. Such an error might affect several mechanical or electrical components simultaneously. This scenario is investigated by assuming that improper equipment anchorage reduces the median fragility of electrical components $S_{11}-S_{14}$ by 25 percent.

A summary of the components with original (see Table 2.1) and modified median fragilities is provided in Table 6.1. The impact of these errors on the HCLPF and probability of core damage sequence CD (Eqn 2.17) is summarized in Table 6.2. The most substantial effect on both the HCLPF and P(CD) comes from the reduction of $25 \%$ in median fragilities of electrical components $S_{11}-S_{15}$ (line 4), which decreases the HCLPF by $22 \%$ and increases the mean of $P(C D)$ by $78 \%$. These elements appear in the CD Boolean as singletons in series. The reactor building and reactor pressure vessel also appear as singletons in CD. Postulated error in the reactor building increases the mean $P(C D)$ by about $32 \%$, while postulated error in the pressure vessel support increases the mean $P(C D)$ by about $76 \%$. Errors in the internals have a negligible effect on both HCLPF and $P(C D)$ (line 1). In contrast to the other components above, the reactor internals failure appears as a multiple cutset in sequence CD. If all errors were to occur simultaneously, the HCLPF would be reduced by $25 \%$ and the mean $P(C D)$ would increase by $160 \%$.

\subsubsection{Millstone 3}

The components considered in the error analysis are identified in Table 2.2.

\section{Emergency Generator Enclosure Building ( $\left.\mathbf{S}_{3}\right)$}

Failure occurs due to failure of strip footings supporting the exterior walls. Defective concrete placement is assumed to cause the median fragility to decrease $25 \%$ from $0.88 \mathrm{~g}$ to $0.66 \mathrm{~g}$.

\section{Refueling Water Storage Tank ( $\mathbf{S}_{4}$ )}

Failure occurs due to buckling of the tank wall due to overturning moment. Improper anchorage is assumed to cause the median fragility to decrease $25 \%$ from $0.88 \mathrm{~g}$ to $0.66 \mathrm{~g}$.

\section{Reactor Pressure Vessel Core Geometry (S6)}

Failure occurs by excessive bending of the upper support plate preventing insertion of control rods. A fabrication and installation error is assumed to decrease the median fragility $25 \%$ from $0.99 \mathrm{~g}$ to $0.74 \mathrm{~g}$. 


\section{Containment Crane Wall Collapse (S27)}

Failure occurs by in-plane shear. The shear strength of the wall is governed, in part, by concrete strength. For a lightly reinforced wall, poor quality concrete could cause the median fragility to decrease $20 \%$ from $2.2 \mathrm{~g}$ to $1.76 \mathrm{~g}$.

A summary of the components with original (see Table 2.2) and modified median frangilities is provided in Table 6.3. The impact of these errors on probabilities of plant damage states TE, SE and V3 most affected is presented in Table 6.4. None of the errors postulated affect $P(T E)$ and $P(S E)$ by more than approximately a factor of 2 . The error of $20 \%$ in crane wall capacity causes $P(V 3)$ to increase by an order of magnitude because $S_{27}$ appears in the $V_{3}$ sequence as a singleton; however, the rate of occurrence of such an error is small and the contribution of this event to core damage is of the same order of magnitude (at the $95 \%$ level) as the contributions of TE and SE. Thus, the contributions of these postulated errors are not significant.

\subsection{Summary}

The sensitivity analysis in the preceding section was based on a set of postulated error scenarios. At the current state of the art, there is no other way to obtain insight on how errors might affect seismic risk and margin analysis. Subject to the assumptions above, it is concluded that plausible error scenarios have a minimum impact on plant risk and a minor but nonnegligible impact on the HCLPF values. For components appearing in multiple cutsets, the error effect is negligible; for components appearing as singletons, the effect of error is noticeable. The large variability in the seismic hazard curve family overshadows the effect of small variations in component fragility. On the other hand, the shift in plant fragility caused by errors may cause the HCLPF to decrease by about 25 percent; proper treatment of D/C error may become important in seismic margin studies where fragility modeling is relatively more important. Additional studies are required to determine how conceptual and modeling errors might affect the plant logic and Booleans used to evaluate core damage probability and seismic margins. 
Table 6.1 - Modifications to Median Fragility Due to D/C Error - LGS

Component No.

$\mathrm{S}_{3}$

$\mathrm{S}_{4}$

S6

$S_{11}$

$S_{12}$

$S_{13}$

$S_{14}$
Original $A_{m}$

$$
0.67 \mathrm{~g}
$$

$1.05 \mathrm{~g}$

$1.25 \mathrm{~g}$

$1.46 \mathrm{~g}$

$1.49 \mathrm{~g}$

$1.49 \mathrm{~g}$

$1.49 \mathrm{~g}$
Modified Am

$0.50 \mathrm{~g}$

$0.79 \mathrm{~g}$

$0.63 \mathrm{~g}$

$1.10 \mathrm{~g}$

$1.12 \mathrm{~g}$

$1.12 \mathrm{~g}$

$1.12 \mathrm{~g}$
\%Decrease

25

25

50

25

25

25

25

Table 6.2 - Effect of D/C Error on Core Damage Probability - LGS

$\begin{array}{lccccc}\quad \text { Error } & \text { HCLPF } & 5 \% & 50 \% & \text { Mean } & 95 \% \\ \text { (1) Internals } & 0.31 \mathrm{~g} & 2.9-8 & 7.3-7 & 5.1-6 & 2.5-5 \\ \text { (2) R. Bldg. } & 0.29 \mathrm{~g} & 3.0-8 & 9.5-7 & 6.6-6 & 3.2-5 \\ \text { (3) P. Ves. } & 0.28 \mathrm{~g} & 3.2-8 & 1.1-6 & 9.0-6 & 3.9-5 \\ \text { (4) El. Equip. } & 0.25 \mathrm{~g} & 2.6-8 & 1.4-6 & 8.8-6 & 4.7-5 \\ \text { (5) All } & 0.24 \mathrm{~g} & 1.6-7 & 1.9-6 & 1.3-5 & 5.8-5 \\ \text { (6) Baseline } & 0.32 \mathrm{~g} & 2.7-8 & 7.2-7 & 5.0-6 & 2.4-5\end{array}$

Table 6.3 - Modifications to Median Fragility Due to D/C Error -Millstone 3

Component No. Original $A_{m}$

$\mathrm{S}_{3}$

$\mathrm{S}_{4}$

$S_{6}$

$S_{27}$
$0.88 \mathrm{~g}$

$0.88 \mathrm{~g}$

$0.99 \mathrm{~g}$

$2.20 \mathrm{~g}$
Modified Am

$0.66 \mathrm{~g}$

$0.66 \mathrm{~g}$

$0.74 \mathrm{~g}$

$1.76 \mathrm{~g}$
\%Decrease

25

25

25

20

Table 6.4 - Effect of D/C Error on Plant Damage State Probability Millstone 3

Component Seq 50\% Mean 95\%

$\begin{array}{lllll}\text { (1) Em. Gen. } & \text { TE } & 2.8-6 & 8.5-6 & 3.8-5 \\ \text { (2) RWST } & \text { SE } & 3.0-7 & 1.6-6 & 7.0-6 \\ \text { (3) Core geom. } & \text { SE } & 5.1-7 & 2.2-6 & 9.1-6 \\ \text { (4) Crane wall } & \text { V3 } & 2.1-7 & 3.2-6 & 2.3-5 \\ \text { (5) Baseline } & \text { TE } & 1.6-6 & 4.3-6 & 1.8-5 \\ & \text { SE } & 3.6-7 & 1.5-6 & 5.9-6 \\ & \text { V3 } & 5.2 .-8 & 3.5-7 & 1.6-6\end{array}$




\subsection{CONCLUSIONS AND RECOMMENDATIONS}

Seismic PRA provides a tool for integrated evaluations of plant vulnerability to extreme events. A properly conducted PRA offers insights on the relative safety of different structures, components and systems and enables dominant risk contributors to be identified. In contrast to traditional engineering design, which devises safety checks to ensure that a system continues to perform, seismic PRA methodologies focus on how a complex engineered system ian fail. The procedure is performanceoriented rather than prescriptive, as are most design codes, and provides the rational framework for the treatment of uncertainty that is absent or concealed in a deterministic analysis. PRA also provides a framework for integrating data and expert opinion, which is essential when dealing with the analysis of rare events. This framework fosters communication within and between the design team, owner/operator, and regulator, by placing safety issues and uncertainties in demand and capacity where they can be examined rationally. Perhaps most important, the PRA provides an audit trail for regulatory decision-making, which is especially important when public safety issues are highly visible and controversial.

The analysis of three typical plants in Section 5 showed that core damage probabilities, expressed in the form of a frequency distribution, are most affected by the basic seismic hazard modeling at the plant site. This result is consistent with previous findings (ASCE, 1986). Fragility modeling, in general, appears to have less impact on estimated core damage probabilities. Correlation in component fragilities had little impact on core damage probabilities for the plants examined because of the enormous variability in the basic seismic hazard. The uncertainty in the seismic hazard overwhelms the fragility characteristics and the weakest component or cutset in the sequence governs the sequence probability.

It may be concluded on the basis of the plants examined herein that simplifications in the plant logic for risk or margin assessment purposes can be obtained by neglecting sequences with probabilities 2 orders of magnitude or less below the mean core damage probability. This would suggest culling those sequences with probabilities of less than 10-7/year. Sequences with the probabilities less than the mean probability of failure of major components such as the reactor pressure vessel (in LGS, this probability was approximately $5 \times 10^{-7}$ ), where the offsite consequences are severe, also can be disregarded.

The core damage frequency distribution, HCLPF, or other quantitative information required for regulatory decision-making can be estimated quite closely from a simplified Boolean with a knowledge of the few dominant contributors to risk. This is illustrated by the results presented 
in Table 5.9 for correlated events. Screening out those components with median capacities larger than about 10 times the SSE, or with HCLPFs greater than 3 times the SSE or 2 times the margin review earthquake would simplify the accident sequence Booleans, has a negligible impact on core damage probabilities or plant HCLPF values, and allows fragility analysts to concentrate on modeling accurately those components that are important. Higher order cutsets also can be eliminated because they contribute little to the accident sequence probabilities. Components with median fragilities in the range 2 to 5 SSE and appearing in the plant logic Booleans as singleton cutsets appear to be most significant to accident sequence probabilities. This has been observed previously (Kennedy and Ravindra, 1984). Simplified models should be sought wherever possible. Increasing computerization and automation makes the fundamental behavior of the system opaque and reduces insights that otherwise might be obtained from simple models.

The definition of seismic hazard and uncertainty at very low probability levels is beyond the state of the art of seismology. There would seem to be little way to reduce this uncertainty in the near future. Difficulties in interpretation and evaluation that arise from the large uncertainty in the seismic hazard are likely to remain because the prospects of reducing this uncertainty are poor. Accordingly, it makes sense to focus efforts in the IPEEE program on the results of seismic margin studies, where the seismic hazard is effectively uncoupled from issues related to the plant logic and component fragilities.

Factors that are relatively unimportant in a seismic PRA may become important in a margin analysis where the dominating influence of the seismic hazard is removed. The selection of fragility model clearly is more important. For example, the use of a Weibull rather than a lognormal fragility model reduces the plant level HCLPF at LGS by about one-third. On the other hand, the plant level HCLPF at Maine Yankee was relatively insensitive to the fragility model chosen. This lack of robustness in the margins methodology creates a potentially difficult issue for plants in the Eastern United States, particularly if the sensitivity of the HCLPF to fragility modeling is of the same order as the difference between the margin review earthquake and SSE. Additional research on and refinements to fragility modeling would be desirable to support the increasing number of seismic margin reviews.

Seismic fragility analysis is still relatively coarse in light of available system reliability analysis techniques. Fragility models of structures, particularly reinforced concrete structures, need to be improved. Structural behavior may affect several safety-related systems. Although structural fragilities often involve system behavior, they usually are based on an evaluation of the weakest link in the structural 
system; system reliability analysis has shown that the performance of the weakest link in a statically indeterminate structure may not relate well to the performance of the system as a whole in reliability terms.

The focus in fragility modeling has been on gross failure characteristics (for example, the LGS reactor building fragility term $\mathrm{S}_{4}$ was based on flexural deformations of the shear wall that would be sufficient to impair function of attached equipment), rather than on developing behavioral models involving basic structural variables for which statistical data are available. Implementing this approach has required the use of large judgmental factors of uncertainty in modeling strength, inelastic energy absorption, strong motion duration and damping; the parameter $\beta U$ in the fragility is often 0.30 or larger. While such sources of uncertainty undeniably will remain, it might be possible to reduce their magnitudes through the use of system reliability analysis techiniques that have been developed during the past decade.

In view of the increasing emphasis on margin evaluation and the sensitivity of these evaluations to fragility models, research should be inisiated to confirm current fragility modeling techniques indejendently using systems reliability analysis. Structures, mechanical and electrical components all should be considered in this appraisal. The following dominant contributors should be addressed: loss of offsite power, tank anchorage, electrical switchgear, and diesel generators and peripherals. Equipment fragilities have been based on generic test data. When such equipment dominates an accident sequence, efforts should be made to obtain plant-specific data.

The potential impact of gross design and construction errors on seismic risk estimates can be assessed by postulating error scenarios, modifying the affected component fragilities, recalculating the core damage probabilities and comparing them to the error-free case. The underlying assumption is that the error does not cause the overall hazard scenario modeled by the plant logic to change. This assumption may not be tenable. Such analyses performed in this study and by others indicate that "plausible" design and construction errors have little effect on plant safety. However, the validity of such analyses of $D / C$ error depend on the extent to which plausible error scenarios can be identified and on whether effects of error can be incorporated in the PRA simply by adjusting the component fragilities. One might argue that if one can identify a particular $D / C$ error that impacts safety significantly, it ceases to be an error and should be treated as an additional design scenario. The presence of error may require modification of the plant logic. More research is required on this topic. 
Precursors to accidents often entail errors in operation, maintenance and plant management. In seismic PRAs, human error rates often have been increased by a factor of 10 to evaluate accident sequence probabilities. The results presented herein indicate that this increase generally has a small effect on core damage probabilities. Nontheless, better estimates of cognitive and procedural error rates under stress should be obtained. Human error can be included in the PRA by adding branches to the accident sequence analysis trees. However, this involves additional complexity in the plant logic and a better understanding of how operator actions affect the development of various accident sequences. The evaluation of human error by modification of fragility paramieters is more limited in its approach and does not indicate the potential scale of importance of human error.

PRAs and margin assessments do not deal effectively with "partial" equipment failures. Many systems continue to operate at a reduced efficiency following an accident. This degradation is difficult to implement in the plant logic. Partial system failures need to be dealt with more effectively, and the role of operator intervention needs to be implemented. Equipment recovery should be treated in estimating plant fragility and the possibility of beneficial operator actions should be taken into account. Innovative behavior has a generally positive influence on performance (Pidgeon, 1987). Failure to provide for beneficial human intervention is a defect in risk and margin assessment. Safety improvements suggested by the results of seismic PRA or margin analyses naturally have focussed on engineering or technical issues. Organization and management issues have not been addressed, at least systematically, but may be less costly and equally effective in reducing risk. It would be interesting to explore this further, particularly in evaluating the role of human intervention in reducing risk.

At their current state of development PRAs suffer from two main weaknesses: completeness and actuarial significance. The completeness issue arises from limitations in ability to model a complex engineering system such as a nuclear plant accurately at the current state of the art. Assumptions concerning the possible accident scenarios, behavior of safety-related plant systems during extreme events, presumptions concerning operator action, are at the heart of this weakness. The plant logic models and supporting analysis are approximations. The actuarial issue relates to the lack of data needed to describe the demands and response of the systems statistically. Coupled together, these weaknesses make it difficult to ascribe much significance to the core damage probability estimates, at least in a relative frequency sense. It should be emphasized that the quality of the model selected for analysis and the quality of the data used in the analysis produce an estimate of risk the quality of which cannot be better than the lesser of the two. 
Althnigh these weaknesses can be addressed, to a degree, through the assignment of uncertainty measures in the analysis, the resulting confidence intervals on the risk estimates are very broad. These broad uncertainty bands are a natural consequence of the use of expert opinion in analysis of uncertainty. We seem to be at the stage now where it is easy to obtain risk estimates but is difficult to obtain good ones.

Despite the large uncertainty bands on the risk estimates, there is a natural desire on the part of regulators to have a single numerical value of probability to support decision-making. Possible choices would include the mean, median and mode. There is not a strong theoretical justification for selecting any one of these because the notion of repetitive sampling that underlies ordinary statistical inference and parameter estimation is absent. In decision theory, the mean failure probability implies indifference toward uncertainty on the part of the decision-maker (Raiffa, 1970). The mean propagates more consistently through the plant logic than the median. However, the mean is sensitive to extreme values or outliers; its estimate fluctuates and is unstable. It was observed in Section 5 that the mean core damage probability occurs at about the 75th fractile of the frequency distribution. As conservative hypotheses that affect the characteristics of the seismic hazard or fragility are changed, the mean may increase to the 85th fractile or higher. The estimate of the mean is largely dependent on the more conservative hypotheses that underlie the seismic hazard family. The median (or mode) is relatively insensitive to outliers and thus may be a more appropriate point estimator when the ciata are very limited. However, it does not propagate consistently through the plant logic. Moreover, the median is insensitive to uncertainty in the estimate, and this key feature of decision analysis is lost. The ratio of the mean core damage probability to the median is approximately 7 for LGS and Millstone 3; this ratio tends to be greater for seismic than internal events because of the effect of the uncertainty in the seismic hazard curve.

Neither the mean nor the median presents as comprehensive picture of risk as does the frequency distribution of core damage probability. Information on the fundamental uncertainties is lost with a simple summary statistic. There does not seem to be a reasonable way to characterize risk by a single number - mean, median, or mode - without considering the uncertainty associated with the risk estimate as well. With such broad uncertainty bands, it is difficult for such estimates to be used in support of a single published target numerical regulatory safety goals. Moreover, it does not seem possible to determine what is an acceptable probability of core damage and to prepare a corresponding regulatory guideline. Whether (or not) a calculated risk is acceptable can be answered only in the context of whether the process by which the risk is determined is acceptable. Although there is some consistency in the 
mean annual core damage probabilities due to earthquakes calculated to date $\left(3.0^{-6}\right.$ to $3.0^{-5}$; see Sues, et al, 1990), the experience base is not adequate for this sort of calibration to have much actuarial significance.

At their current stage of development, then, it is prudent not to place too much emphasis on the mean (or median) core damage probabilities that are computed from a seismic PRA. Rather, the thought process that goes into the PRA and identification of the relative or dominant risk contributors, and other information that can be gleaned irrespective of the validity of the final risk estimates should be emphasized. The use of a seismic margin analysis as a basis for assessing plant vulnerability, with its focus on the review level earthquake as a numerical goal for the HCLPF, has some philosophical as well as practical advantages if a point estimate to describe safety or performance is desired.

On the other hand, comparisons of risk among plants or among design or retrofit alternatives within a plant may be more meaningful when made on a relative rather than an absolute basis, provided that plant logic and uncertainties are handled in a consistent manner in evaluating the various alternatives. Such a comparative risk or margins assessment requires that a protocol be developed to ensure that the various sources of uncertainty are handled in a consistent manner. Since the professional community involved in seismic PRA studies is relatively small and closed, such a protocol may already be in effect ad hoc.

PRAs and margin studies have been performed for different plants using very similar fragility modeling assumptions and data. The reports on fragility models in some of the published PRAs are almost identical, except for some differences in numerical values. Thus, some of the consistency observed in seismic PRAs to date may be illusory, since the same group of individuals has been involved in practically all of them. This common basis has some interesting implications for comparative evaluations of different plants. If, for example, $X$ and $Y$ are two estimates of core damage probability and the safety difference $X-Y$ is of interest in rank-ordering to establish priorities, then the mean and variance in the safety difference is,

$$
\begin{aligned}
& E[X-Y]=E[X]-E[Y] \\
& V[X-Y]=V[X]+V[Y]-2 \rho_{X Y} \sqrt{V[X] V[Y]}
\end{aligned}
$$

If the PRA methodology is the same and if the same group is performing the estimates, then $\rho_{X Y}$ will be close to 1 and the estimate of uncertainty attachod to the difference between $X$ and $Y$ will be substantially less than if two independent estimates of $X$ and $Y$ are made. The chances of 
systemic error are greater when the same technology is applied by the same individuals to different plants. Independent plant evaluations should be performed by a more diverse group to minimize the likelihood of such error. This is particularly important when the basis of the uncertainty measure involved is expert opinion; here, it seems desirable to broaden the spectrum of individuals involved in providing point estimates or distributions. More careful attention should be paid to the selection of experts and to broadening the pool of experts.

Aging has not been considered in seismic PRAs to date. The aging phenomenon is a natural result of continued service or operation and may be accelerated by the presence of an aggressive environment. In some cases, aging may lead to degradation in the capacity of structural, mechanical and electrical component and may impair their performance of safety-related functions during an extreme event. When the risk assessment addresses performance over a service life, time until next scheduled inspection, or other period of time, meaningful probability estimates require that time-dependent changes in plant systems be taken into account.

Components in which aging contributes to risk can be identified by their importance to core damage probability. Research recently has been initiated to determine the impact of age-related degradation on plant risk (Vesely, et al, 1990; Wolford, et al, 1992). This research has focused on the effect of aging on (active) mechanical and electrical components. Existing internal event PRAs have been utilized to perform this assessment, modifying equipment unavailabilities to take aging and inspection/maintenance into account. Because of limitations in data, only preliminary sensitivity studies have been performed to identify components in which aging is most likely to increase plant risk, and the results are somewhat contradictory. One study indicated that increased failure rates had little impact on core damage probability; another suggested that surveillance and maintenance programs may have a significant impact on core damage probability. Thus, plant maintenance policies should be evaluated for risk reduction effects.

Aging of structural components has not been considered in the above studies. Nor have any of them been performed within the context of a seismic (or other external event) PRA, where the impact of aging on seismic fragilities of structures and components might be significant. Research should be initiated to determine whether aging effects have a significant impact on seismic PRAs, margin assessment, and related decision-making. 


\subsection{ACKNOWLEDGEMENTS}

The research herein was supported, in part, by Grant No. NRC-04-87091 from the U.S. Nuclear Regulatory Commission, with Dr. J. Costello as NRC Technical Monitor. The assistance of Jennifer O'Connor and Mukund Srinivasan, graduate students in the Department of Civil Engineering at Johns Hopkins University, in performing the calculations is gratefully acknowledged.

The initial stages of this study were overseen by a Steering Committee consisting of C.A. Cornell, C. Hofmayer, R. Kassawara, R.P. Kennedy, C. Kot, J.W. Reed; and M. Srinivasan; their ideas were very helpful. The writer would like to thank, in particular Dr. John W. Reed, for his incisive review of the manuscript and Dr. M.K. Ravindra for his advice and contributions on the section dealing with design/construction errors. 


\subsection{REFERENCES}

Abramowitz, M. and Segun, I.A. eds. (1968). "Handbook of mathematical functions." Dover Publications, New York.

Alderson, M. (1987). "An examination of the sensitivities resulting from simplified seismic probabilistic risk modeling." Proceedings, Structural Mechanics in Reactor Technology, Vol. M, A.A. Balkema, Rotterdam, pp. 117-122.

Algermissen, S.T., et al (1982). "Probabilistic estimates of maximum acceleration and velocity in rock in the contiguous United States." Open File Report 82-1033, U.S. Geological Survey, Denver, CO.

Allen, D.E. (1979). "Errors in concrete structures." Canadian J. Civil Engrg. $6(3): 465-467$.

Azarm, M.A., et al (1984). "A Review of the Limerick Generating Station severe accident risk Assessment." NUREG/CR-3493, U.S. Nuclear Regulatory Commission, Washington DC.

Bandyopadhyay, K.K., et al (1987). "Seismic fragility of nuclear power plant components (phase II)." NUREG/CR-4659, U.S. Nuclear Regulatory Commission, Washington, DC.

Bernreuter, D.L., Savy, J.B., Mensing, R.W. and Chung, D.H. (1984). "Seismic hazard characterization of the Eastern United States: Methodology and interim results for ten sites." Report NUREG/CR-3756, U.S. Nuclear Regulatory Commission, Washington, DC.

Bernreuter, D.L., Savy, J.B. and Mensing, R.W. (1987). "Seismic hazard characterization of the eastern United States: Comparative Evaluation of the LLNC and EPRI Studies." NUREG/CR-4885, U.S. Nuclear Regulatory Commission, Washington, DC.

Bernreuter, D.L., Savy, J.B., Mensing, R.W. and Chen, J.C. (1989). "Seismic hazard characterization of 69 nuclear plant sites east of the Rocky Mountains." NUREG/CR-5250 (8 Volumes), U.S. Nuclear Regulatory Commission, Washington, DC.

Bier, V.M. (1989). "On the treatment of dependence in making decisions about risk." Transactions, 10th International Conference on Structural Mechanics in Reactor Technology, Vol. P, pp. 63-68.

Blockley, D.I. (1977). Analysis of structural failures." Proceedings Inst. of Civil Engrs., Part 1 62:51-74. 
Budnitz, R.J., et al (1985). "An approach to the quantification of seismic margins in nuclear power plants." NUREG/CR-4334, U.S. Nuclear Regulatory Commission, Washington, DC.

Budnitz, R. (1992). "Enhancing the seismic margin review methodology to obtain risk insights." Proceedings 19th Water Reactor Safety Information Meeting, NUREG/CP-0119(3):13-24..

Campbell, K.W. (1985). "Strong motion attenuation relations: a ten year perspective." Earthquake Spectra 1:759-804.

Casciati, F. and Faravelli, L. (1991). "Fragility analysis of complex structural systems." Research Studies Press, John Wiley and Sons, Ltd., Somerset, UK.

Collins, J.D. and Hudson, J.M. (1981). "Applications of risk analysis to nuclear structures." Probabilistic Methods in Structural Engineering, ASCE, pp. 157-178.

Cornell, C.A. and Newmark, N.M. (1978). "On the seismic reliability of nuclear power plants." ANS Topical Meeting on Probabilistic Reactor Safety, Newport Beach, CA.

Cornell, C.A. (1968). "Engineering seismic risk analysis." Bull. Seismological Soc. Am 58(5):1583-1606.

Cover, L.E., Bohn, M.P., Campbell, R.D. and Wesley, D.A. (1985). "Handbook of nuclear power plant seismic fragilities." NUREG/CR-3558, U.S. Nuclear Regulatory Commission, Washington, DC.

Donovan, N. (1974). "A statistical evaluation of strong motion data including the 1971 San Fernando earthquake." Proceedings 5th World Conference on Earthquake Engineering, Rome, Vol. 1: 1252-1261.

EPRI (1988). :"A methodology for assessment of nuclear power plant seismic margin." Report NP-6041, Electric Power Research Institute, Palo Alto, CA.

El-Bassioni, A. et al (1985). "PRA review manual." Report NUREG/CR3485, U.S. Nuclear Regulatory Commission, Washington, DC.

Ellingwood, B., MacGregor, J.G., Galambos, T.V. and Cornell, C.A. (1982). "Probability-based load criteria: load factors and load combinations." J. Str. Div., ASCE 108(5):978-997. 
Ellingwood, B. (1987). "Design and construction error effects on structural reliability." J. Str. Engrg. ASCE 113(2):409-422.

Ellingwood, B. (1990). "Validation studies of seismic PRAs." Nuclear Engineering and Design 123(2):189-196.

EPRI (1986). "Seismic hazard methodology for the central and eastern United States." EPRI NP-4726, Electric Power Research Institute, Palo Alto. CA.

Garcia, A.A., et al (1986). "A review of the Millstone 3 probabilistic safety study." Report NUREG/CR-4142, U.S. Nuclear Regulatory Commission, Washington, DC.

George, L.L. and O'Connell, W.J. (1985). "Importance and sensitivity of parameters affecting the Zion seismic risk." UCID-20475, Lawrence Livermore National Laboratory, Livermore, CA.

Gonzalez-Cuesta, M. and Okrent, D. (1986). "A method for quantification of nuclear reactor seismic risk due to design and construction errors based on deficiencies identified in the past." Nuclear Engineering and Design 96

Goodman, J. (1984). "Estimating fragility curves using few experimental data." Proc. Symposium on Advances in Probabilistic Structural Mechanics, San Antonio, TX, ASME PVP 93:53-61.

Goodman, J. (1985). "Structural fragility and the principle of maximum entropy," Structural Safety, 3(1):37-46.

Goodman, J. and Hadjian, A.H. (1985). "The elements of fragility models." Proceedings of Workshop of Seismic and Dynamic Fragility of Nuclear Power Plant Components." NUREG/CRP-0070, U.S. Nuclear Regulatory Commission, Washington, DC, pp. 48-61.

Goodman, J. (1987). "Analytical forms of structural fragility." Proceedings, Structural Mechanics in Reactor Technology, Vol. M, A.A. Balkema, Rotterdam, pp. 153-158.

Hall, R.E., Azarm, M.A. and Boccio, J.L. (1984). "The identification of the safety importance of seismically sensitive nuclear power plant components through the use of PRA." in Seismic Events Probabilistic Risk Assessments, PVP-Vol. 79, ASME, pp. 45-52. 
Hall. W.J. (1982). "Observation on some current issues pertaining to nuclear power plant seismic design." Nuclear Engineering and Design 69:365-378.

Holman, G.S. and Chou, C.K. (1987). "Using component test data to develop failure probabilities and improve seismic performance." Proceedings, Structural Mechanics in Reactor Technology, Vol. A, A.A. Balkema, Rotterdam, pp. 313-325.

Hwang, H.H.M. (1989). "Determination of HCLPF value for seismic margins study." Transactions, 10th International Conference on Structural Mechanics in Reactor Technology, Vol. M, pp. 179-184.

Iman, R.L. and Conover, W.J. (1980). "Small sample sensitivity analysis techniques for computer models with an application to risk assessment." Communications in Statistics Part A - Theory and Methods, A9(17):17491842.

Kanda, J. and Dan, K. (1987). "Distribution of seismic hazard in Japan based on an empirical extreme value distribution." Structural Safety 4(3):229-239.

Kaplan, S., Bier, V.M. and Bley, D.C. (1989). "A note on families of fragility curves - is the composite curve equivalent to the mean curve?" Transactions, 10th International Conference on Structural Mechanics in Reactor Technology, Vol. P, pp. 163-168.

Kelly, G. Barrett, R. and Buslik, A. (1986). "Millstone 3 risk evaluation report." Report NUREG-1152, U.S. Nuclear Regulatory Commission, Washington, DC.

Kennedy, R.P. and Ravindra, M.K. (1984). "Seismic fragilities for nuclear power plant studies." Nuclear Engineering and Design 79(1):47-68.

Kennedy, R.P. et al (1984). "Engineering characterization of ground motion." NUREG/CR-3805, U.S. Nuclear Regulatory Commission, Washington, DC.

Kennedy, R.P. (1985). "Various types of reported seismic margins and their uses." Report EPRI NP-4101-SR, Electric Power Research Institute, Pao Alto, CA. pp. 2-1 - 2-15.

Kennedy, R.P. and Campbell, R.D. (1985). "Comments on seismic fragility of nuclear power plant components." Proceedings of Workshop on Seismic and Dynamic Fragility of Nuclear Power Plant Components." NUREG/CP. 0070, U.S. Nuclear Regulatory Commission, Washington, DC, pp. 22-32. 
Kouts, H.J.C, et al (1990). "Special committee review of the Nuclear Regulatory Commission's Severe Accident Risk Report." Report NUREG1420, U.S. Nuclear Regulatory Commission, Washington, DC.

Lewis, H.W. (1985). "Medians and means in probabilistic risk assessment." Nuclear Science and Engineering, 91:220-222.

Mann, N.R., Schafer, R.E. and Singpurwalla, N. (1974). Methods for statistical analysis of reliability and life data. John Wiley and Sons, New York, NY.

McCann, M., et al (1985). "Probabilistic safety analysis procedures guide (Vol. 2)." NUREG/CR-2815, U.S. Nuclear Regulatory Commission, Washington, DC.

McGuire, R. (1976). "Fortran computer program for seismic risk analysis." U.S. Geological Survey Open File Report 76-67.

Melchers, R.E. and Harrington, M.V. (1983). "Structural reliability as affected by human error." Proceedings 4th International Conference on Applications of Probability and Statistics in Soil and Structural Engineering, Florence, Italy, pp. 683-694.

Mensing, R.W. (1985). "Comparison of the effect of hazard and response/fragility uncertaintios on core melt probability uncertainty." UCID-20326, Lawrence Livermore National Laboratory, Livermore, CA.

Naus, D.J. (1986). "Concrete component aging and its significance relative to life extension of nuclear power plants." NUREG/CR-46.25, U.S. Nuclear Regulatory Commission, Washington, DC.

"NEHRP recommended provisions for the development of seismic regulations for new buildings (1992)." FEMA 222, Federal Emergency Management Agency, Washington, DC, January.

Nowak, A.S. and Carr, R.I. (1985). "Sensitivity analysis for structural errors." J. Str. Engrg. 111(8):1734-1746.

Nuttli, O. (1979). "The relation of sustained maximum ground acceleration and velocity to earthquake intensity and magnitude." Report 16, Misc. paper S-7-1, U.S. Army Waterways Experiment Station, Vicksburg, MS.

Pidgeon, N.F., Turner, B.A. and Blockley, D.I. (1987). "Hazard assessment in structural engineering." Reliability and Risk in Civil Engineering, Vol. 1, Proc. ICASP5, pp. 358-365. 
"Probabilistic risk assessment (PRA) reference document (1984)." NUREG1050, U.S. Nuclear Regulatory Commission, Washington, DC.

"PRA Procedures Guide (1983)." Report NUREG/CR-2300 (2 Volumes), U.S. Nuclear Regulatory Commission, Washington, DC.

Prassinos, P.G. Ravindra, M.K. and Savy, J.B. (1986). "Recommendations to the nuclear regulatory commission on trial guidelines for seismic margin reviews of nuclear power plants." Report NUREG/CR-4482, U.S. Nuclear Regulatory Commission, Washington, DC.

Prassinos, P.G., Murray, R.C. and Cummings, G.E. (1987). "Seismic margin review of the maine yankee atomic power station." NUREG/CR-4826 (3 Volumes), U.S. Nuclear Regulatory Commission, Washington, DC.

Raiffa, H. (1970). "Decision analysis" Addison-Wesley, Reading, MA.

Ravindra, M.K. et al (1984). "Sensitivity studies of seismic risk models." Report NP-3562, Electric Power Research Institute, Palo Alto, CA.

Ravindra, M.K., Kennedy, R.P. and Sues, R.H. (1985). "Dominant contributors to seismic risk: an appraisal." Report NP-4168, Electric Power Research Institute, Palo Alto, CA.

Ravindra, M.K. (1987). "Sensitivity of seismi risk estimates to design and construction errors." Contractor Report prepared by EQE, Inc. for the National Bureau of Standards, September, 1987.

Ravindra, M.K, and Ellingwood, B. (1989). "Sensitivity of seismic risk estimates to design and construction errors." Transactions, 10th International Conference on Structural Mechanics in Reactors Technology, Vol. P, pp. 151-156.

Ravindra, M.K. and Murray, R.C. (1990). "Research in support of the IPEEE." Proc. 2nd EPRI Conf. 12/90.

Reed, J.W. and McCann, M. (1984). "Review of seismic PRAs and recommendations for improvement." in Seismic Events Probabilistic Risk Assessments, PVP-79, ASME, New York, pp. 53-60.

Reed, J.W. (1985). "Seismic probabilistic risk assessment for critical facilities." in Structural Safety Studies, ASCE, April, pp. 162-178.

Reiter, L. (1990). "Earthquake hazards analysis: issues and insights." Columbia University Press, New York, NY. 
"Review insights on the probabilistic risk assessment for the Limerick Generating Station (1984)." Report NUREG-1068, U.S. Nuclear Regulatory Commission, Washington, DC.

Riddell, R. and Newmark, N.M. (1984). "Statistical analysis of the response of nonlinear systems subjected to earthquakes." Structural Research Series No. 468, Dept. of Civil Engrg., Univ. of III., Urbana-Champaign.

"Severe Accident Risk Assessment - Limerick Generating Station (in two volumes)." Prepared for Philadelphia Electric Company by NUS Corporation, 1983.

"Severe accident risks: an assessment for five U.S. nuclear power plants (1989)." Report NUREG-1150, U.S. Nuclear Regulatory Commission, Washington, DC

Shiu, K.K., Reed, J.W. and McCann, M. (1985). "Review of seismic probabilistic risk assessment and the use of sensitivity analysis." Proceedings of Workshop on Seismic and Dynamic Fragility of Nuclear Power Plant Components." NUREG/CP-0070, U.S. Nuclear Regulatory Commission, Washington, DC, pp. 217-226.

"Special committee review of the nuclear regulatory commission's severe accident risks report (NUREG-1150)." NUREG-1420, U.S. Nuclear Regulatory Commission, Washington, DC, 1990.

Sues, R.H., Amico, P.J. and Campbell, R.D. (1990). "Significance of earthquake risk in nuclear power plant risk assessments." Nuclear Engineering and Design 123 (1990):27-44.

Taylor, J.R. (1975). "A study of failure causes based on U.S. power reactor abnormal occurrence reports." Proceedings, IAEA Symposium on Reliability of Nuclear Power Plants, International Atomic Energy Agency, Vienna, Austria, pp. 119-130.

Turkstra, C.J., Knoll, F. and Allen, D. (1983). "Organization of the designconstruction process." Proceedings, IABSE Workshop on Quality Assurance Within the Building Process, Rigi, Switzerland, pp. 63-72.

"Uncertainty and conservatism in the seismic analysis and design of nuclear facilities (1986)." prepared by Working Group on Quantification of Uncertainties, ASCE, New York.

Vesely, W.E., Kurth, R.E. and Scalzo, S.M. (1990). "Evaluations of core melt frequency effects due to component aging and maintenance." NUREG/CR5510, U.S. Nuclear Regulatory Commission, Washington, DC. 
Volmer, R.H., Shao, L.C., Chokshi, N.C. and Thadani, A.C. (1987). "Regulatory perspective on seismic PRA and margin studies." Proceedings, Structural Mechanics in Reactor Technology, VOL. M, A.A. Balkema, Rotterdam, pp. 291-297.

"WASH-1400, Reactor safety study: an assessment of accident risks in US commercial nuclear power plants (1975)." NUREG-75-014, US Nuclear Regulatory Commission, Washington, DC.

Wells, J.E., et al (1987). "Seismic risk assessment of a BWR." Proceedings, Structural Mechanics in Reactor Technology, Vol. A, A.A. Balkema, Rotterdam, pp. 337-342.

Wolford, A.J., Atwood, C.L. and Roesener, W.S. (1992). "Aging data analysis and risk assessment - development and demonstration study." NUREG/CR5378, U.S. Nuclear Regulatory Commission, Washington, DC. 


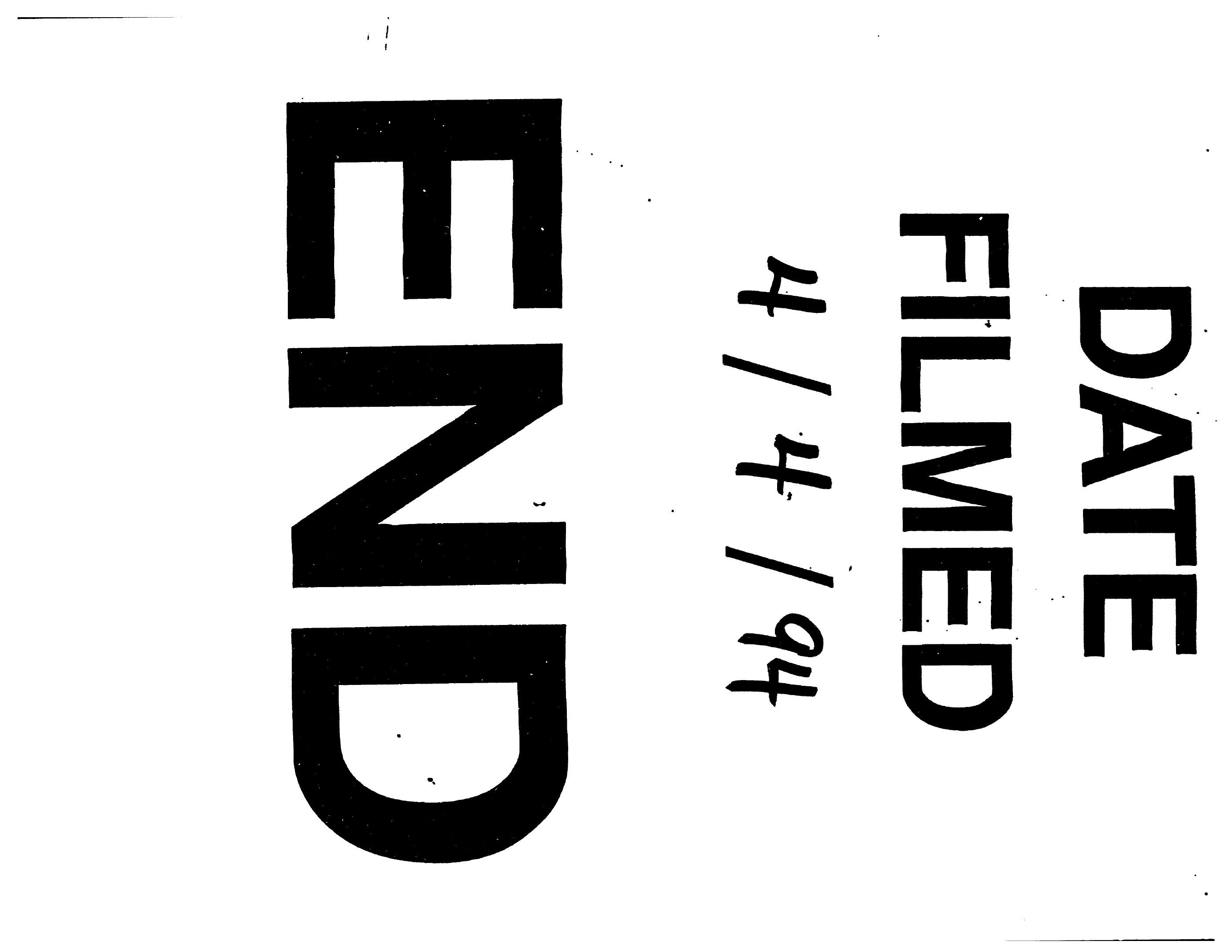




$$
-
$$

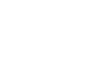

